\title{
Avaliação da exposição da população à poluição relacionada ao tráfego no município de São Paulo
}

Giovana lara Ferreira Moser de Toledo

Tese apresentada ao programa de Pós-

Graduação em Saúde Pública para obtenção do título de doutor em Saúde Pública.

Área de Concentração: Saúde Ambiental

Orientadora: Prof $^{\mathrm{a}}{ }^{\mathrm{Dr}}{ }^{\mathrm{a}}$ Adelaide Cássia Nardocci

São Paulo

2010 
É expressamente proibida a comercialização deste documento tanto na sua forma impressa como eletrônica. Sua reprodução total ou parcial é permitida exclusivamente para fins acadêmicos e científicos, desde que na reprodução figure a identificação do autor, título, instituição e ano da tese/dissertação. 


\section{DEDICATÓRIA}

Ao meu marido João Paulo que se dispôs a me acompanhar nesta trajetória.

À minha mãe e meu pai (in memorian) pelo apoio incondicional. 


\section{AGRADECIMENTOS}

À Adelaide Cassia Nardocci por ter aceitado a tarefa de ser minha orientadora, por sempre ter encontrado abordagens perspicazes para o tema de pesquisa, mas principalmente por ter acreditado que eu era capaz, nos momentos em que tudo parecia dar errado.

Á Prof ${ }^{a}$ Jun Wu pela contribuição com o trabalho como um todo, mas principalmente por ter me ensinado a utilizar o CALINE.

Ao Prof João Vicente de Assunção pela contribuição com os fatores de emissão veiculares e pelas importantes contribuições durante o exame de qualificação.

À Prof ${ }^{-}$Maria de Fátima Andrade, Prof Edmilson Dias de Freitas e Leila Martins pelas valiosas contribuições com os aspectos meteorológicos do modelo e pelos dados modelados de temperatura, altura da camada de mistura e classe de estabilidade.

À Prof ${ }^{a}$ Maria Regina Alves Cardoso pela contribuição na análise dos resultados de saúde e principalmente pelas palavras de incentivo na parte final do trabalho.

À Clarice Umbelino de Freitas pelas dicas estatísticas das análises de saúde.

À Isabel Gusman por tornar mais leve a minha estadia na UCI. 
Ao Marco, Samuel e Cida pela amizade e companheirismo. Sem o apoio de vocês as inúmeras horas na frente do computador teriam sido muito mais difíceis.

Ao Paulo Seiti (CET) e João Cucci (CET) Neto por contribuírem com as informações de trânsito.

Ao Marcel Pedroso pela ajuda com as bases de dados de saúde.

À minha família e amigos pela compreensão nos momentos em que estive ausente.

Ao James e Nicole pela amizade durante o ano que passamos em Irvine.

À CAPES pelo apoio financeiro, durante a minha estada na UCl. 


\section{RESUMO}

TOLEDO, G.I.F.M,Avaliação da exposição à poluição relacionada ao tráfego na cidade de São Paulo. 2010. Tese (doutorado em Saúde Pública) - Faculdade de Saúde Pública, Universidade de São Paulo, São Paulo.

Introdução - São Paulo é uma das maiores cidades da América Latina, com quase 11 milhões de habitantes e cerca de 6 milhões de veículos. Embora o tráfego seja a mais importante fonte de poluição atmosférica, poucos estudos investigaram a relação da poluição veicular com a saúde da população. A maioria dos estudos analisou os efeitos da poluição do ar à saúde utilizando valores médios de poluição ambiental para toda a área da cidade, os quais não evidenciam os gradientes de exposição na área intra-urbana. Objetivos- Avaliar a exposição da população à poluição relacionada ao tráfego e sua associação com as internações por doenças respiratórias de crianças e adolescentes de 0 a 18 anos. Métodos - As concentrações de $\mathrm{CO}$, NOx e $\mathrm{PM}_{10}$, foram calculadas a partir do modelo de dispersão CALINE-4 para os períodos de verão (Janeiro) e Inverno (Julho). Os casos de internação hospitalar por doenças respiratórias $(\mathrm{AlH}+\mathrm{ClH})$ foram georreferenciados por local de residência. $\mathrm{O}$ setor censitário do IBG foi considerado como unidade de análise. Um modelo de regressão logística foi usado, para estimar a associação entre exposição à poluição relacionada ao tráfego e hospitalização por doenças respiratórias, e controlado pelo IDH como indicador sócio econômico. Resultados - Do ponto de vista espacial, os poluentes veiculares estudados tiveram maior concentração na área central do centro expandido de São Paulo. Do ponto de vista temporal, as maiores concentrações foram observadas no inverno. A poluição veicular estava diretamente associada às internações de crianças e adolescentes (0-18) anos por doenças respiratórias. Crianças e adolescentes que moravam em 
setores censitários classificados no $4^{\circ}$ quartil de $\mathrm{CO}$ no período de inverno tiveram chance $80 \%$ maior de serem internadas por doenças respiratórias. Conclusões - Os poluentes veiculares analisados aumentam a chance de crianças e adolescentes (0-18 anos) serem internadas por doenças respiratórias. As condições socioeconômicas, avaliadas pelo IDH, também aumentam as chances de internação. O método usado neste estudo é importante para avaliações em micro-escala da relação entre os poluentes veiculares e a saúde da população. Outras cidades brasileiras ou cidades de países em desenvolvimento podem se beneficiar desta abordagem, dado que modelos são mais baratos e rápidos que campanhas de amostragem de poluentes atmosféricos ou aquisição/manutenção de estações de monitoramento da qualidade do ar.

Descritores: poluição relacionada ao tráfego; avaliação da exposição; poluição do ar; doenças respiratórias; São Paulo. 


\section{ABSTRACT}

TOLEDO, G.I.F.M.,Traffic-related exposure assessment at São Paulo city. 2010. Thesis (PhD in Public Health) - School of Public Health, University of Sao Paulo, Sao Paulo.

Introduction- Sao Paulo is one of the largest cities in Latin America, with almost 11 million inhabitants and around 6 million vehicles. Although traffic is the main source of air pollution, few studies investigated the relationship between vehicle pollution and health outcomes. Most studies analyzed health effects using average concentrations of environmental pollution for the whole city, which cannot give evidence for intra-urban gradients of exposure. Objectives- To evaluate the population's exposure to traffic-related air pollution and its association with hospital admission for respiratory diseases among children and adolescents aged 0-18 years. Methods - Concentrations of $\mathrm{CO}, \mathrm{NOx}$ and $\mathrm{PM}_{10}$ were modeled using CALINE-4 dispersion model, in two periods: summer (January) and winter (June). Hospitalizations due to respiratory diseases (by private and public assistance) were geocoded by the residence address. IBGE's census sectors were considered as unit of analysis. A logistic regression model was used to estimate the association between exposure to traffic-related air pollution and hospitalization for respiratory disease which, allowing for $\mathrm{HDI}$ as a socioeconomical indicator. Results- Spatially, pollutants presented higher concentration at the central area of the Expanded Center of Sao Paulo city. Temporally, higher concentrations were observed at winter periods. Trafficrelated pollutants was directly associated with hospitalization for respiratory disease among children and adolescents aged 0-18 years. Children and adolescents who lived in census sectors ranked in the $4^{\circ}$ quartile of $\mathrm{CO}$ in the winter period had $80 \%$ greater chance of being hospitalized for respiratory 
diseases. Conclusions- Traffic-related pollutants increase the chance of children being hospitalized for respiratory diseases. Socioeconomic conditions (evaluated by the HDI) also raised the chance of hospitalization. The method used in this study is important for micro-scale evaluations of the relationship between vehicular pollutants and population health. Other Brazilian cities or cities from developing countries may benefit from this approach, since models are less expensive and faster than air quality monitoring campaigns or acquisition/maintenance of air quality monitoring stations.

Descriptors: traffic-related pollution; exposure assessment; respiratory diseases; Sao Paulo. 


\section{APRESENTAÇÃO}

A intenção inicial deste trabalho foi avaliar o risco de exposição a poluentes atmosféricos tóxicos: dioxinas e furanos e Hidrocarbonetos Policíclicos Aromáticos - PAHs. Pensou-se em aplicar modelos capazes de estimar em micro-escala a distribuição destes poluentes, com o objetivo de avaliar a exposição da população a eles. No entanto, este tipo de modelagem necessitava de diversas informações não disponíveis, como por exemplo, dados de monitoramento para calibração do modelo e inventário de fontes fixas, informações estas ainda não existentes para a cidade de São Paulo. Por esta razão optou-se por trabalhar com os poluentes rotineiramente medidos na cidade de São Paulo - CO, NOx e PM 10 .

Por meio de uma bolsa de estudos do Programa de Doutorado no País com Estágio no Exterior - PDEE (bolsa sanduíche), concedida pela CAPES, foi possível a realização de um estágio de doutorado de um ano, no Departamento de Epidemiologia da Universidade da Califórnia, Irvine (UCI) - EUA, sob orientação da $\operatorname{Prof}^{\underline{a}} \mathrm{Dr}^{\underline{a}}$ Jun $\mathrm{Wu}$, cuja contribuição foi fundamental para 0 desenvolvimento deste trabalho. Este estágio possibilitou nosso acesso a uma versão modificada do modelo CALINE-4, capaz de calcular as concentrações ambientais dos poluentes estudados nos diversos setores censitários da área de estudo.

O levantamento dos dados de entrada para o modelo foi o maior desafio. Felizmente, pudemos contar com a inestimável colaboração de várias instituições e pesquisadores. Os professores Maria de Fátima Andrade e Edmilson Dias de Freitas, do Instituto de Astronomia e Geofísica e Ciências Atmosféricas (IAG) da Universidade de São Paulo, gentilmente contribuíram 
com os aspectos meteorológicos do modelo e forneceram dados modelados de temperatura, altura da camada de mistura e classe de estabilidade para o ano de estudo.

A Companhia de Engenharia de Tráfego - CET, do município de São Paulo, nos forneceu, inicialmente, uma base de ruas com informações de volume de tráfego, simuladas pelo EMM2, as quais são utilizadas para planejamento das atividades da Companhia. No entanto, infelizmente, estes dados não se mostraram adequados para o estudo da exposição a poluentes veiculares.

Desta forma, optamos então por utilizar as medições de volume veicular que haviam sido coletadas no âmbito do Projeto de Políticas Públicas financiado pela FAPESP, conduzido pela Faculdade de Saúde Pública da USP em parceria com a Secretaria de Estado da Saúde de São Paulo. Além disso, também foi usado um conjunto de dados de medições avulsas realizadas pela CET. Como esperávamos, os resultados obtidos foram muito melhores que os anteriores. Os dados deste modelo foram utilizados para as análises de saúde conduzidas neste trabalho.

Durante esta trajetória pudemos constatar que, no que se relaciona à avaliação da exposição da população aos poluentes atmosféricos do município de São Paulo e à redução dos efeitos à saúde humana ainda há muito por fazer, mas, acreditamos que este trabalho trouxe importante contribuição. 


\section{ÍNDICE}

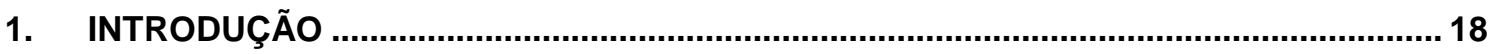

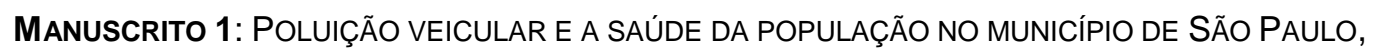

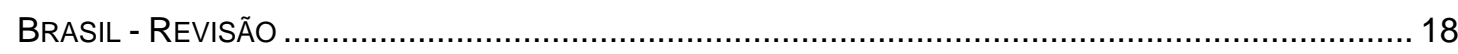

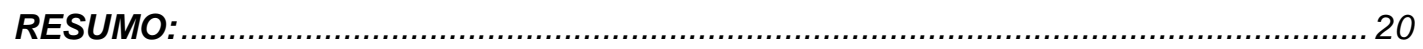

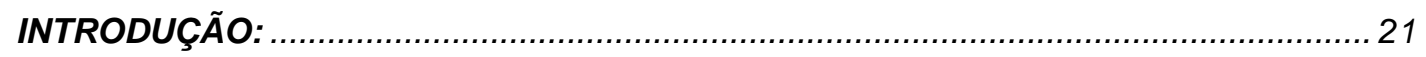

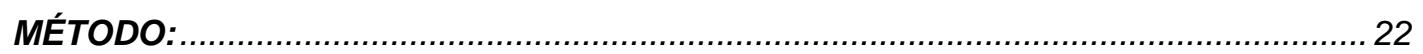

POLUIÇÃO DO AR E EFEITOS À SAÚDE NA CIDADE DE SÃO PAULO: :.................... 23

AVALIAÇÃO DA EXPOSIÇÃO À POLUIÇÃO RELACIONADA AO TRÁFEGO:.............. 28

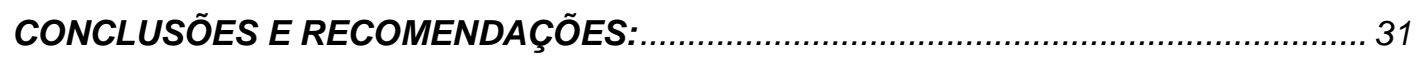

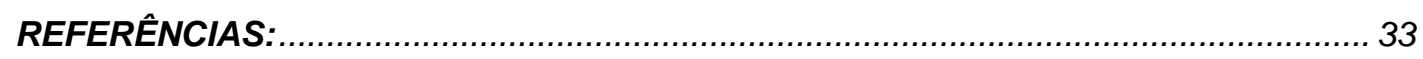

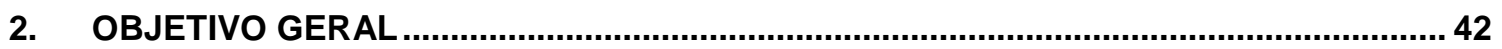

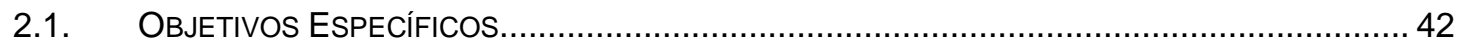

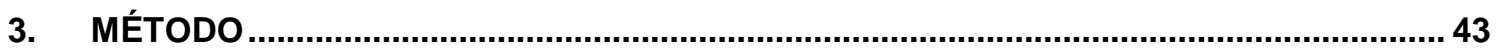

3.1. EStIMATIVA DA EMISSÃO DE POLUENTES VEICULARES NO CENTRO EXPANDIDO DE SÃO

PAULO 43

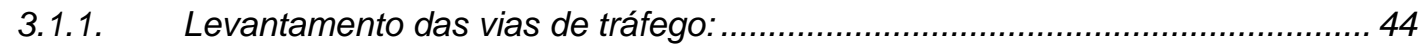

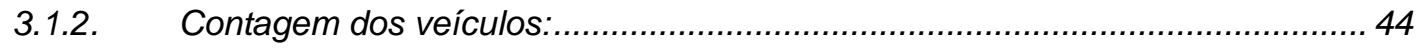

3.1.3. Aplicação do modelo de cálculo das concentrações de poluentes emitidos por veículos 46

3.1.4. Validação do Modelo.

53

3.1.5. Associação entre a poluição veicular calculada e internações por doenças respiratórias 54

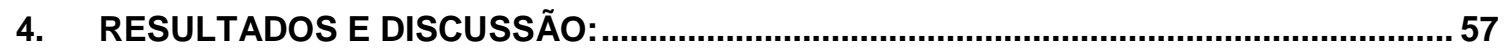

MANUSCRITO 2: AVALIAÇÃO DOS USO DE DADOS MODELADOS DE TRÁFEGO EM ESTUDOS DE EXPOSIÇÃO À POLUIÇÃO VEICULAR: UM ESTUDO DE CASO NO MUNICÍPIO DE SÃO PAULO, BRASIL .... 57

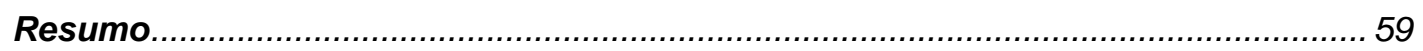

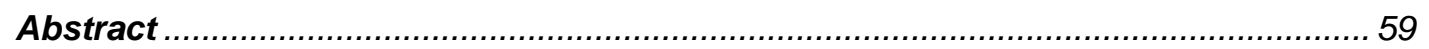

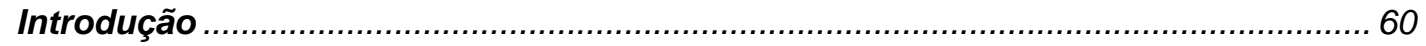

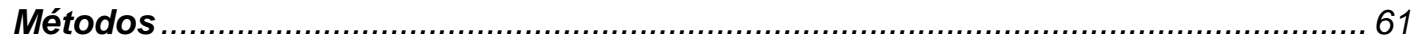

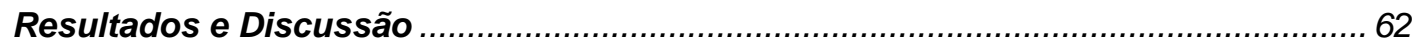

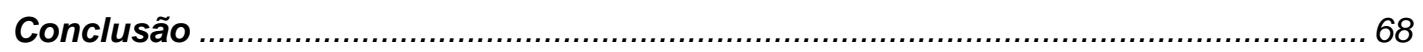


MANUSCRITO 3: EXPOSURE ASSESSMENT TO LOCAL TRAFFIC GENERATED AIR POLLUTION IN SAO

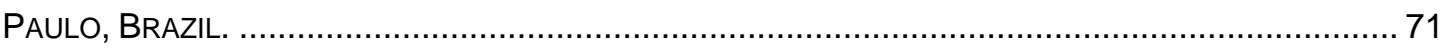

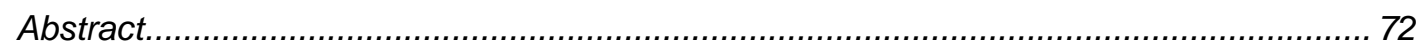

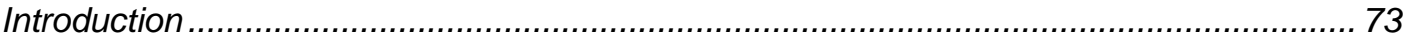

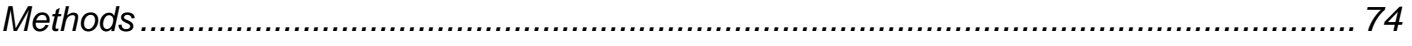

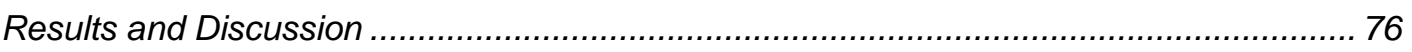

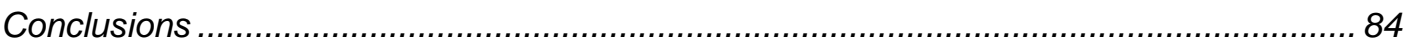

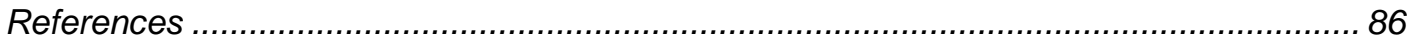

MANUSCRITO 4: EVALUATION OF TRAFFIC RELATED AIR POLLUTION AND HOSPITAL ADMISSION BY RESPIRATORY PROBLEMS IN CHILDREN AND ADOLESCENTS (0-18 YEARS) LIVING IN SAO PAULO,

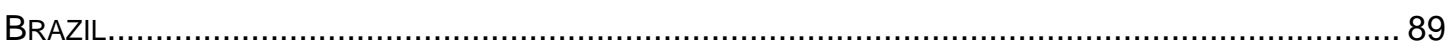

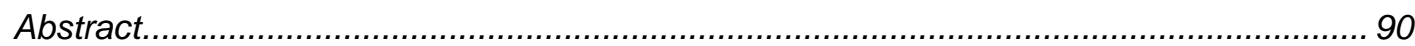

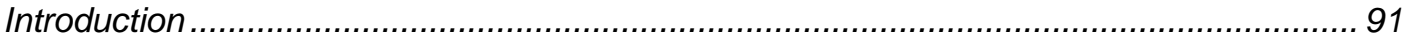

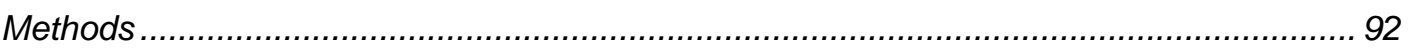

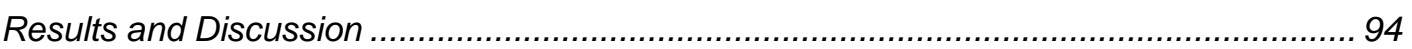

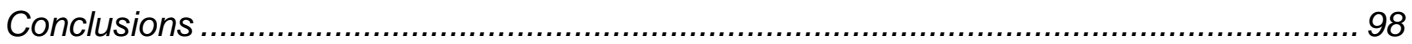

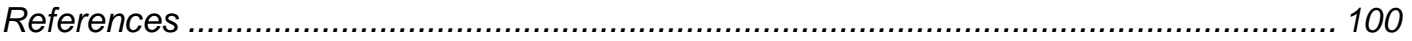

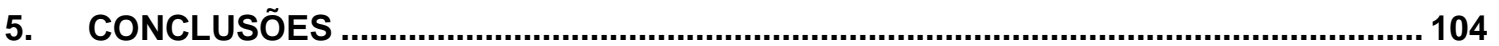

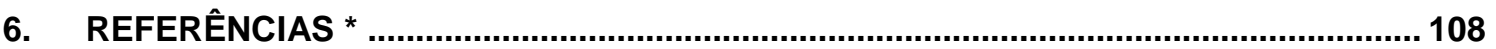

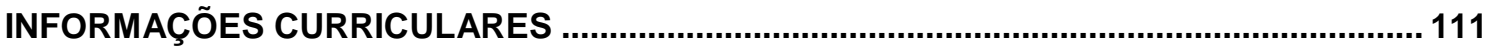




\section{LISTA DE ABREVIATURAS}

AlH Autorização de Internação Hospitalar

AQS Air Quality Station

CALINE-4 California Line Source Model-4

CAPES Coordenação de Aperfeiçoamento Pessoal de Nível Superior

CET Companhia de Engenharia de Tráfego

CETESB Companhia Ambiental do Estado de São Paulo

CID-10 Classificação Internacional de Doenças - 10

$\mathrm{CIH} \quad$ Comunicação de Internação Hospitalar

EMME-2 Equilibre Multimodal/Multimodal Equilibrium

EUA Estados Unidos da América

FSP Faculdade de Saúde Pública

HDI Human Development Index

HPA Hidrocarbonetos Policíclicos Aromáticos

IAG Instituto de Astronomia Geofísica e Ciências Atmosféricas

IBGE Instituto Brasileiro de Geografia e Estatística

ICD-10 International Classification of Deseases -10

IDH Índice de Desenvolvimento Humano

OR Odds Ratio

RC Razão de Chance

RMSP Região Metropolitana de São Paulo

$\mathrm{UCl} \quad$ University of California - Irvine

USP Universidade de São Paulo 


\section{LISTA DE FIGURAS}

Figura 3-1: Subáreas meteorológicas utilizadas na modelagem das concentrações de poluentes emitidos por fontes móveis veiculares...........50

Manuscrito 2: Avaliação dos uso de dados modelados de tráfego em estudos de exposição à poluição veicular: um estudo de caso no município de São Paulo, Brasil

Figura1: Distribuição diária da media horária das concentrações de CO simuladas e medidas............................................................................63

Figura 2: Comparação entre os dados de tráfego modelados e medidos..........64 Figura 3: Número de Veículos e contribuição de cada tipo de veículo para a concentração do poluente. .65

Figura 4: Distribuição do CO modelado para o mês de verão e base de dados de veículos. 66

Figura 5: Distribuição do CO modelado para o mês de inverno e base de dados de veículos. 67

Manuscrito 3: Exposure assessment to local traffic generated air pollution in Sao Paulo, Brazil.

Figure 1: Location of the air quality station used to calibrate the model .76

Figure 2: Number of vehicles and contribution of each vehicle type to pollutant concentration 78

Figure 3: Comparison between modeled pollutants concentration and vehicle

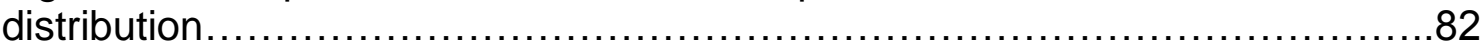

Figure 4: Comparison between vehicular and measured daily average CO

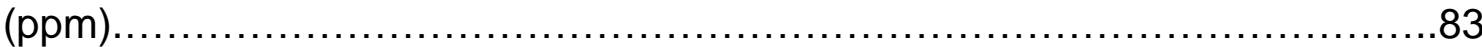

Figure 5: Prevalence of exposure of inhabitants aged 0 to 18 years old to $\mathrm{CO}$ during winter period. 85

Manuscrito 4: Evaluation of traffic related air pollution and hospital admission by respiratory problems in children and adolescents (0-18 years) living in Sao Paulo, Brazil

Figure 1: Distribution of modeled $\mathrm{CO}(\mathrm{ppm})$ during summer period and vehicles 


\section{LISTA DE TABELA}

Tabela 3-1: Número médio de veículos segundo a classificação das vias ....... 46 Tabela 3-2: Dados de emissão de poluentes veiculares para o ano de 2005 na RMSP 52

Manuscrito 2: Avaliação dos uso de dados modelados de tráfego em estudos de exposição à poluição veicular: um estudo de caso no município de São Paulo, Brasil

Tabela 1: Dados de emissões veiculares utilizados no estudo 61

Tabela 2: Comparação entre a média da concentração dos poluentes modelados e medidos.

Tabela 3: Correlação das médias diárias dos poluentes medidos e modelados 63

Tabela 4: Correlação entre os dados médios medidos pela EMQA em um raio de $3 \mathrm{~km}$ do entorno da estação e os dados calculados pelo CALINE-4.

Manuscrito 3: Exposure assessment to local traffic generated air pollution in Sao Paulo, Brazil.

Table 1: Comparison between modeled and measured concentrations (CETESB

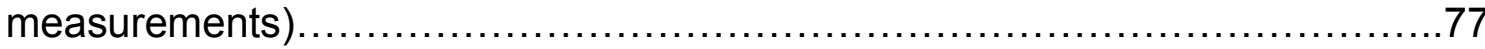
Table 2: Comparison between AQ Stations (CETESB) measurements and the daily average modeled pollutant in a $1 \mathrm{~km}$ buffer. .83

Table 3: Correlation between pollutant concentrations and total number of vehicles.

Manuscrito 4: Evaluation of traffic related air pollution and hospital admission by respiratory problems in children and adolescents (0-18 years) living in Sao Paulo, Brazil

Table 1: Comparison between modeled and ambient pollutant concentrations. .95

Table 2: Logistic regression analyze of odds ratio, corrected by HDI - Summer period

Table 3: Logistic regression analyze of odds ratio, corrected by HDI. - Winter period. 


\section{INTRODUÇÃO}

Manuscrito 1: Poluição veicular e a saúde da população no município de São Paulo, Brasil - Revisão

Giovana lara Ferreira Moser de Toledo ${ }^{(1)}$

Adelaide Cássia Nardocci ${ }^{(1)}$

${ }^{(1)}$ Departamento de Saúde Ambiental da Faculdade de Saúde Pública da Universidade de São Paulo. Avenida Dr. Arnaldo, 715. Cerqueira César. 01246-904. São Paulo/SP.

Artigo encaminhado para a Revista Brasileira de Epidemiologia 


\section{POLUIÇÃO VEICULAR E SAÚDE DA POPULAÇÃO NO MUNICÍPIO DE SÃO PAULO, BRASIL}

Giovana Iara Ferreira Moser de Toledo ${ }^{(1)}$

Adelaide Cássia Nardocci ${ }^{(1)}$

${ }^{(1)}$ Departamento de Saúde Ambiental da Faculdade de Saúde Pública da Universidade de São Paulo. Avenida Dr. Arnaldo, 715. Cerqueira César. 01246-904. São Paulo/SP. 


\section{RESUMO:}

A poluição do ar é um problema ambiental de extrema importância para a cidade de São Paulo, cuja maior fonte, atualmente, são os veículos, responsáveis pela emissão de 1,56 milhões de toneladas de CO por ano. Cerca de 11 milhões de habitantes estão expostos a essa poluição. Desde a década de 90, diversos estudos vêm identificando relações entre a poluição do ar no município de São Paulo e problemas respiratórios e cardiovasculares, crescimento fetal, aumento na mortalidade e hospitalizações, particularmente em populações sensíveis como crianças e idosos. A grande maioria destes estudos considera uma distribuição isotrópica dos poluentes para toda a área. Isto impede a avaliação das especificidades existentes no local e a avaliação da influência do tráfego. Internacionalmente, encontramos diversos métodos para a avaliação da exposição humana a poluentes atmosféricos, os quais são apresentados ao longo deste artigo. Acredita-se que a associação de modelagens das concentrações de poluentes a métodos de georreferenciamento seja a abordagem mais adequada para estudos similares no município de São Paulo. As vantagens do uso destes métodos são a capacidade de identificar situações e áreas prioritárias, a obtenção de informações detalhadas para a adoção de medidas ou políticas públicas e, ainda, a simulação de diferentes cenários. No entanto, a aplicação de métodos dessa natureza, em estudos no município de São Paulo, depende da melhoria dos dados de entrada dos modelos, sendo necessário o aprimoramento da rede de monitoramento da qualidade do ar e de condições meteorológicas e a implementação de estudos do tráfego (tanto para a quantificação de veículos, como para a avaliação da distribuição espacial e temporal destes).

Palavras -Chave: Poluição do ar; Tráfego; Exposição; São Paulo; Saúde da População 


\section{INTRODUÇÃO:}

Os efeitos da poluição do ar adversos à saúde humana constituem importante tema de Saúde Pública, atualmente, em todo o mundo. A preocupação com este tema, no município de São Paulo, teve início na década de 1970, quando a Agência Ambiental do Estado (CETESB) iniciou o monitoramento das concentrações de $\mathrm{SO}_{2}$ e fumaça no ar. No entanto, foi apenas na década de 1990, que este assunto ganhou importância considerável ${ }^{1,2}$.

Até a década de 1980, a poluição do ar em São Paulo era de origem predominantemente industrial. Nesta época, as indústrias automobilística, química, siderúrgica, têxtil e alimentícia fixadas no município alavancavam a economia. Na década de 1990, o aumento do controle das emissões industriais e mudanças na ocupação do solo fizeram com que muitas destas indústrias se transferissem para outras áreas do Estado ${ }^{1}$. Atualmente, a poluição emitida pela frota veicular é a principal fonte de poluição atmosférica ${ }^{3}$.

O número de veículos que circula na Região Metropolitana de São Paulo (RMSP) é crescente e, em 2008, chegou a 9,2 milhões de veículos, representando 1/5 da frota nacional. A emissão anual, de origem veicular, é de 1,56 milhões de toneladas de monóxido de carbono (CO), 367 mil toneladas de óxidos de nitrogênio e 62,3 mil toneladas de material particulado, o que corresponde a $90 \%$ da poluição atmosférica emitida em São Paulo ${ }^{3}$.

Além do grande número de veículos, a idade da frota é outro fator agravante da poluição. Em 2005, cerca de $58 \%$ da frota era anterior a 1997, sendo que estes veículos não dispunham de sistemas de controle de poluição e muitos não eram submetidos à manutenção periódica, para garantir o funcionamento adequado do motor e minimizar a emissão de poluentes*.

O município de São Paulo ocupa uma área de $1.523 \mathrm{~km}^{2}$ e tem uma população de quase 11 milhões de habitantes ${ }^{4}$. A malha viária total é de $18.000 \mathrm{~km}$ de ruas e avenidas, muitas com intenso volume de tráfego todos os dias, apesar de medidas de restrições de circulação de veículos em horários de pico, adotadas nos últimos anos na região central. A frota de ônibus para o transporte público chega a 15.000 veículos ${ }^{5}$.

\footnotetext{
* De acordo com a base de registro de veículos, fornecida pelo Departamento Estadual de Trânsito de São Paulo (DETRAN-SP.
} 
A poluição do ar na Região Metropolitana é monitorada pela CETESB, por meio de 22 estações fixas de monitoramento que medem as concentrações dos poluentes: monóxido de carbono, dióxido de enxofre, óxidos de nitrogênio, material particulado e ozônio. As medições de $\mathrm{SO}_{2}$ e fumaça começaram a ser realizadas a partir de 1973. A partir de 1981, iniciou-se o monitoramento automático da qualidade do ar no município e, em 1999, teve início o monitoramento manual de material particulado fino $\left(\mathrm{PM}_{2,5}\right)$, o que ainda não ocorre de maneira sistemática ${ }^{3}$.

Neste período, muitos estudos encontraram relações entre as concentrações de poluentes atmosféricos no município de São Paulo e agravos à saúde, como doenças respiratórias e cardiovasculares e baixo peso ao nascer, medidos a partir do número de internações hospitalares, mortalidade e atendimento em serviços de saúde, especialmente em crianças e idosos ${ }^{6,7,8,9,10}$. No entanto, apesar destes estudos mostrarem a importância da qualidade do ar como fator de risco no município de São Paulo, ainda existem lacunas importantes no conhecimento da magnitude dos impactos da exposição a estes poluentes na saúde da população.

O objetivo deste artigo foi analisar os estudos desenvolvidos no município de São Paulo a respeito da poluição do ar e seus efeitos na saúde humana. Além disso, pretendeu-se, com base nos estudos desenvolvidos internacionalmente discutir novos métodos para tal.

\section{MÉTODO:}

Para o levantamento dos estudos sobre os efeitos à saúde da poluição do ar no município de São Paulo, foram utilizados como descritores os termos "air pollution" e "São Paulo" nos últimos dez anos. Foram encontrados 144 artigos, assim distribuídos nas seguintes bases: CAB, 59; LILACS, 42 e PUBMED, 43.

A partir da leitura dos resumos, foram descartados os não diretamente relacionados ao tema, como os que envolviam biomarcadores, estudos específicos de variáveis climáticas e estudos com outros contaminantes de solo e água. Alguns estudos anteriores a 1998 foram citados, por serem considerados relevantes. 
Com o objetivo de analisar os métodos atuais, que têm sido empregados na avaliação de exposição à poluição relacionada ao tráfego, foi realizado um levantamento com o descritor "traffic -related air pollution" e selecionados os trabalhos publicados a partir de 1998. Foram encontrados 122 artigos no Pubmed. Da mesma forma, a partir da leitura dos resumos, foram descartados estudos que abordavam temas não diretamente relacionados, como estudos laboratoriais, poluição indoor, que utilizavam biomarcadores, que abordavam o tráfego, mas não avaliavam a exposição à poluição do ar, de ruído e outros.

Após a obtenção dos artigos completos, foi executada a fase de análise, que consistiu em agrupar as informações sobre os métodos de avaliação da exposição à poluição do ar relacionada ao tráfego.

\section{POLUIÇÃO DO AR E EFEITOS À SAÚDE NA CIDADE DE SÃo PAULO:}

Nos últimos anos, muitos estudos encontraram associação entre as concentrações de poluentes atmosféricos e efeitos à saúde das pessoas no município de São Paulo, a partir de dados de mortalidade, internação hospitalar e atendimentos ambulatoriais por doenças respiratórias e cardiovasculares em crianças e idosos e, ainda, de mortalidade intrauterina.

A maioria dos estudos com idosos, considerou pessoas com idade superior a 65 anos e correlacionou a concentração dos diversos poluentes no ar com dados de internações hospitalares e mortalidade.

Uma forte associação foi encontrada entre a mortalidade de idosos e as concentrações ambientais de $\mathrm{PM}_{10}{ }^{6}$. Em outro estudo, foi analisada a relação entre poluição do ar e mortalidade, por todas as causas, de doenças respiratórias e cardiovasculares em idosos. Os resultados mostraram que um aumento de 3-4\% da taxa de mortalidade diária por doenças cardiovasculares estava associado ao aumento de $\mathrm{PM}_{10}$ e $\mathrm{SO}_{2}$. Para doenças respiratórias, o aumento na mortalidade diária foi maior $(6 \%)$. As mortes por doenças cardiovasculares também estavam associadas aos níveis de $\mathrm{CO}(4 \%)^{8}$.

Ainda, foi verificado que um aumento de $10 \mu \mathrm{g} / \mathrm{m}^{3}$ de $\mathrm{SO}_{2}$ resultava em um aumento de 2,4\% na mortalidade diária de idosos, com um intervalo de tempo de 3 dias entre o aumento da poluição e o aumento na mortalidade ${ }^{11}$. Em outro estudo, os poluentes $\mathrm{O}_{3}$ e $\mathrm{SO}_{2}$ estavam associados à pneumonia e à gripe em idosos, mas, estes poluentes não possuíam efeitos independentes ${ }^{10}$. Também verificou- 
se que um incremento de $10 \mu \mathrm{g} / \mathrm{m}^{3}$ de $\mathrm{PM}_{10}$ resultou em um aumento de $1,4 \%$ a $14,2 \%$ na chance de morte por problemas respiratórios e, ainda, relatou-se que as maiores taxas de mortalidade foram observadas em famílias com piores condições socioeconômicas ${ }^{12}$.

Os dados diários de mortalidade e internações hospitalares nos municípios de São Paulo e Rio de Janeiro e sua associação com os níveis de poluição foram investigados. Os pesquisadores observaram, no município de São Paulo, associação entre internações hospitalares e mortalidade em idosos por doenças respiratórias e cardiovasculares para os poluentes: $\mathrm{PM}_{10}(2 \%), \mathrm{SO}_{2}(10 \%)$ e $\mathrm{CO}$ (3\%). Para $\mathrm{O}_{3} \mathrm{e} \mathrm{NO}_{2}$ não foram encontradas associações significantes ${ }^{13}$.

Em outro estudo, verificou-se que todos os poluentes, mas especialmente o $\mathrm{CO}$, estavam associados a um aumento da procura de serviços de emergência por casos de angina e infarto agudo do miocárdio $^{14}$. Trabalho mais recente identificou que os efeitos da poluição do ar na arritmia é predominantemente agudo e inicia-se em concentrações abaixo dos padrões atuais de qualidade do ar e, ainda, que as concentrações de $\mathrm{CO}$ e $\mathrm{NO}_{2}$ têm importante relação com o tráfego ${ }^{15}$.

No caso de crianças, foi verificada associação entre as concentrações de NOx e a mortalidade de menores de 5 anos, no período de 1990 a $1991^{16}$. Em trabalho similar, foi encontrado que a mortalidade das crianças menores de 5 anos estava associada aos poluentes $\mathrm{CO}, \mathrm{SO}_{2}$ e $\mathrm{PM}_{10}$, sendo a proporção de mortes atribuídas a estes poluentes de $15 \%, 13 \%$ e $7 \%$, respectivamente ${ }^{17}$.

A relação entre os níveis de $\mathrm{SO}_{2}, \mathrm{CO}, \mathrm{PM}_{10}, \mathrm{O}_{3}$ e $\mathrm{NO}_{2}$ e seus efeitos em crianças foi avaliada. $\mathrm{O}$ estudo considerou o número de visitas às unidades de emergência médica, encontrando associação positiva para todos os poluentes, sendo a mais forte para $\mathrm{PM}_{10}$ e a mais fraca para $\mathrm{O}_{3}$. $\mathrm{O}$ estudo constatou um aumento de $20 \%$ no número de crianças que procuraram o serviço de emergência para tratamento de problemas respiratórios nos dias mais poluídos ${ }^{7}$.

Os efeitos da poluição do ar em crianças menores de 13 anos foram investigados. Os poluentes $\mathrm{PM}_{10}$ e $\mathrm{O}_{3}$ apresentaram associação mais forte com admissão hospitalar por doenças respiratórias e um nível médio de $70 \mu \mathrm{g} / \mathrm{m}^{3}$ estava associado a um aumento de $12 \%$ no número de admissões hospitalares, com um período de 1 a 7 dias entre o aumento da poluição e a verificação do seu efeito na saúde das pessoas ${ }^{18}$. 
Em outro estudo, verificou-se um aumento do número de internações de crianças, por doenças respiratórias e pneumonia devido ao aumento nas concentrações de $\mathrm{O}_{3}(5-8 \%), \mathrm{NO}_{2}(9 \%)$ e $\mathrm{PM}_{10}$ $(9 \%)^{19}$.

Os efeitos das concentrações de $\mathrm{O}_{3}, \mathrm{SO}_{2}, \mathrm{PM}_{10}, \mathrm{CO}$, e $\mathrm{NO}_{2}$ em vários grupos etários de crianças (< 2 anos, 3-5 anos, 6-13 anos e 14-19 anos) foram estudados e observou-se que o grupo de crianças menores de 2 anos foi o mais suscetível, sendo observado um aumento de até 9,4\% nas admissões hospitalares por causas respiratórias, em função do aumento das concentrações de $\mathrm{PM}_{10}$. Os autores relatam que o segundo grupo mais afetado foi o de jovens de 14-19 anos ${ }^{9}$.

Em outro estudo, foi avaliada a prevalência de sintomas respiratórios em três áreas da Região Metropolitana de São Paulo (Tatuapé, Osasco e Juquitiba), em dois períodos distintos (1986 e 1998). Este monstrou que a diminuição dos níveis de poluição, na região do Tatuapé, estava associada à redução na prevalência de sintomas respiratórios. Entretanto, de maneira geral, o aumento da poluição veicular, considerando o aumento do número de veículos observado no período, neutralizou os resultados dos programas de controle da poluição industrial ${ }^{20}$.

A influência da poluição atmosférica na morbidade respiratória de menores de 15 anos e na mortalidade de idosos também foi estudada. Neste estudo, foi observado que a admissão hospitalar por doença respiratória em menores de 15 anos estava fortemente associada ao aumento de $\mathrm{PM}_{10} \mathrm{e}$ que a mortalidade de idosos também estava associada aos níveis de $\mathrm{PM}_{10}$ e $\mathrm{CO}^{21}$.

Um estudo desenvolvido em várias cidades brasileiras, inclusive em São Paulo, sugere uma associação entre a alta exposição a poluentes fotoquímicos e alta prevalência de sintomas de asma, rinite e eczema atópico ${ }^{22}$.

Um estudo envolvendo várias cidades da América Latina concluiu que o $\mathrm{PM}_{10}$ tem um importante papel nos efeitos a curto e médio termo na mortalidade, mas que, na América Latina as associações não diferem conforme o nível educacional ${ }^{23}$.

Além de idosos e crianças, alguns estudos também investigaram os efeitos da poluição do ar em fetos. Exemplo disso foi o estudo que avaliou a associação existente entre as concentrações diárias de $\mathrm{NO}_{2}, \mathrm{SO}_{2}, \mathrm{CO}, \mathrm{O}_{3}, \mathrm{PM}_{10}$ e a mortalidade intrauterina, encontrando forte associação para o $\mathrm{NO}_{2} \mathrm{e}$ 
associação moderada para o $\mathrm{SO}_{2}$ e CO. Foi encontrada forte associação quando todos os poluentes ${ }^{24}$ foram considerados.

Em outro estudo foi demonstrado que a exposição materna a $\mathrm{CO}$ e $\mathrm{PM}_{10}$, durante o primeiro trimestre da gravidez contribui para a diminuição do peso ao nascer e que um aumento da ordem de $1 \mathrm{ppm}$ de CO pode levar a um decréscimo de $23 \mathrm{~g}$ no peso ao nascer ${ }^{25}$. Estudo similar avaliou a influência dos poluentes $\mathrm{CO}, \mathrm{SO}_{2}, \mathrm{NO}_{2}, \mathrm{O}_{3}$ e $\mathrm{PM}_{10}$, também encontrando associação entre a exposição materna no primeiro trimestre de gravidez a $\mathrm{CO}, \mathrm{NO}_{2}$ e $\mathrm{PM}_{10}$ e baixo peso ao nascer ${ }^{26}$.

Apesar de o tráfego ser considerado a principal fonte de poluição no município de São Paulo, existem poucos estudos abordando mais especificamente a poluição relacionada à emissão veicular. Para investigar esse assunto, a função pulmonar de um grupo de motoboys e taxistas foi comparada à de um grupo controle. Os motoboys apresentaram a pior função pulmonar, o que pode estar diretamente associado à maior exposição aos poluentes emitidos pelo tráfego ${ }^{27}$. Outro estudo comparou a pressão sanguínea e o eletrocardiograma de controladores de tráfego, com os níveis de $\mathrm{CO}, \mathrm{PM}_{10}, \mathrm{NO}_{2}$ e $\mathrm{SO}_{2}$ e constatou que o aumento de $1,1 \mathrm{ppm}$ de $\mathrm{CO}$ pode levar a um aumento de $2,4 \mathrm{mmHg}$, na média, das pressões média sistólicas e diastólicas ${ }^{28}$.

Outro trabalho que avaliou a influência dos poluentes emitidos por veículos à saúde da população analisou a correlação entre os níveis de $\mathrm{CO}, \mathrm{O}_{3}, \mathrm{SO}_{2}, \mathrm{NO}_{2}$ e $\mathrm{PM}_{10}$ e problemas respiratórios em idosos, antes e após a implementação do programa de restrição de circulação de veículos na região central de São Paulo, denominado "rodízio", e verificou que este reduziu a concentração dos poluentes sem, entretanto, influenciar positivamente a saúde dos idosos ${ }^{29}$.

Um estudo recente encontrou associação entre a mortalidade perinatal e a exposição à poluição relacionada ao tráfego em um estudo caso-controle, em que os endereços das residências dos casos e controles foram georreferenciados para calcular suas distâncias ponderadas das vias de alto volume de trafego ${ }^{30}$.

Ainda, dois trabalhos apontam que o impacto econômico devido aos efeitos à saúde decorrentes da exposição à poluição atmosférica no município de São Paulo é muito significativo. Estes estudos ainda indicam que estes efeitos e seus consequentes custos poderiam ser evitados ${ }^{31,32}$. 
Os estudos analisados evidenciam o impacto da poluição do ar na saúde da população do município de São Paulo, sendo que os idosos são os mais atingidos, pois o aumento nas taxas de internação e mortalidade é cerca de duas vezes maior do que em crianças. As associações mais fortes foram encontradas entre os poluentes $\mathrm{SO}_{2}, \mathrm{PM}_{10}$ e $\mathrm{CO}$, especialmente, om doenças respiratórias.

Embora os trabalhos tenham realizado as correlações entre alguns poluentes e desfechos de saúde (como mortalidade e internação), não é possível avaliar o efeito isolado de cada poluente. Os estudos analisados trabalharam com períodos, populações e condições diferentes dificultando a avaliação das consequiências causadas pelos poluentes na saúde da população da cidade de São Paulo, de maneira isolada.

A quase totalidade destes estudos é de séries temporais e para a caracterização da exposição à poluição do ar foram utilizados os dados das estações de monitoramento da qualidade do ar. Estes dados são dispersos e não evidenciam gradientes de exposição na região intra-urbana associados, em especial, às vias de maior tráfego.

Como exemplo, é possível citar as estações de monitoramento de Cerqueira César e Congonhas que possuem representatividade de microescala (poucos metros no entorno da estação). ${ }^{33,34}$ A estação de Cerqueria César está localizada em situação topograficamente privilegiada, facilitando a dispersão de poluentes e fazendo com que a população possa estar expostas a níveis maiores de poluição que aqueles medidos por esta estação ${ }^{34}$. Ainda a estação de congonhas, por estar situada entre vias de tráfego com alto volume de veículos, pode medir níveis de poluição maior que aqueles aos quais a população está sujeita ${ }^{33}$. A estação de monitoramento do Ibirapuera parece ser a que mais representa a situação média de exposição e a poluição de background ${ }^{35}$. Embora a utilização de média dos valores de poluição para representar a exposição da população não seja adequado, estes ainda são um dos únicos dados de medida sistemática possíveis de serem utilizados.

Deve ser destacado, ainda, que os estudos de séries temporais são fortemente dependentes da qualidade dos dados de saúde e, ainda, há problemas de registros importantes, especialmente no que se relaciona aos dados de internação hospitalar. Os dados utilizados são dados oriundos do Sistema Único de Saúde - SUS, o qual atende especialmente a população de níveis socioeconômicos mais baixos, dado que pode introduzir vieses nas análises. Além disto, estes estudos são pouco efetivos para a avaliação de cenários e ou da eficiência de medidas específicas de controle da poluição do ar. 


\section{AVALIAÇÃO DA EXPOSIÇÃO À POLUIÇÃO RELACIONADA AO TRÁFEGO:}

A complexidade dos ambientes urbanos, o aumento da contribuição das fontes móveis, e a diversidade de poluentes e dos efeitos à saúde da população têm impulsionado o desenvolvimento de métodos para a avaliação da exposição humana à poluição relacionada ao tráfego em áreas urbanas, atualmente consideradas como áreas prioritárias de estudo.

São seis os métodos principais de avaliação de exposição humana aos poluentes de fontes veiculares: 1) avaliação baseada na proximidade das vias; 2) interpolação estatística; 3) modelos de análise de uso do solo; 4) modelos de dispersão; 5) modelos integrados de emissão e meteorologia e 6) modelos híbridos - que combinam o monitoramento pessoal com um dos métodos anteriores ${ }^{36}$.

Estudos baseados na proximidade consideram que quanto mais próximo da fonte de poluição, maiores serão as concentrações dos poluentes e, portanto, maior a exposição, ou seja, a distância entre as pessoas e a via é tomada como uma proxy da exposição aos poluentes relacionados ao tráfego. Estes estudos são úteis para avaliar o decaimento de poluentes e de seus efeitos em função da distância da via e também em análises exploratórias. No entanto, têm sido criticados por considerarem um número restrito de co-variáveis, não diferenciarem os tipos de poluentes envolvidos e a influência das condições meteorológicas e topográficas. E, ainda, em ambientes urbanos complexos, indivíduos mais próximos da fonte não necessariamente são os mais expostos ${ }^{36}$.

Um exemplo de aplicação deste tipo de método é o estudo em que os pesquisadores avaliaram a relação entre a exposição ao material particulado fino e o desenvolvimento do Alzheimer. Para tal, foram avaliadas mulheres entre 68 e 79 anos, que viviam há mais de 20 anos no mesmo local. A exposição ao material particulado proveniente de fontes veiculares foi estimada pela distância da residência até a rua movimentada mais próxima. Os autores concluíram que a exposição crônica ao material particulado de fontes veiculares pode estar envolvida no desenvolvimento da doença de Alzheimer $^{34}$. Além deste estudo, diversos outros aplicaram o mesmo tipo de metodologia $38,39,40,41,42,43,44,45,46,47,48,49,50,51,52,53,54,55$.

Com o desenvolvimento das ferramentas de geoprocessamento, a aplicação deste método foi facilitada e o custo é bastante reduzido. 
$\mathrm{Na}$ interpolação estatística aplicada à avaliação da exposição, os dados de concentrações dos poluentes obtidos em estações de monitoramento são interpolados por meio de técnicas de geoestatística, como, por exemplo, o kriging, para a obtenção dos valores para outros locais, usualmente para o centro de uma determinada grid. A vantagem principal deste método é o uso de dados reais de poluição e a possibilidade da realização de estudos de dose-resposta. No entanto, este método não considera a influência das condições meteorológicas e de outros fatores específicos do terreno na dispersão dos poluentes e, ainda, pode envolver erros significativos nas áreas de borda. A qualidade dos resultados depende da existência de uma densa rede de monitoramento, ou da coleta primária de dados, o que, em ambos os casos, envolve custos bastante elevados ${ }^{36}$.

Em estudo que utilizou metodologia desta natureza, foi avaliada a relação entre a poluição atmosférica e a prevalência de diabetes mellitus. Técnicas de informação geográfica foram utilizadas para atribuir valores individuais de $\mathrm{NO}_{2}$, baseados em uma rede de amostradores. Os pesquisadores afirmam que a poluição do ar está associada à diabetes mellitus e que mais investigações são necessárias para determinar a relação de causa-efeito ${ }^{56}$. Outro exemplo de estudo desta natureza foi desenvolvido na Polônia ${ }^{57}$.

Outro método disponível para avaliar a exposição aos poluentes atmosféricos é a análise de uso do solo, em que a estimativa da poluição é determinada a partir de padrões de emissão, em função das características do uso do solo e do tráfego da área. As vantagens desta técnica incluem a possibilidade de se analisar áreas que não possuem dados de monitoramento e o baixo custo. As desvantagens são a dificuldade de inserção de condições específicas de uma determinada área e o trabalho em escala pequena e, ainda, a extrapolação de dados para áreas com uso e ocupação ou topografia muito típicos ${ }^{36}$.

O uso de modelo de análise de uso do solo foi utilizado para o cálculo das concentrações de hidrocarbonetos na investigação da exposição aos poluentes atmosféricos durante a gravidez e sua associação com o peso ao nascer ${ }^{55}$. Diversos outros estudos utilizaram este método para investigar a associação entre a poluição do ar e efeitos a saúde $59,60,61,62,63,64,65,66,67$.

O município de São Paulo dispõe de mapas de uso e ocupação do solo No entanto, seriam necessários estudos para determinação dos padrões de emissão em função das categorias de uso e ocupação do solo, uma vez que a adoção de estimativas disponíveis na literatura para outras áreas introduziria muitas incertezas no estudo. 
Os modelos de dispersão também têm sido empregados para estimar a exposição a poluentes atmosféricos. Neste caso, informações de emissão, dados meteorológicos e topográficos são necessários para estimar a concentração dos poluentes. Alguns modelos integram módulos meteorológicos e químicos na simulação da dinâmica atmosférica dos poluentes, possibilitando uma estimativa mais realista da dispersão dos poluentes, quando comparada ao modelo de dispersão simples. É possível, ainda, combinar as informações empíricas de monitoramento ambiental com a distribuição da população.

Estes modelos ainda apresentam, como vantagem, o fato de poderem considerar as variações da poluição no tempo e espaço e poderem ser aplicados para diferentes escalas. No entanto, requerem dados reais de poluição para validação e, muitas vezes, o desencontro temporal dos dados de entrada pode levar a estimativas errôneas. O custo da obtenção dos dados de entrada do modelo pode ser bastante elevado. A necessidade de computadores de alto desempenho, softwares e pessoal treinado também pode ser um fator limitante para o uso destes modelos ${ }^{36}$.

O impacto à saúde devido à exposição aos poluentes veiculares e à poluição outdoor foi avaliado na Áustria, França e Suíça. A utilização de modelos permitiu o cálculo da concentração de $\mathrm{PM}_{10}$ para uma grid de $1 \mathrm{~km}^{2}$ e, a partir desta estimativa, foi possível determinar a fração veicular. Esses dados foram associados à mortalidade ( $\geq 30$ anos), hospitalização por causas cardiovasculares ou respiratórias, incidência de bronquite crônica ( $\geq 25$ anos), episódios de bronquite em crianças e ataques de asma. Os resultados mostraram que $6 \%$ da mortalidade da população foi devida à exposição a poluentes atmosféricos, sendo que 50\% destas mortes foram por conta das emissões veiculares. O tráfego ainda foi responsável por 25.000 novos casos de bronquite crônica em adultos, mais de 290.000 casos de bronquite em crianças e 0,5 millhões de ataques de asma. Os pesquisadores concluíram que, apesar de os riscos relativos serem baixos, as consequências para a saúde pública são consideráveis. Além disso, mostrou que o controle da poluição veicular deve ser prioritário para a melhoria da qualidade do $\operatorname{ar}^{68}$. Diversos outros estudos utilizaram métodos semelhantes ${ }^{69,70,71,72,73,74,75,76}$.

Estes estudos são viáveis para o município de São Paulo, sendo a maior dificuldade a qualidade dos dados disponíveis para a alimentação do modelo. A vantagem importante do uso de modelos é a possibilidade de análise de cenários, com alta resolução, o que é muito útil para estudos de cenários 
resultantes de medidas de controle, como restrição do uso de veículos, mudança de combustíveis ou de perfil da frota.

Os modelos híbridos de avaliação da exposição humana aos poluentes ambientais combinam o uso de monitoramento pessoal com um dos métodos citados anteriormente. Neste caso, o principal objetivo é validar resultados de exposição ambiental com o monitoramento em outras escalas. Este método tem como vantagem poder validar as medidas de concentrações ambientais de poluentes como parâmetro para avaliação da exposição humana. No entanto, o monitoramento pessoal é bastante caro e a escolha do poluente a ser monitorado depende da facilidade/custo da análise e sua aplicação requer que as demais técnicas de avaliação da exposição já tenham sido empregadas anteriormente ${ }^{36}$.

Um exemplo da aplicação deste tipo de metodologia é o estudo em que foram combinadas as técnicas de interpolação de dados de estação de monitoramento da qualidade do ar e modelos de uso e ocupação do solo, para avaliar a exposição a poluentes atmosféricos e correlacioná-la à mortalidade e incidência de câncer de pulmão. $\mathrm{O}$ estudo mostrou que o maior risco relativo relacionado à poluição de fundo e por tráfego está associado à mortalidade por causas respiratórias $^{77}$. Outros estudos usaram métodos combinados para avaliar a exposição ao tráfego $^{78,79,80,81,82,83,84}$.

Outros métodos de avaliação da exposição aos poluentes veiculares, como por exemplo, o uso de questionários, em que são reportados os níveis de tráfego, monitores instalados em residências, amostradores pessoais ou passivos e dados de estação de monitoramentos também são aplicáveis $85,86,87,88,89,90,91,92,93,94,95,96,50,97,98,99,100$.

\section{CONCLUSÕES E RECOMENDAÇÕES:}

O município de São Paulo ocupa uma área bastante extensa (cerca de $11.000 \mathrm{~km}^{2}$ de área urbanizada), com uma complexa distribuição das fontes móveis e estacionárias de poluição do ar e, portanto, uma distribuição heterogênea desses poluentes. Além disso, a distribuição dos poluentes ainda sofre influência de parâmetros atmosféricos, como direção e velocidade do vento, umidade relativa do ar, temperatura, radiação, pressão atmosférica, entre outros. A própria estrutura do município se apresenta como um aspecto não capaz de favorecer a dispersão isotrópica dos 
poluentes ao longo da cidade, como, por exemplo, a presença de altos edifícios, os quais influenciam a maneira natural de deslocamento de ventos e a presença de ilhas de calor.

Considerando os fatores acima citados, é de se esperar que o monitoramento da qualidade do ar seja uma tarefa complexa. Atualmente, a Companhia Ambiental do Estado de São Paulo (CETESB) é responsável pelo controle da qualidade do ar por meio de 12 estações de monitoramento, sendo 10 destas estações localizadas nas regiões centrais da cidade ${ }^{3}$. A distribuição geográfica das estações, portanto, não é capaz de representar a poluição atmosférica presente em São Paulo, uma vez que, ao longo do tempo, as fontes veiculares ganharam maior importância que as fontes fixas.

O prejuízo causado à saúde humana devido à exposição a poluentes atmosféricos já foi amplamente investigado em São Paulo. No entanto, a maioria dos trabalhos considera um único valor médio diário de concentração dos poluentes para todo o município, não evidenciando os gradientes de exposição existentes, principalmente os pontos críticos de picos de poluição. Ainda, deve ser enfatizado que, apesar de $98 \%$ da emissão de CO ser proveniente de fontes móveis, poucos estudos avaliaram o real impacto da emissão veicular na saúde da população. Os estudos evidenciam a associação entre a exposição média da população e os danos à saúde, mas não existem estimativas da distribuição do grau de exposição para toda a população. Por esta razão, pouco podem contribuir para a identificação de áreas críticas e ações prioritárias para gestão do problema e para avaliação da eficácia de medidas já implementadas. Estudos realizados em escalas menores são capazes de levar em conta especificidades que são desconsideradas em estudos de larga escala. Exemplo disso são áreas onde as concentrações de poluentes são maiores, mas que são desconsideradas quando se toma como homogênea a concentração de poluentes em todo o município.

Diversas especificidades a respeito da exposição da população à poluentes atmosféricos ainda precisam ser mais profundamente investigados. Por exemplo, é preciso estudar a contribuição de cada tipo de veículo (diesel, gasolina, álcool e flex) e de cada tipo de poluente para os desfechos de saúde. Além disso, a maioria dos trabalhos investigou a mortalidade ou internação. No entanto, os atendimentos que não resultaram em internação não foram investigados.

Atualmente, há uma diversidade de métodos de avaliação da exposição à poluição gerada pelo tráfego que podem ser utilizados isoladamente ou em conjunto. O desenvolvimento das técnicas de geoprocessamento também tem ampliado as possibilidades de abordagem. 
As dificuldades investigativas levantadas não são exclusividade do Brasil. Na maioria dos países em desenvolvimento, o principal desafio é a falta de dados adequados. No entanto, isto não pode ser um impedimento mas, pelo contrário, deve ser uma motivação para a busca de solução para um importante problema de saúde pública, especialmente nas grandes regiões metropolitanas. Diversas alternativas metodológicas podem ser empregadas no sentido de complementar os estudos já existentes.

\section{REFERÊNCIAS:}

1. RIBEIRO H., ASSUNÇÃO J.V. Historical overview of air pollution in São Paulo metropolitan area, Brazil: influence of mobile sources and related health effects. In: SUCHAROV L.J., BREBBIA, C.A.(Edit). Urban transport and the environment in the $21^{s t}$ century. Boston: Ed Wit Press, 2001. p 351-360.

2. LACASAÑA-NAVARRO M., AGUILAR-GARDUÑO C., BROMIEU,I. Evolucion de la contaminacion del aire e impacto de los programas de control em tres megaciudades de America Latina. Salud Pública Méx. 1999; 41(3): 203-215.

3. COMPANHIA DE TECNOLOGIA DE SANEAMENTO AMBIENTAL, Relatório de qualidade do ar no estado de São Paulo 2008. São Paulo: CETESB. 2009. p 340. [Acesso em 24/09/09] Disponível em: http://www.cetesb.sp.gov.br/Ar/publicacoes.asp.

4. INSTITUTO BRASILEIRO DE GEOGRAFIA E ESTATÍSTICA (IBGE. [Acesso em 29/11/2009]. Disponível em www.ibge.gov.br.

5. PREFEITURA MUNICIPAL DA CIDADE DE SÃO PAULO (PMSP). Disponível em: www.prefeitura.sp.gov.br. Acesso em 29/11/2009.

6. SALDIVA, P. H. et al. Air pollution and mortality in elderly people: a time-series study in Sao Paulo, Brazil. Arch Environ Health. 1995; 50(2): 159-163.

7. LIN C. A. et al. Air pollution and respiratory illness of children in Sao Paulo, Brazil. Paediatric and Perinatal Epidemiology. 1999; 13:477-488.

8. GOUVEIA N., FLETCHER, T., Time series analysis of air pollution and mortality: effects by cause, age and socioeconomic status. J Epidemiol Community Health. 2000; 54:750-755.

9. BRAGA, A.L.F., et al. Health effects of air pollution exposure on children and adolescents in São Paulo. Brazil. Pediatr Pulmonol. 2001; 31:106-113. 
10. MARTINS L.C., LATORRE D.O., CARDOSO M.R.A., GONÇALVES F.L.T, SALDIVA P.H.N., BRAGA A.L.F, Poluição atmosférica e atendimentos por pneumonia e gripe em São Paulo, Brasil. Rev Saúde Pública. 2002; 36: 88-94.

11. BOTTER D.A., JORGENSEN B., PERES A.A.Q. A longitudinal study on mortality and air pollution for Sao Paulo, Brazil. Journal of exposure analysis and environmental epidemiology. 2002; 12(5): 335-343.

12. MARTINS M.C.H., FATIGATI F.J., VÉSPOLI T.C., MARTINS L.C., PEREIRA L.A.A., MARTINS M.A., SALDIVA P.H.N., BRAGA A.L.F., Influence of socioeconomic conditions on air pollution adverse health effects in elderly people: an analysis of six regions in Sao Paulo, Brazil. J Epidemiol Community Health. 2004;58: 41-46.

13. GOUVEIA, N. et al. Poluição do ar e efeitos na saúde nas populações de duas grandes metrópoles brasileiras. Epidemiologia e Serviços de Saúde. 2003; 12(1): 29-40.

14. LIN, C.A. et al. Association between air pollution and ischemic cardiovascular emergency room visits. Environ Res. 2003; 92:59-63.

15. Santos UP et al Cardiac arrhythmia emergency room visits and environmental air pollution in Sao Paulo, Brazil. J Epidemiol Community Health. 2008 62(3):267-72.

16. SALDIVA, P. H. et al. Association between air pollution and mortality due to respiratory diseases in children in Sao Paulo, Brazil: a preliminary report. Environ Res. 1994; 65: 218225.

17. CONCEIÇÃO G.M.S., MIRAGLIA S.G., KISHI H.S., SALIVA P.H. SINGER J.M., . Air pollution and child mortality: a time-series study in São Paulo, Brazil. Environ Health Perspect.2001; 103(3): 347-350.

18. BRAGA A.L.F., et al. Air pollution and pediatric respiratory hospital admissions in São Paulo, Brazil. Journal of Environmental Medicine. 1999; 1:95-102.

19. GOUVEIA N., FLETCHER T., Respiratory diseases in children and outdoor air pollution in Sao Paulo, Brazil: a time series analysis. Occup Environ Med. 2000; 57(7): 477-483.

20. RIBEIRO H., CARDOS, M.R.A. Air pollution and children`s health in Sao Paulo (19861998). Soc Sci Med. 2003. 57: 2013-2022.

21. FREITAS C., BREMNER S.A., GOUVEIA N., PEREIRA L.A.A., SALDIVA P.H.N, Internações e óbitos e sua relação com a poluição atmosférica em São Paulo, 1993 a 1997. Rev Saúde Pública.2004. 38(6):751-757.

22. SOLE, D. et al. Prevalence of symptoms of asthma, rhinitis and atopic eczema in Brazilian adolescents related to exposure to gaseous air pollutants and socioeconomic status. $J$ Investig Allergol Clin Immunol. 2007; 17(1):6 - 13. 
23. O’NEILL M.S. et al. Air pollution and mortality in Latin America: the role of education. Epidemiology.2008; 19(6): 810 - 819.

24. PEREIRA, L. A.A. et al. Association between air pollution and intrauterine mortality in Sao Paulo, Brazil. Environ Health Perspect. 1998; 106(6): 325-329.

25. GOUVEIA N., BREMNER S.A., NOVAES, H.M.D. Association between ambient air pollution and birth weight in São Paulo, Brazil. J Epidemiol Community health.2004; 58:11-17.

26. MEDEIROS A., GOUVEIA,N.; Relationship between low birthweight and air pollution in the city of São Paulo, Brazil. Rev Saúde Pública. 2005; 39(6): 1-7.

27. FERREIRA C A S, SANTOS F.L, COSTA I.P, PEREIRA L.V. REGO P.B.L. Análise da função pulmonar de motoboys: o efeito da poluição atmosférica: prevenção, a melhor forma de cuidar. Mundo da Saúde. 2009; 32(2): 170-174.

28. SANTOS U.P. et al. Effects of air pollution on blood pressure and heart rate variability: a panel study of vehicular traffic controllers in the city of Sao Paulo, Brazil. European Heart Journal.2005; 26:193-200.

29. MARTINS L.C., LATORRE M.R.D.O., SALDIVA P.H.N., BRAGA A.L.F., Relação entre poluição atmosférica e atendimentos por infecção de vias aéreas superiores no município de São Paulo: avaliação do rodízio de veículos. Rev Bras Epidemiol. 2001; 4(3): 220-229.

30. de MEDEIROS, A.P. et al, Traffic-related air pollution and perinatal mortality: a casecontrol study. EnviroN Health Perspect. 2009; 117(1):127 - 132.

31. BELL M.L., DAVIS D.L., GOUVEIA N, BORJA-ABURTO V.H., CIFUENTES L.A., The avoidable health effects of air pollution in three latin American cities: Santiago, Sao Paulo and Mexico City. Environ Res.2006; 100(3):431 - 440.

32. MIRAGLIA S.G., SALDIVA P.H., BÖHM G.M., An evaluation of air pollution health impacts and costs in Sao Paulo, Brazil. Environmental Management. 2005. 35(5): 667 676.

33. COMPANHIA DE TECNOLOGIA DE SANEAMENTO AMBIENTAL, Caracterização das estações da rede de monitoramento da qualidade do ar na RMSP - Estação Congonhas. São Paulo: CETESB. 2004. p 64. [Acesso em 07/02/10] Disponível em: http://www.cetesb.sp.gov.br/Ar/publicacoes.asp.

34. COMPANHIA DE TECNOLOGIA DE SANEAMENTO AMBIENTAL, Caracterização das estações da rede de monitoramento da qualidade do ar na RMSP - Estação Cerqueira César. São Paulo: CETESB. 2004. p 51. [Acesso em 07/02/10] Disponível em: http://www.cetesb.sp.gov.br/Ar/publicacoes.asp. 
35. COMPANHIA DE TECNOLOGIA DE SANEAMENTO AMBIENTAL, Caracterização das estações da rede de monitoramento da qualidade do ar na RMSP - Estação Ibirapuera. São Paulo: CETESB. 2004. p 66. [Acesso em 07/02/10] Disponível em: http://www.cetesb.sp.gov.br/Ar/publicacoes.asp.

36. JERRETT, M et al. A review and evaluation of intraurban air pollution exposure models. Journal of Exposure Analysis and Environmental Epidemiology. 2005; 15:185-204.

37. RANFT U., SCHIKOWSKI T., SUGURU D., KRUTMANN J., KRÄMER U., Long- term exposure to traffic-related particulate matter impairs cognitive function in the elderly. Environmental Research. 2009; 109(8):1004 - 1011.

38. WILLIAMS, L. A. et al. Proximity to traffic, inflammation, and immune function among women in the Seatle, Washington, area. Environmental Health Perspective. 2009; 117(3):373 - 378 .

39. MEDEIROS, A.P.P, et al. Traffic-related air pollution and Perinatal Mortality: a case control study. Environmental health Perspectives. 2009; 117(1):127-132.

40. CHANG, J. et al. Repeated respiratory hospital encounters among children with asthma and residential proximity to traffic. Occupational and environmental medicine. 2009. 66(2): 90 -98 .

41. KAN, H. et al, Prospective analysis of traffic exposure as a risk factor for incidence coronary heart disease: the Athereosclerosis Risk in Communities (ARIC) study. Environmental Perspective 2008; 116(11):1463 - 1468.

42. MEDINA-RAMÓN, M.; Residential exposure to traffic-related air pollution and survival after heart failure. Environmental Health Perspective. 2008; 116(4):481 - 485.

43. MORGENSTERN, V. et al. Atopic deseases, allergic sensitization, and exposure to trafficrelated air pollution in children. American journal of respiratory and critical care medicine. 2008; 177(12):1331 - 1337.

44. CESARONI G., BADALONI C., PORTA D., FORASTIERE F., PERUCCI C.A., Comparison between various indices of exposure to traffic-related air pollution and their impact on respiratory health in adults. Occup Environ Med. 2008; 65(10):683 - 690.

45. KAN H., HEISS G., ROSE K.M., WHTSEL E., LURMANN F., LONDON S.J., Traffic exposure and lung function in adults: the Atherosclerosis Risk in communities study. Thorax. 2007; 62(10):873 - 879.

46. TONNE C., MELlY S., MITTLEMAN M., COULL B., GOLDBERG R., SCHWARTZ J., A case control analysis of exposure to traffic and acute myocardial infarction. Environmental Health Perpectives. 2007; 115(1):53 - 57. 
47. ZMIROU, D. et al. Traffic related air pollution and incidence of childhood asthma: results of the Vesta case-control study. J Epidemiol Community Health. 2004; 58(1):18 - 23.

48. PONCE N.A., HOGGART K.J., WILHELM, M., RITZ, B., Preterm birth: the interaction of traffic-related air pollution with economic hardship in Los Angeles neighborhoods. Am J Epidemiol. 2005; 162( 2):140 - 148.

49. YANG C.Y, CHANG C.C, CHUANG H.Y., HO C.K. WU T.N. TSAI S.S., Evidence for increased risks of preterm delivery in a population residing near a freeway in Taiwan. Arch Environ Health. 2003; 58(10):649 - 654.

50. ISING, H. et al. Respiratory and dermatological diseases in children with long-term exposure to road traffic emissions. Noise and Health. Schriftenr ver wassen boden lufthyg.2003; 112:81-99.

51. SHIMA M., NITTA Y., ADACHI M. Traffic-related air pollution and respiratory symptoms in children living along trunk roads in Chiba Prefecture, Japan. $J$ Epidemiol.2003; 13(2):108 - 119.

52. WILHELM M., RITZ, B. Residential proximity to traffic and adverse birth outcomes in Los Angeles County, California, 1994-1996. Environ Health Perspect. 2003; 112(2):207 216.

53. HOEK G., BRUNEKREEF B., GOLDBOHM S., FISCHER P., van den BRANDT, Association between mortality and indicators of traffic-related air pollution in Netherlands: a cohort study. The Lancet.2002; 360(19):1203-1209.

54. HOEK G., FISCHER P., van den BRANDT P., GOLDBOHM S., BRUNEKREEF B., Estimation of long-term average exposure to outdoor air pollution for a cohort study on mortality. J Expo Anal Environ Epidemiol. 2001; 11(6):459 - 469.

55. KRÄMER U. KOCH T., RANFT U., RING J., BEHRENDT H., Traffic-related air pollution is associated with atopy in children living in urban areas. Epidemiology. 2000; 11(1):64 - 70 .

56. BROOK, R.D., JERRET M., BROOK J.R., BARD R.L., FINKELSTEIN M.M., The relationship between diabetes mellitus and traffic-related air pollution. J Occup Environ Med. 2008; 50(1):32-38.

57. LIEBHART, J. et al. Prevalence and risk factors for asthma in Poland: results from the PMSEAD study. J Investig Allergol Clin Immunol. 2007; 17(6): 367 - 374.

58. AGUILERA, I. et al, Association between GIS-based exposure to urban air pollution during pregnancy and birth weight in the INMA Sabadell Cohort. Environ Health Perspect. 2009; 117(8):1322-1327. 
59. SU, J.G., JERRETT M., BECKERMAN B., WILHELM M., GHOSH J.K., RITZ B., Predicting traffic-related air pollution in Los Angeles using a distance decay regression selection strategy. Environmental Research. 2009; 109(6):657 - 670.

60. JERRET, M. et al. A cohort study of traffic-related air pollution and mortality in Toronto, Ontario, Canada. Environmental Health Perspective. 2009; 117(5): 772 - 777.

61. von KLOT, S. et al. Elemental carbon exposure at residence and survival after acute miocardial infarction. Epidemiology. 2009; 20(4): 547- 554.

62. POPLAWSKI, K. et al. Intercity transferability of land use regression models for estimating ambient concentrations of nitrogen dioxide. Journal of exposure science and environmental epidemiology. 2008; 19(1):107-117.

63. ROSENLUND M., PICCIOTTO S., FORASTIERE F., STAFOGGIA M., PERUCCI C.A.,. Traffic-related air pollution in relation to incidence and prognosis of coronary heart disease. Epidemiology. 2008; 19(1): 121- 128.

64. ROSENLUND, M. Comparison of regression models with land-use and emissions data to predict the spatial distribution of traffic-related air pollution in Rome. Journal of exposure science and environmental epidemiology. 2008; 18(2): 192-199.

65. SLAMA, R. et al. Traffic-related atmospheric pollutants levels during pregnancy and offspring's term birth weight: a study relying on a land-use regression exposure model. Environmental Health Perspective. 2007. 115(9):1283 - 1292.

66. ZANDBERGEN, P. A. Influence of geocoding quality on environmental exposure assessment of children living near high traffic roads. BMC Public Health. 2007; 7(37).

67. BRAUER M., LENCAR C., TAMBURIC L., KOEHOORN M. DEMERS P., KARR C., A cohort study of traffic-related air pollution impacts on birth outcomes. Environmental Health Perspectives. 2008. 116(5): 680 - 686.

68. KÜNZLI, N. et al. Public health impact of outdoor and traffic related air pollution: an european assessment. The Lancet. 2000; 356(2): 795-801.

69. LINDGREN, A. et al. Traffic exposure associated with allergic asthma and allergic rhinitis in adults. A cross-sectional study in southern Sweden. Int J Health Geogr. 2009; 8(25).

70. DELFINO, R.J. et al. Repeated hospital encounters for asthma in children and exposure to traffic-related air pollution near the home. Annals of allergy, asthma and immunology. 2009; 102(2):138-144.

71. HARVARD S., DEGUEN S., ZMIROU-NAVIER D., SCHILLINGER C., BARD D., Traffic-related air pollution and socioeconomic status: a spatial autocorrelation study to assess environmental equity on a small-area scale. Epidemiology. 2009; 20(2): 223-230. 
72. NORDLING, E. et al. Traffic-related air pollution and childhood respiratory symptoms, function and allergies. Epidemiology. 2008; 19(3): 401-408.

73. CYRYS, J. et al. Gis-based estimation of exposure to particulate matter and $\mathrm{NO}_{2}$ in an urban area: stochastic versus dispersion modeling. Environmental Health Perspective. 2005; 113(8): 987-992.

74. COLVILE, R.N. et al. Sustainable development of urban transport systems and human exposure to air pollution. Science of the total environment. 2004; 334-335: 481-487.

75. BRAUER, M. et al. Air pollution from traffic and the development of respiratory infections and asthmatic and allergic symptoms in children. Am J Respir Crit Care Med. 2002; 166(8): $1092-1098$.

76. GEHRING, U. et al. Traffic-related air pollution and repiratory health during the first 2 years of life. Eur RespirJ. 2002; 19( 4): 690 - 698.

77. Brunekreef B, Beelen R, Hoek G, Schouten L, Bausch-Goldbohm S, Fischer P, Armstrong B, Hughes E, Jerrett M, van den Brandt P. Effects of long-term exposure to traffic-related air pollution on respiratory and cardiovascular mortality in the Netherlands: the NLCS-AIR study.Res Rep Health Eff Inst. 2009; 139:5-71.

78. ROSENLUND M., FORASTIERE F., PORTA D., de SARIO M., BADALONI C., PERUCCI C.A., Traffic-related air pollution in relation to respiratory symptoms, allergic sensitization and lung function in schoolchildren. Thorax. 2009. 64(7): 573-580.

79. van ROOSBROECK, S. LI R., HOEK G., LEBRET E., BRUNEKREEF B., SPIEGELMAN D. Traffic-related outdoor air pollution and respiratory symptoms in children: the impact of adjustment for exposure measurements error. Epidemiology. 2008; 19(3):409-416.

80. van ROOSBROECK S., HOEK G., MELIEFSTE K., JANSSEN N.A., BRUNEKREEF B., Validity of residential traffic intensity as an estimate of long-term personal exposure to traffic-related air pollution among adults. Environ Sci Technol. 2008; 42(4):1337 - 1344.

81. MODIG, L. et al. Vehicle exhaust exposure in an incident case-control study of adult asthma. Eur Respir J 2006; 28(1): 75-81.

82. GAUDERMAN, W.J. et al. Childhood asthma and exposure to traffic and nitrogen dioxide. Epidemiology. 2005; 16(6): 737 - 743.

83. HEINRICH, J. et al. Exposure to traffic related air pollutants: self reported traffic intensity versus GIS modeled exposure. Occup Environ Med. 2005; 62(8):517 - 523. 
84. BRAUER, M. et al. Estimating long-term average particulate air pollution concentrations: application of traffic indicators and geographic information systems. Epidemiology. 2003; 14(2): 228-239.

85. BERGLIND, N. et al. Ambient air pollution and daily mortality among survivors of myocardial infaRction. Epidemiology.2009; 20(1): 110-118.

86. FAN, Z.T. et al. Acute exposure to elevated $\mathrm{PM}_{2.5}$ generated by traffic and cardiopulmonary health effects in health older adults. Journal of exposure scientifical environmental epidemiology. 2008; 19(5): 525 - 533.

87. ESCAMILLA-NUÑEZ, M.C. et al. Traffic-related air pollution and respiratory symptoms among asthmatic children, resident in Mexico city: the EVA cohort. Resp Res.2008; 9(1):74 -85 .

88. JERRET, M. et al. Traffic-related air pollution and asthma onset in children: a prospective cohort study with individual exposure measurement. Environ Health Perspect. 2008; 116(10):1433 - 1438 .

89. LEE Y.L., SU H.J., SHEU H.M., YU H.S., GUO Y.L.,. Traffic-related air pollution, climate, and prevalence of eczema in Taiwanese school children. J Invest Dermatol. 2008; 128(10): 2412-2420.

90. NORMAN R., CAIMCROSS E., WITI J., BRADSHAW D., Estimating the burden of disease attributable to urban outdoor air pollution in South Africa. South african MedicalJjournal. 2007; 97:782 - 790.

91. LANKI, T. et al. Associations of traffic related air pollutants with hospitalization for first acute myocardial infarction: the HEAPSS study. Occup Environ Med. 2006; 63(12): 844 851.

92. KUEHNI C.E., STRIPPOLI MP. F., ZWAHLEN M., SILVERMAN M., Association between reported exposure to road traffic and respiratory symptoms in children: evidence of bias. International Journal of Epidemiology. 2006; 35(3): 779-786.

93. SILVAM M.F. Emissão de metais por veículos automotores e seus efeitos à saúde pública. [Dissertação de Mestrado]. São Paulo: Faculdade de Saúde Pública da USP;2007.

94. HWANG B.F., LEE Y.L., LIN Y.C. JAAKKOLA J.J., GUO Y.L., Traffic related air pollution as a determinant of asthma among Taiwanese school children. Thorax. 2005; 60(6): $467-473$.

95. HONG, Y.C.et al. Exposure to air pollution and pulmonary function in university students. Int Arch Occup Environ Health.2005; 78(2):132 - 138. 
96. KIM J.J., SMORODINSKY S., LIPSETT M., SINGER B.C., HODGSON A.T., OSTRO B., Traffic-related air pollution near busy roads: the east bay children's respiratory health study. American Journal of respiratory and critical care medicine. 2004; 170(5):520 - 526.

97. JANSSEN, N.A. et al. The relationship between air pollution from heavy traffic and allergic sensitization, bronchial hyperresponsiveness, and respiratory symptoms in Dutch schoolchildren. Environ Health Perspect. 2003; 111(12): 1512-1518.

98. ZMIROU, D. et al. Five epidemiological studies in transport and asthma: objectives, design and descriptive results. J Expo Anal Environ Epidemiol. 2002; 3(12):186 - 196.

99. GUO, Y.L. et al. Climate, traffic-related air pollutants, and asthma prevalence in middleschool children in Taiwan. Environmental Health Perspective. 1999; 107(12): 1001-1006.

100. HIRSCH, T. et al. Inner city air pollution and respiratory health and atopy in children. Eur Respir J.1999; 14(3): 669-677. 


\section{OBJETIVO GERAL}

Avaliação da exposição da população à poluição relacionada ao tráfego veicular e sua associação com internação por doenças respiratórias de crianças e adolescentes de 0 a 18 anos, em São Paulo.

\subsection{Objetivos Específicos}

- Modelar a emissão de poluentes veiculares (CO, NOx e $\left.\mathrm{PM}_{10}\right)$ no centro expandido do município de São Paulo.

- Avaliar a disponibilidade e adequação dos dados existentes para uso do modelo CALINE-4 para a da distribuição dos poluentes veiculares na cidade de São Paulo

- Avaliar da distribuição espacial das concentrações de $\mathrm{CO}, \mathrm{NOx}$ e $\mathrm{MP}_{10}$ em micro-escala na área do centro expandido de São Paulo;

- Avaliar a associação das concentrações veiculares calculadas pelo modelo e as internações por doenças respiratórias de crianças e adolescentes de 0 a 18 anos residentes na área. 


\title{
3. MÉTODO
}

A pesquisa realizada é do do tipo estudo de caso, em que foram estimadas e georreferenciadas as concentrações de $\mathrm{CO}, \mathrm{NOx}$ e $\mathrm{MP}_{10}$ emitidas por fontes veiculares em cada um dos setores censitários do centro expandido de São Paulo. Em seguida, foram levantadas as taxas de internações por doenças respiratórias de crianças e adolescentes de 0 a 18 anos residentes nesta área, durante o ano de 2005. Por fim, foi investigada a existência de associação entre as internações por doenças respiratórias e a poluição atmosférica, categorizada em cinco níveis. Cada uma destas etapas é descrita a seguir.

\subsection{Estimativa da emissão de poluentes veiculares no centro expandido de São Paulo}

\begin{abstract}
A partir de uma base de ruas georreferenciada do município de São Paulo, na qual foram inseridas as informações sobre a frota circulante, foram estimadas as emissões e as concentrações dos poluentes $\mathrm{CO}, \mathrm{NOx}$ e $\mathrm{MP}_{10}$ na área de estudo.
\end{abstract}




\subsubsection{Levantamento das vias de tráfego:}

As informações sobre as vias de tráfego em uma base de dados digital georreferenciada foi fornecida pela da Companhia de Engenharia de Tráfego (CET). Essa base de dados possui o número de faixas de rolamento existentes nas ruas, o que permitiu o cálculo da largura da rua, um dos dados de entrada do modelo. A largura das faixas considerada foi de $3,5 \mathrm{~m} .^{1}$

Desta base de dados foi recortada a área do centro expandido de São Paulo, a qual compreende a região que é circundada pelas Marginais do Rio Tietê e Pinheiros, Avenida dos Bandeirantes, Av. D. Affonso Taunay, Complexo Viário Maria Maluf, Av Tancredo Neves, Av das Juntas Provisórias, Av. Prof Luís Inácio de Anhaia Melo e Av. Salim Farah Maluf.

\subsubsection{Contagem dos veículos:}

Em uma primeira etapa, para caracterização do número de veículos nas vias do centro expandido no ano de 2005 , foram utilizados os dados coletados pela CET em 32 pontos por categoria de veículos (automóveis, caminhões, ônibus e motos). Os pontos amostrados foram inseridos na base e o valor das contagens foram estendidos até $5 \mathrm{~km}$ de distância para cada lado do ponto, o que compreendeu cerca de $7 \%$ dos links da base de dados de ruas. Para as vias onde não havia dados de contagem de veículos, foram utilizados os valores do número de veículos simulados pela CET com o modelo EMME-2.

\footnotetext{
${ }^{1}$ Comunicação pessoal de João Cucci Neto, recebida em 23 de julho de 2008, por de correio eletrônico.
} 
O modelo EMME-2 é um modelo muito utilizado para planejamento na área de transportes.Ele leva em conta características das viagens (ex.: número de viagens por dia, origem e destino, modo de viagem, etc), informações sócioeconômicas (tais como tamanho das famílias, projeção do número de habitantes, etc) e ainda, informações detalhadas a respeito das vias de tráfego, combinadas com informações de congestionamento, velocidade dos deslocamentos, número de ocupantes dos veículos, entre outras, para previsão dos volumes de tráfego nas vias (MWVCOG, 2010).

Em uma segunda etapa,foram utilizados dados de contagem veicular realizados na área. Parte dos dados foi disponibilizada pela CET e eram resultantes de medições avulsas realizadas nos períodos de pico da manhã e da tarde em 153 pontos na área do centro expandido. Outra parte, foram medidas realizadas pela Faculdade de Saúde Pública da USP, em conjunto com a Secretaria de Saúde da Prefeitura de São Paulo, como parte do Projeto FAPESP 2006/61616-5 em 105 pontos, cujo método de contagem foi o mesmo da CET.

Todos os dados foram inseridos na base de ruas e também foram estendidos por $5 \mathrm{~km}$ a partir do ponto de contagem. Neste caso, para as ruas que ficaram sem informações, foram atribuídos os valores médios dos volumes medidos por tipo de via (Trânsito rápido, Arterial 1, Arterial 2, Arterial 3, Coletora 1, Coletora 2, Local e Pedestre). A Tabela 3-1: Número médio de veículos segundo a classificação das vias: 
Tabela 3-1: Número médio de veículos segundo a classificação das vias

\begin{tabular}{|l|c|c|c|}
\hline \multicolumn{1}{|c|}{ TIPO DE VIA } & AUTOMÓVEL & MOTO & DIESEL \\
\hline Trânsito Rápido & 3361 & 447 & 81 \\
\hline Arterial 1 & 2057 & 276 & 119 \\
\hline Arterial 2 & 725 & 76 & 60 \\
\hline Arterial 3 & 725 & 76 & 60 \\
\hline Coletora 1 & 150 & 15 & 11 \\
\hline Coletora 2 & 122 & 13 & 9 \\
\hline Local & 18 & 2 & 1 \\
\hline Pedestre & 0 & 0 & 0 \\
\hline
\end{tabular}

A definição da composição da frota em função do tipo de combustível foi realizada a partir dos dados fornecidos pelo Departamento de Trânsito (Detran).

Os percentuais de veículos movidos à gasolina, álcool e flex, registrados no município de São Paulo, no ano de 2005 foram de 79,8\%, 16\% e 4,2\%, respectivamente. Estes dados foram utilizados para o cálculo da emissão por tipo de veículo.

3.1.3. Aplicação do modelo de cálculo das concentrações de poluentes emitidos por veículos

Foi utilizado o modelo CALINE-4 modificado para o cálculo das concentrações dos poluentes emitidos por fontes veiculares.

CALINE-4 é um modelo de qualidade do ar de fonte linear, desenvolvido pelo Departamento de Transporte da Califórnia (CALTRANS). O objetivo do modelo é avaliar os impactos da qualidade do ar em locais próximos às vias de tráfego. Para tal, ele se baseia nas equações de difusão Gausiana. Uma vez fornecidos os dados a respeito das fontes de emissão, meteorologia e geometria das vias 
é possível determinar a concentração de poluentes para os receptores. Neste modelo as vias são divididas em links. As concentrações de poluentes para cada um dos links são computadas e em seguida somadas para determinação da concentração dos poluentes no local da exposição do receptor. A região existente exatamente em cima da via de tráfego é tratada como uma zona uniforme de emissão e turbulência (zona de mistura). Isso permite que a turbulência mecânica causada pelo movimento dos veículos e a turbulência térmica causada pela exaustão dos veículos não sejam os mecanismos dominantes de dispersão (BENSON, 1989). A versão original do CALINE-4, desenvolvida pelo CALTRANS, permite a especificação de até vinte linhas de dispersão e vinte receptores. Uma modificação deste modelo, realizada pela Universidade da Califórnia permitiu a utilização de múltiplas linhas de dispersão e receptores, permitindo que este modelo seja utilizado em estudos epidemiológicos.

A fim de se lidar com as complexidades das emissões de cada um dos tipos de veículos existentes no município de São Paulo, foram rodados modelos específicos para cada uma das classes de veículos existentes: 1) carros movidos exclusivamente à gasolina; 2) carros movidos exclusivamente à álcool; 3) carros flex; 4) diesel (caminhões e ônibus) e 5) motos. Isso foi necessário porque cada um destes veículos possui diferentes taxas de emissão de poluentes. Os resultados destas modelagens foram somados a fim de se obter uma única concentração para cada um dos poluentes estudados (CO, NOx, $\mathrm{PM}_{10}$ ). Essa operação foi realizada com o programa de análise estatística SAS 9.0 .

Além disso, para cada uma das classes de veículos, foi realizada uma modelagem para representar o período de verão e outra, para o período de inverno. Foi realizada uma modelagem das concentrações horárias dos 
poluentes para o mês de janeiro (a fim de se representar o período de verão) e uma modelagem das concentrações horárias dos poluentes para o mês de junho (a fim de se representar o período de inverno). Tradicionalmente, os meses de janeiro e junho são períodos de férias, quando o tráfego é alterado. No entanto, este estudo usou apenas as condições meteorológicas destes meses, a fim de melhor caracterizar os períodos de verão e inverno. Foi mantido o volume de veículos característico dos meses típicos do ano, nos quais não se observam diferenças no número de veículos.

Para selecionar os meses que foram modelados, os dados horários de $\mathrm{CO}$ (fornecidos pela CETESB) foram divididos em dois grupos: inverno (abril a setembro) e verão (outubro a março). Foram calculadas as médias mensais de CO para as estações Pinheiros, Ibirapuera, Mooca e Santana nos anos de 2000 a 2005. Para o inverno, foi selecionado o mês de junho por apresentar a maior concentração média de CO. Para o verão tanto o mês de janeiro quanto o mês de novembro apresentaram as menores concentrações de CO. Assim foram feitas análises para verificar se ambas as médias eram estatisticamente diferentes. Como o teste estatístico demonstrou que as médias eram estatisticamente iguais, optou-se por utilizar o mês de janeiro como o mês característico da estação de verão, por este ter mais dados disponíveis.

Além disso, para decidir se seria necessário subdividir a área de estudo (centro expandido) em subáreas, de acordo com as condições meteorológicas, fez-se uma análise de estatística, aplicando-se o teste $\mathrm{T}$ aos dados de velocidade do vento e direção do vento das estações Pinheiros, Mooca, Ibirapuera e Santana, do ano de 2005. O objetivo desta análise foi verificar se os dados eram estatisticamente diferentes. Caso fossem iguais, poderiam ser utilizados os dados de uma única estação para toda a área. 
A análise estatística mostrou que os dados eram estatisticamente diferentes e que, portanto seria necessário subdividir a área de estudo em subáreas, de acordo com as características meteorológicas de direção e velocidade do vento.

Optou-se por usar para a subárea Santana os mesmos dados meteorológicos da subárea Ibirapuera. Isso porque, de acordo com levantamento bibliográfico realizado, estas áreas teriam as mesmas características. Essa decisão foi baseada no trabalho realizado por KARAM et al (2003), cujo estudo foi mais detalhado que as análises aqui realizadas, justificando a adoção dos resultados por eles obtidos. A Figura 3-1: Subáreas meteorológicas utilizadas na modelagem das concentrações de poluentes emitidos por fontes móveis veiculares, apresenta a divisão da área de estudo utilizada para a aplicação do modelo de previsão das concentrações de poluentes emitidos por fontes veiculares. 


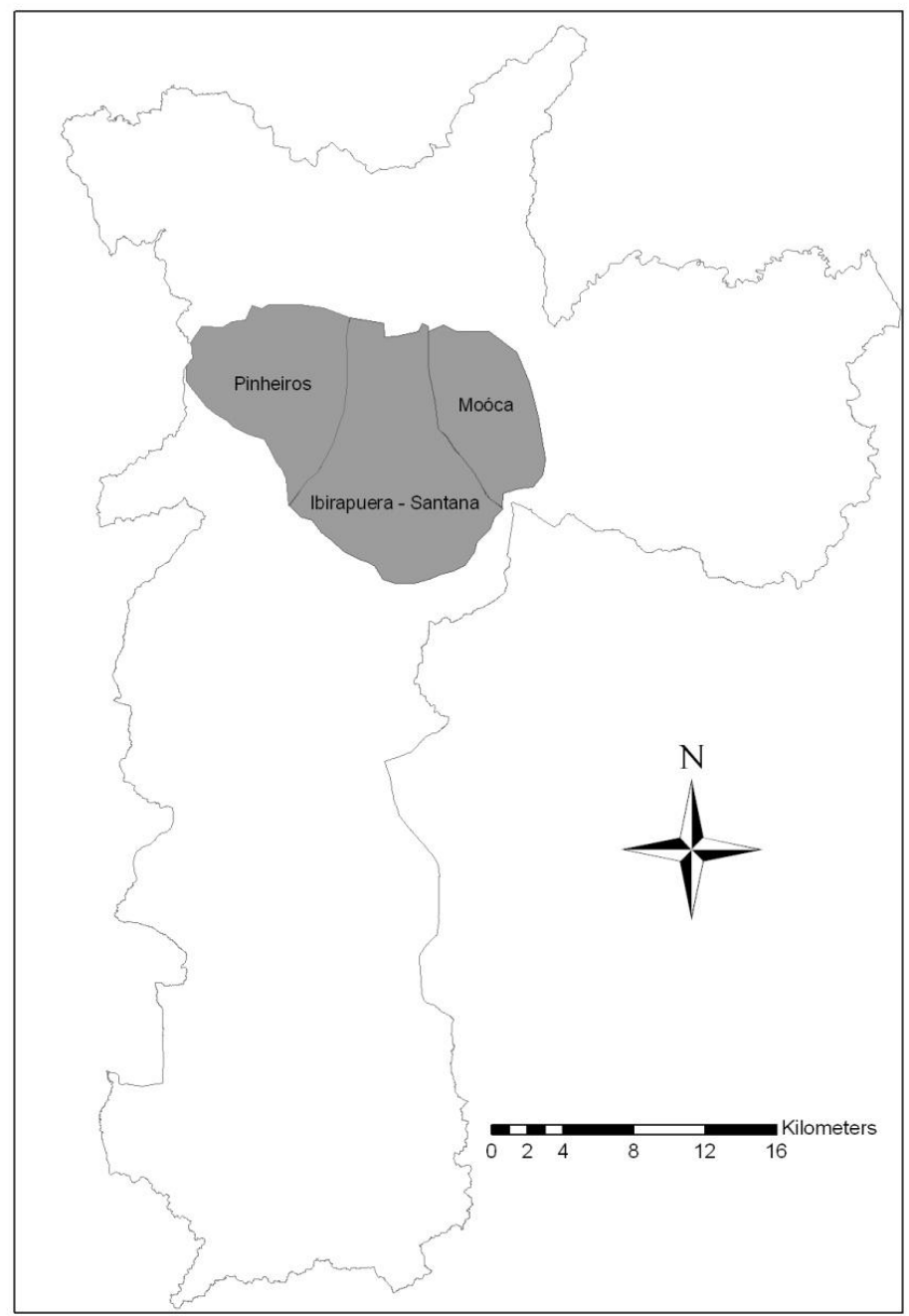

Figura 3-1: Subáreas meteorológicas utilizadas na modelagem das concentrações de poluentes emitidos por fontes móveis veiculares

O modelo CALINE-4 foi utilizado para o cálculo das concentrações de monóxido de carbono. Para os demais poluentes, foi feita apenas uma estimativa, ajustando-se as taxas de emissão. Não é possível, neste modelo, considerar as transformações sofridas pelos NOx e PM ${ }_{10}$. 
Os dados de entrada do modelo são divididos em 5 seções: 1)Dados das vias de tráfego; 2)Dados dos receptores; 3)Dados da quantidade de veículos; 4)Dados da emissão dos poluentes e 5)Dados Meteorológicos.

\section{Dados das Vias de Tráfego:}

Foi necessário adicionar ao modelo informações sobre cada um dos links de ruas da base de dados. Foram adicionadas as informações de $X$ e $Y$ (par de coordenadas geográficas) para o início e fim do link, além da largura da via, calculada de acordo com o mencionado no item 3.1.1.

\section{Dados dos Receptores:}

A localização dos receptores foi considerada como sendo o centróide do setor censitário. Sendo assim, não foi calculada a concentração no local exato da residência dos indivíduos, e sim, a concentração no centróide do setor censitário, admitindo-se que esta concentração era igual em todo o setor censitário. No modelo foram introduzidas as identificações de cada um dos setores censitários, bem como as coordenadas geográficas dos seus centróides. Estes últimos foram obtidos com a ferramenta XToll Pro do programa computacional de georreferenciamento ArcGis.

\section{Dados da Quantidade de Veículos:}

O modelo requer a introdução dos dados da quantidade de veículos. Sendo assim, para cada um dos links das vias de tráfego, foram introduzidas as quantidades de veículos, de acordo com as categorias estudadas (carros movidos exclusivamente à gasolina, carros movidos à exclusivamente à álcool, 
carros flex, diesel e motos). A forma como estes dados foram obtidos está descrita no item 3.1.2.

\section{Dados da Emissão dos Poluentes:}

Os dados de emissão dos poluentes foram obtidos a partir do Relatório de Qualidade do Ar do Estado de São Paulo, emitido pela CETESB. Para tal, foi utilizado relatório referente ao ano de 2005. Estes dados de emissão são dados médios de cada uma das categorias de veículos e que buscam representar a diversidade de modelos e idade dos veículos existentes. Os valores utilizados estão apresentados a seguir na Tabela 3-2: Dados de emissão de poluentes veiculares para o ano de 2005 na RMSP:

Tabela 3-2: Dados de emissão de poluentes veiculares para o ano de 2005 na RMSP

\begin{tabular}{|l|c|c|c|}
\hline Classe Veicular & $\mathbf{C O}(\mathbf{g} / \mathbf{K m})$ & NOx $(\mathbf{g} / \mathbf{K m})$ & $\mathbf{M P}_{\mathbf{1 0}}(\mathbf{g} / \mathbf{K m})$ \\
\hline Gasolina & $10,70^{(1)}$ & $0,66^{(1)}$ & $0,08^{(1)}$ \\
\hline Álcool & $19,70^{(1)}$ & $1,16^{(1)}$ & $0,00221^{(2)}$ \\
\hline Flex & $0,44^{(1)}$ & $0,11^{(1)}$ & $0,00221^{(2)}$ \\
\hline Diesel & $15,00^{(1)}$ & $10,74^{(1)}$ & $0,57^{(1)}$ \\
\hline Moto & $16,40^{(1)}$ & $0,12^{(1)}$ & $0,05^{(1)}$ \\
\hline
\end{tabular}

Fonte: (1) CETESB, Relatório da Qualidade do Ar no Estado de São Paulo 2005(2006).

(2) SILVA et al, 2009.

As emissões dos veículos flex foram obtidas com esses veículos sendo abastecidos com álcool. Estas emissões se diferenciam das emissões dos veículos estritamente a álcool devido as diferenças na tecnologia dos motores. No Relatório da Qualidade do Ar no Estado de São Paulo (CETESB, 2006) não ficam explicitadas as considerações realizadas no cálculo da taxa de emissão 
de poluentes por veículos movidos à diesel. Neste caso, não é possível determinar se o valor mencionado na Tabela 3-2 considera as emissões de ônibus e caminhões ou de apenas uma destas categorias.

\section{Dados Meteorológicos:}

Foram introduzidos os dados de direção e velocidade do vento, desvio-padrão da direção do vento, classe de estabilidade, altura da camada de mistura e temperatura. Os dados horários de direção e velocidade do vento e desviopadrão da velocidade do vento, para os meses de janeiro e junho de 2005, foram obtidos junto à CETESB. Os dados de classe de estabilidade, altura da camada de mistura e temperatura foram fornecidos pelo Departamento de Ciências Atmosféricas do Instituto de Astronomia, Geofísica e Ciências Atmosféricas da Universidade de São Paulo (IAG/USP). Nos casos de dados inexistentes para a velocidade e direção do vento, foi utilizada a média calculada por classe de estabilidade.

\subsubsection{Validação do Modelo}

Após aplicação do modelo, foram realizadas análises de correlação $(\alpha=0,05)$ entre as concentrações calculadas pelos dois modelos (com os dados de tráfego modelados e com os dados de tráfego medidos) e as concentrações reais medidas pelas estações da CETESB. Para tal foi selecionada uma área de $1 \mathrm{Km}$ em torno das estações de monitoramento da CETESB e obtidas as concentrações médias de $\mathrm{CO}$, NOx e $\mathrm{MP}_{10}$. 
3.1.5. Associação entre a poluição veicular calculada e internações por doenças respiratórias

As concentrações dos poluentes obtidas pelo modelo foram correlacionadas com as taxas de internações por doença respiratória de crianças e adolescentes residentes na área de estudo.

Georreferenciamento do endereço residencial das pessoas internadas por doenças respiratórias:

Foram georreferenciados os casos de internação por doença respiratória por endereço de residência do paciente a partir do banco de dados de Autorização de Internação Hospitalar (AlH) e de Comunicação de Internação Hospitalar $(\mathrm{ClH})$. O georreferenciamento dos dados foi realizado considerando-se 0 endereço completo. Para os casos em que não foi possível realizar o georreferenciamento dos dados por endereço utilizou-se o Código de Endereçamento Postal - CEP para a localização dos mesmos. Do total de dados georreferenciados, $94,5 \%$ foram localizados pelo endereço completo, e $5,5 \%$ foram localizados pelo CEP.

Foram excluídos os dois setores censitários cujo número de casos era exageradamente alto. Nestes setores situam-se hospitais de grande relevância (Hospital das Clínicas e Hospital São Paulo) e acredita-se que, na base de dados, o endereço do paciente tenha sido substituído pelo endereço do hospital, causando uma grande concentração de casos neste local. 
Agravos à saúde estudados:

Foram selecionados os casos cujo diagnóstico principal pertencia aos seguintes grupamentos da CID-10 (Classificação Internacional de Doenças):

- J00-J06: Infecções agudas das vias aéreas superiores;

- J10-J18 (Exceto J17): Influenza (gripe) e pneumonia;

- J20-J22: Outras infecções agudas das vias aéreas superiores;

- J40-J47: Doenças crônicas das vias aéreas inferiores.

\section{Período analisado:}

Foram analisados dois períodos distintos: verão e inverno. Para o período do verão, as internações ocorridas nos meses de Janeiro, Fevereiro e Março de 2005 foram selecionadas. Para o período de inverno, foram utilizados os casos de internações que ocorreram nos meses de Junho, Julho e Agosto de 2005.

\section{População Estudada:}

Foi estudada a população residente no centro expandido do município de São Paulo, na faixa etária de 0-18 anos.

\section{Análise Estatística:}

Para identificar a possível associação entre a exposição à poluição relacionada ao tráfego e a ocorrência de doenças respiratórias, usou-se um modelo de regressão logística múltiplo. 
Para tal, calculou-se, para cada um dos setores censitários, a incidência das doenças respiratórias dividindo-se o número de internações pelo número de pessoas residentes da faixa etária estudada no centro expandido. Considerouse que os setores que possuíam incidência maior que o $1^{\circ}$ quartil eram setores com casos (1), os demais setores foram considerados como controles (0).

A poluição foi divida em 5 classes de intensidade: 0) com valores de concentração de poluentes menores ou iguais ao 1Q Quartil; 1) com valores maiores que $01^{\circ}$ quartil e menores ou iguais a mediana; 2) com valores maiores que a mediana e menores ou iguais a $75 \%$; 3) com valores maiores que $75 \%$.e menores ou iguais a $90 \%$ e 4) com valores maiores que $90 \%$.

Calculou-se a razão de chances (odds ratio) para cada uma das classes de poluição, ajustando-se pelo índice de desenvolvimento humano (IDH) em duas categorias (valor de corte igual à mediana).

\section{Razão de Chance= Proporção de expostos entre os casos}

Proporção de expostos entre o controle 


\section{RESULTADOS E DISCUSSÃO:}

Manuscrito 2: Avaliação dos uso de dados modelados de tráfego em estudos de exposição à poluição veicular: um estudo de caso no município de São Paulo, Brasil

Giovana lara Ferreira Moser de Toledo ${ }^{(1)}$

Adelaide Cássia Nardocci ${ }^{(1)}$

(1)Departamento de Saúde Ambiental da Faculdade de Saúde Pública da Universidade de São Paulo. Avenida Dr. Arnaldo, 715. Cerqueira César. 01246-904. São Paulo/SP.

Artigo encaminhado para a Revista Engenharia Sanitária e Ambiental 


\title{
AVALIAÇÃO DO USO DE DADOS MODELADOS DE TRÁFEGO EM ESTUDOS DE EXPOSIÇÃO À POLUIÇÃO VEICULAR: UM ESTUDO DE CASO NO MUNICÍPIO DE SÃO PAULO, BRASIL
}

\author{
EVALUATION OF THE USE OF MODELED TRAFFIC \\ DATA IN TRAFFIC-RELATED AIR POLLUTION \\ EXPOSURE ASSESSMENT: A CASE STUDY IN SAO \\ PAULO, BRAZIL
}

Giovana Iara Ferreira Moser de Toledo ${ }^{(1)}$

É Bacharel em Ciências Biológicas pela Pontifícia Universidade Católica de São Paulo (1998), mestre em Engenharia Sanitária pela POLI/USP (2003) e doutoranda do Departamento de Saúde Ambiental da Faculdade de Saúde Pública da USP.

Adelaide Cássia Nardocci ${ }^{(1)}$

É Bacharel em Física pela Universidade Estadual de Londrina (1987), mestre em Engenharia Nuclear pela COPPE/UFRJ (1990) e doutora em Saúde Pública pela Universidade de São Paulo (1999). É professora doutora do Departamento de Saúde Ambiental da FSP/USP.

${ }^{(1)}$ Departamento de Saúde Ambiental da Faculdade de Saúde Pública da Universidade de São Paulo. Avenida Dr. Arnaldo, 715. Cerqueira César. 01246-904. São Paulo/SP. giovana_moser@yahoo.com.br

Título resumido: Uso modelagens de tráfego em estudos de exposição à poluição veicular 


\title{
Resumo
}

O município de São Paulo tem cerca de 6 milhões de veículos que são a principal fonte de emissão de poluentes atmosféricos, sendo um importante problema de saúde pública. O objetivo foi avaliar o uso dos dados de tráfego obtidos pelo EMME-2 para a avaliação da exposição da população à poluição veicular. O número de veículos nas vias foi simulado com o EMME-2 e para o cálculo das concentrações de $\mathrm{CO}, \mathrm{NOx}$ e $\mathrm{PM}_{10}$ foi usado o modelo CALINE-4. Os resultados encontrados evidenciam gradientes nas concentrações dos poluentes veiculares no centro expandido da cidade de São Paulo e reforçam a importância da realização de estudos mais detalhados da exposição da população. No entanto, o estudo também mostra a necessidade de melhoria no levantamento das informações necessárias tanto para a entrada dos modelos como também para calibração e validação dos resultados.

Palavras chave: poluição do ar, emissão veicular, CALINE-4, avaliação da exposição, tráfego urbano.

\begin{abstract}
São Paulo city has around 6 million vehicles, which are the main source of atmospheric pollutants; and it represents an important problem of public health. The aim of this study was to evaluate the use of traffic data obtained by EMME-2 to assess traffic-related human exposure. The number of vehicles was simulated using EMME-2 and in order to calculate $\mathrm{CO}$, NOx and $\mathrm{PM}_{10}$ concentrations, the model CALINE-4 was used. Results show a gradient of pollutant concentration in the expanded center of Sao Paulo city and it highlights the importance of the development of detailed exposure assessment studies. Besides, this study also shows the necessity of an improvement at the required information, not only for model inputs, but also for model validation and calibration.
\end{abstract}

Keywords: air pollution, vehicle emissions, CALINE-4, exposure assessment, traffic, modeling. 


\section{Introdução}

São Paulo é uma das maiores e mais desenvolvidas cidades da América do Sul, com cerca de 11 milhões de habitantes. A frota do município é de aproximadamente 6 milhões de veículos, com tendência crescente. A malha viária tem 18 mil quilômetros de vias e o gerenciamento do tráfego é realizado pela Companhia de Engenharia de Tráfego (CET), criada em 1976. Apesar da extensão da malha viária e da importância do controle do tráfego para a vida diária dos paulistanos, ainda não existem muitos dados a respeito do comportamento diário da frota, pois a contagem de veículos é realizada em 32 ruas do município, nos horários de pico da manhã e tarde. O município conta também com muitas câmeras e radares. No caso das câmeras, as imagens não são armazenadas impossibilitando a contagem. Os radares são operados por empresas privadas, e segundo informações da CET, estes dados não são repassados à companhia.

Além dos dados de medição, o Setor de Planejamento de Transporte da CET utiliza o software canadense EMME-2, desenvolvido pela empresa INRO. Ele permite estudar a infra-estrutura viária da região, representada por uma rede multimodal, utilizando um banco de dados que considera a demanda e o tempo de viagens, o levantamento socioeconômico por origem e destino, entre outros.

A Companhia Ambiental do Estado de São Paulo (CETESB) estima que 97,5\% do $\mathrm{CO}$ e $96 \%$ do NOx tem origem veicular (CETESB, 2008), o que corresponde à cerca de $1,5 \times 10^{6}$ toneladas de $\mathrm{CO}$ e $3,5 \times 10^{5}$ toneladas de NOx emitidas na atmosfera por ano. A frota de São Paulo possui $16 \%$ de veículos movidos à álcool, o que a torna única, quando comparada a frota de grandes cidades estrangeiras.

No que se relaciona ao monitoramento da qualidade do ar, a cidade conta com uma rede composta por 12 estações que medem as concentrações de Material Particulado $\left(\mathrm{MP}_{10}\right)$, Dióxido de Enxofre $\left(\mathrm{SO}_{2}\right)$, Monóxido de Nitrogênio (NO), Dióxido de Nitrogênio $\left(\mathrm{NO}_{2}\right)$, Óxidos de Nitrogênio (NOx), Monóxido de Carbono $(\mathrm{CO})$ e mais recentemente o Ozônio $\left(\mathrm{O}_{3}\right)$

O impacto da poluição do ar à saúde da população na cidade de São Paulo tem sido muito estudado nos últimos anos (Toledo e Nardocci, 2010), No entanto, estes estudos em sua maioria, analisam a correlação entre os dados de morbidade e mortalidade com os valores da concentração dos poluentes monitorados e não permitem, portanto, a análise específica da contribuição da poluição emitida pelos veículos. Considerando o elevado número veículos que circulam diariamente e a complexidade da malha viária e da ocupação urbana na cidade, espera-se que as variações espaciais das concentrações de poluentes sejam significativas, resultando, desta forma, em uma distribuição desigual da exposição e dos riscos à saúde. A falta de informações detalhadas tem sido uma das dificuldades principais para aprofundar o conhecimento desta realidade.

Por outro lado, nos últimos anos tem crescido o número de estudos envolvendo modelos, não apenas para a avaliação da exposição à poluição veicular em áreas urbanas, como também para análise do comportamento do tráfego e da emissão e dispersão dos poluentes (Hellén et al, 2005; Kousa et al, 2002; Loh et al, 2009; Sbayti et al, 2001; Smargiassi et al, 2006). Estes modelos, em geral, apresentam vantagens como 
por exemplo, o menor custo e rapidez na elaboração e análise de cenários, se constituindo em importantes ferramentas de planejamento, ainda que, forneçam resultados menos precisos que as medições.

Assim, o objetivo deste trabalho foi avaliar a viabilidade do uso dos dados de tráfego obtidos pelo EMME-2 em estudos de avaliação da exposição da população à poluição veicular no município de São Paulo.

\section{Métodos}

Este estudo avaliou a distribuição das concentrações de $\mathrm{CO}$, NOx e $\mathrm{PM}_{10}$ emitidas pelos veículos na área do centro expandido da cidade de São Paulo onde o tráfego é mais intenso e é composta de 2503 setores censitários. As informações da população por setor censitário foram obtidas da malha de setor censitário do Censo 2000 do Instituto Brasileiro de Geografia e Estatística (IBGE).

Foram utilizados os dados do número de veículos por categoria: veículos pesados (caminhões), veículos leves (carros movidos à gasolina, álcool e flex) e motocicletas medidos pela CET em apenas 32 vias de trânsito rápido. Para as demais vias foram utilizados os dados simulados pelo modelo EMME-2. Todos estes dados estavam combinados em uma base de ruas georreferenciada e foram fornecidos pela CET. Deve ser destacado que os dados simulados não tem a informação sobre o número de ônibus. Essas informações foram obtidas da SPTRANS, no entanto, não puderam ser consideradas, pois estavam em uma base de logradouros diferente da CET. Os fatores de emissão utilizados neste estudo são os apresentados na Tabela 1:

Tabela 1: Dados de emissões veiculares utilizados no estudo

\begin{tabular}{lccc}
\hline \multicolumn{1}{c}{ Classe Veicular } & $\mathbf{C O}(\mathbf{g} / \mathbf{K m})$ & NOx $(\mathbf{g} / \mathbf{K m})$ & $\mathbf{M P}_{\mathbf{1 0}}(\mathbf{g} / \mathbf{K m})$ \\
\hline Gasolina & $10,70^{(1)}$ & $0,66^{(1)}$ & $0,08^{(1)}$ \\
Álcool & $19,70^{(1)}$ & $1,16^{(1)}$ & $0,00221^{(2)}$ \\
Flex & $0,44^{(1)}$ & $0,11^{(1)}$ & $0,00221^{(2)}$ \\
Diesel & $15,00^{(1)}$ & $10,74^{(1)}$ & $0,57^{(1)}$ \\
Moto & $16,40^{(1)}$ & $0,12^{(1)}$ & $0,05^{(1)}$ \\
\hline
\end{tabular}

Fonte: (1) CETESB, Relatório da Qualidade do Ar no Estado de São Paulo 2005 (2006).

(2) SILVA et al, 2009.

O modelo CALINE-4 foi desenvolvido pelo Departamento de Transporte da Califórnia dos Estados Unidos (US-CDT) e permite estimar as concentrações de CO, NOx e PM $_{10}$ emitidas por veículos (Benson, 1992). Foi utilizado um modelo modificado, que permite o cálculo de um maior número de receptores. Este modelo foi cedido pelo Departamento de Epidemiologia da Universidade da Califórnia - Irvine. A concentração dos poluentes foi modelada para uma média horária do número de veículos e estes valores são calculados para o centróide do polígono dos setores, chamado ponto de exposição Em seguida, a concentração dos poluentes foi ajustada para a hora do dia (distribuição horária do número de veículos) e dia da semana (durante a semana ou final 
de semana). Para a consideração dos parâmetros meteorológicos para o cálculo da dispersão foi selecionado o mês de janeiro como representativo do verão e o mês de junho como representativo do inverno. Os dados de classe de estabilidade atmosférica e altura da camada de mistura foram obtidos por meio do modelo "Brazilian Regional Modeling System" B-RAMS e foram fornecidos pelo Instituto de Astronomia, Geofísica de Ciências Atmosféricas da Universidade de São Paulo - AIG/USP. Os dados foram calculados para o ano de 2005. As análises estatísticas foram realizadas com o software SAS

\section{Resultados e Discussão}

As médias das concentrações horárias de $\mathrm{CO}, \mathrm{NOx}$ e $\mathrm{PM}_{10}$ calculadas pelo CALINE-4 para o verão e inverno foram comparadas com os valores médios medidos pela CETESB, como mostrado na Tabela 2 e Figura 1 apresenta a comparação da média da concentração horária dos poluentes medidos e simulados.

Tabela 2: Comparação entre a média da concentração dos poluentes modelados e medidos.

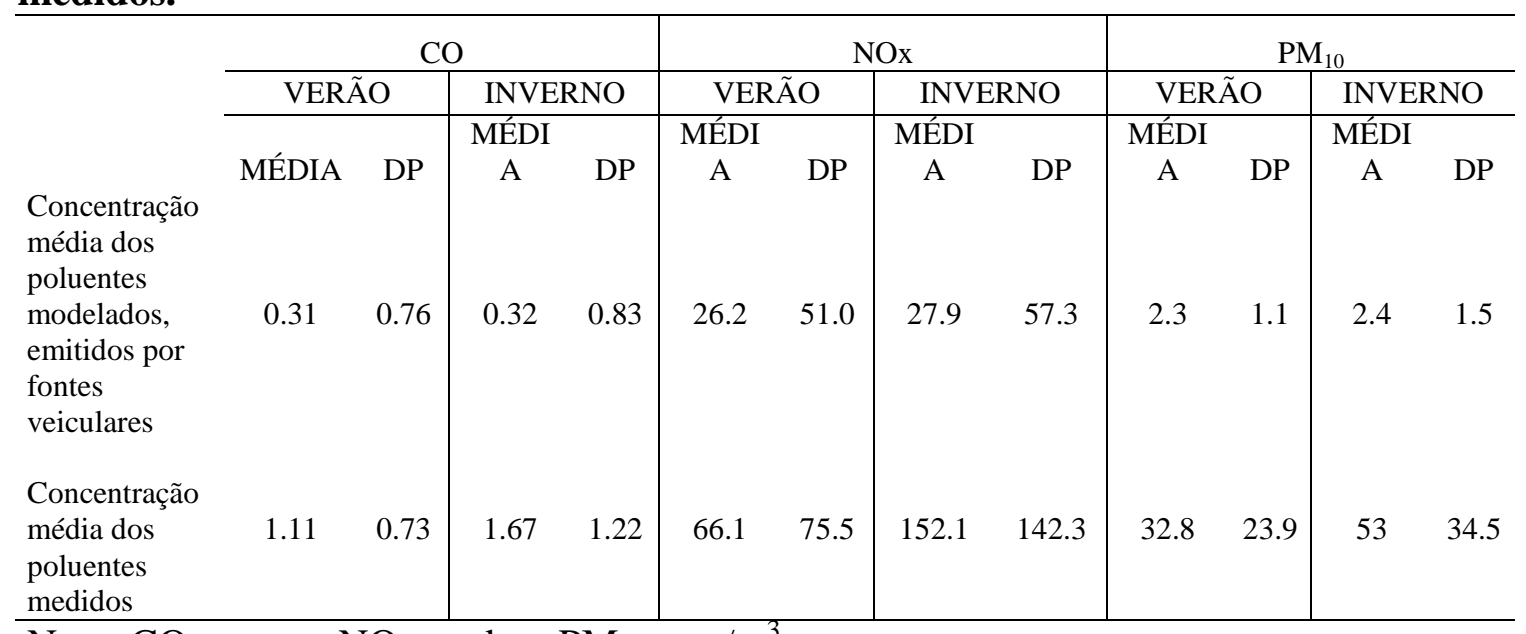

Nota: $\mathrm{CO}-\mathrm{ppm} \quad \mathrm{NOx}-\mathrm{ppb} \quad \mathrm{PM}_{10}-\mathrm{ug} / \mathrm{m}^{3}$ 


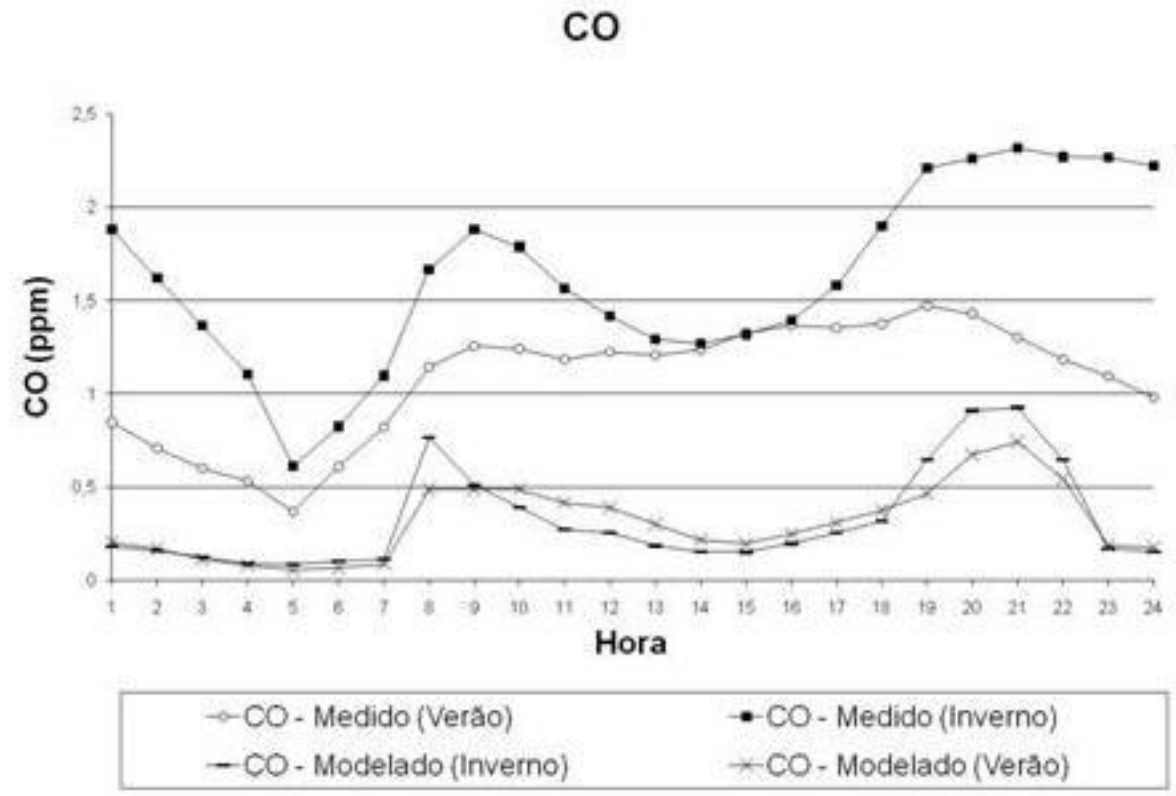

Figura1: Distribuição diária da media horária das concentrações de CO simuladas e medidas.

O comportamento de ambos os dados, mostrados na Figura 1, apresenta os dois picos característicos do horário de rush da manhã e início da noite quando o trânsito apresenta maior número de veículos.

Os valores calculados pelo CALINE-4 foram comparados com os valores medidos pela rede estações de monitoramento da qualidade do ar da CETESB, a fim de se avaliar o desempenho do modelo. A comparação das médias diárias mostrou uma baixa correlação, incluindo uma correlação negativa para o NOx (Tabela 3).

Tabela 3: Correlação das médias diárias dos poluentes medidos e modelados.

\begin{tabular}{|l|c|c|c|c|c|c|}
\hline & $\begin{array}{c}\mathrm{CO} \\
\text { Verão }\end{array}$ & $\begin{array}{c}\mathrm{CO} \\
\text { Inverno }\end{array}$ & $\begin{array}{c}\text { NOx } \\
\text { Verão }\end{array}$ & $\begin{array}{c}\text { NOx } \\
\text { Inverno }\end{array}$ & $\begin{array}{c}\mathrm{PM}_{10} \\
\text { Verão }\end{array}$ & $\begin{array}{c}\mathrm{PM}_{10} \\
\text { Inverno }\end{array}$ \\
\hline Correlação & 0.24 & 0.01 & -0.39 & -0.34 & 0.13 & 0.17 \\
\hline $\mathrm{N}^{\mathbf{o}}$ Pontos & 30 & 31 & 30 & 31 & 30 & 31 \\
\hline
\end{tabular}

Foi realizada também a correlação entre as concentrações médias calculadas para os distritos censitários localizados em um raio de $3 \mathrm{~km}$ ao redor da estação de monitoramento da qualidade do ar. Esta análise foi realizada com o fim de verificar a habilidade do modelo de predizer as concentrações de poluentes nos diferentes locais da área de estudo. Esta correlação foi realizada para 5 estações de monitoramento da qualidade do ar localizadas na área do centro expandido . No entanto, para o NOx havia dados apenas para 3 estações no período de verão e 2 estações no período de inverno. Os 
resultados mostraram uma correlação baixa, principalmente para o período de inverno (Tabela 4).

Tabela 4: Correlação entre os dados médios medidos pela EMQA em um raio de 3 km do entorno da estação e os dados calculados pelo CALINE-4.

\begin{tabular}{|l|c|c|c|c|c|c|}
\hline & $\begin{array}{c}\mathrm{CO} \\
\text { Verão }\end{array}$ & $\begin{array}{c}\mathrm{CO} \\
\text { Inverno }\end{array}$ & $\begin{array}{c}\text { NOx } \\
\text { Verão }\end{array}$ & $\begin{array}{c}\text { NOx } \\
\text { Inverno }\end{array}$ & $\begin{array}{c}\mathrm{PM}_{10} \\
\text { Verão }\end{array}$ & $\begin{array}{c}\mathrm{PM}_{10} \\
\text { Inverno }\end{array}$ \\
\hline Correlação & 0.3 & -0.5 & 0.5 & - & 0.6 & -0.18 \\
\hline $\mathrm{N}^{\mathbf{o}}$ pontos & 5 & 5 & 3 & 2 & 5 & 5 \\
\hline
\end{tabular}

A baixa correlação encontrada pode ter resultado de vários fatores como a não consideração da frota de ônibus, a pouca representatividade espacial dos dados de monitoramento (CETESB, 2004a ; CETESB, 2004b e CETESB, 2004c), as limitações do modelo, como a não consideração da contribuição de vias além de $3 \mathrm{~km}$ de distância do ponto de exposição, as especificidades do modelo de dispersão gaussiana utilizado e ainda, as limitações dos dados de tráfico simulados pelo EMME-2.

A Figura 2 apresenta o gráfico da correlação entre os dados de tráfego medidos vs modelados. Ressalta-se que as medições de tráfego foram realizadas em apenas 2 horários (pico da manhã e noite) e ajustados para uma média diária, enquanto os dados modelados foram calculados para todas as horas do dia.

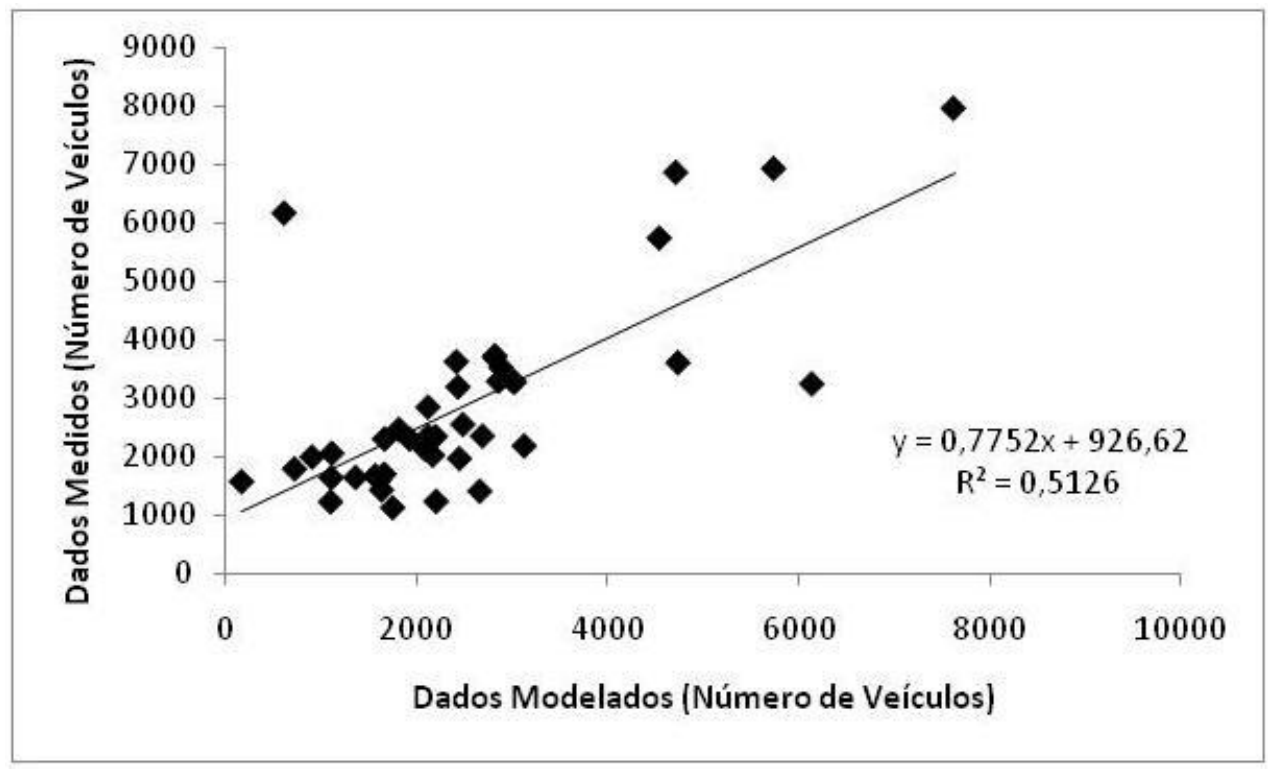

Figura 2: Comparação entre os dados de tráfego modelados e medidos. 
Deve ser enfatizado que o número de dados medidos é relativamente baixo e foram aferidos apenas para as vias de trânsito rápido. Ainda ressalta-se que estes mesmos dados são utilizados pela CET para calibração do EMME-2.

A composição da frota e a contribuição de cada tipo de veículo para a os valores de concentração de poluentes medidos são mostrados na Figura 3.

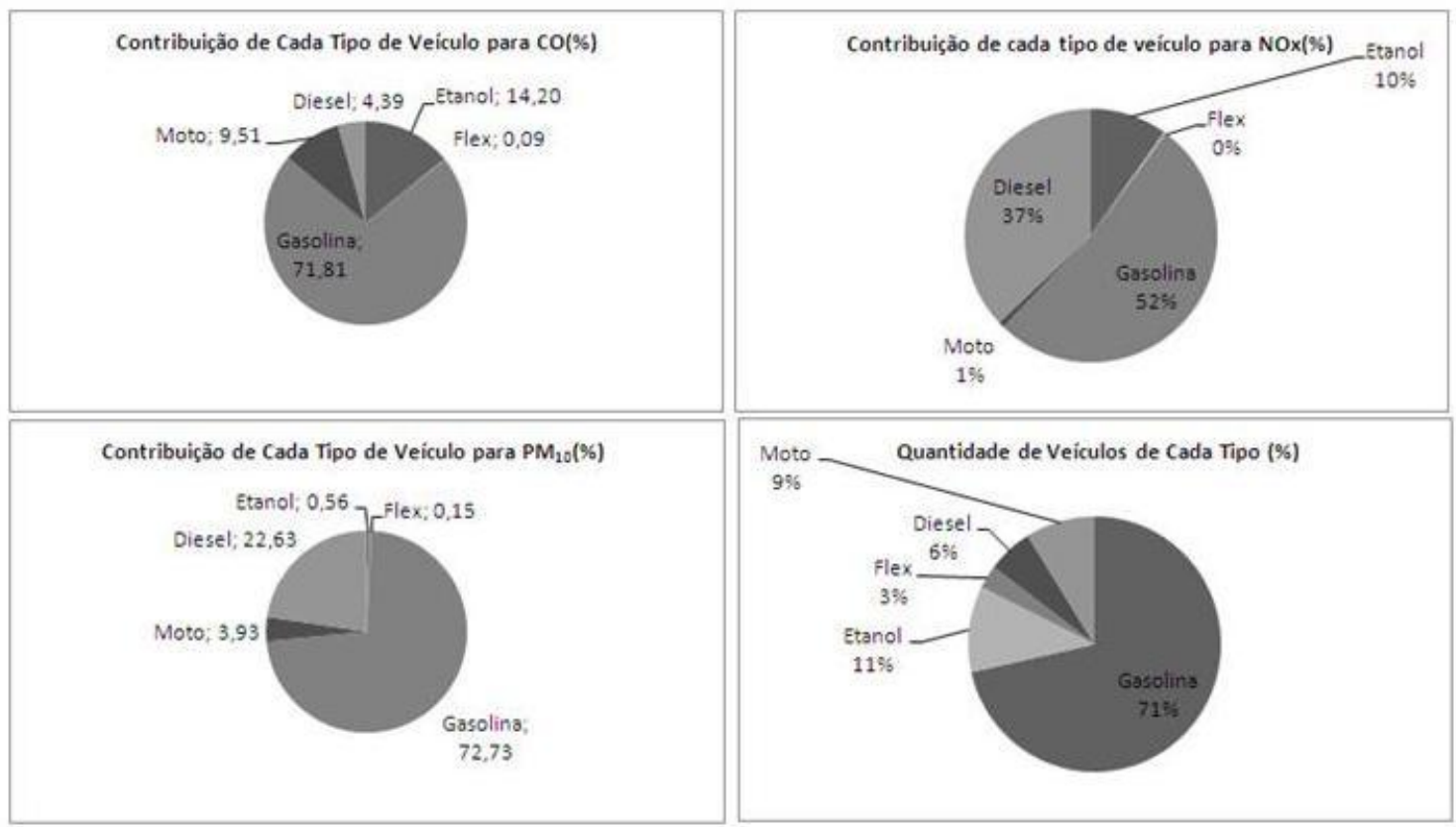

Figura 3: Número de Veículos e contribuição de cada tipo de veículo para a concentração do poluente.

Os veículos movidos à gasolina representam $71,81 \%$ da frota e são também os que mais contribuem para a poluição veicular. Os veículos movidos a diesel tiveram uma contribuição importante para o $\mathrm{NO}_{\mathrm{x}}$ e $\mathrm{PM}_{10}$, o que está associado aos maiores valores das emissão destes poluente. É importante destacar que, neste caso, não está sendo considerada a frota de ônibus o que pode alterar estes valores. Vale destacar neste resultado que a contribuição da emissão de $\mathrm{CO}(9,51 \%)$ e $\mathrm{PM}_{10}(3,93 \%)$ pelas motos não pode ser desconsiderada. Isto se deve não apenas ao crescimento da frota nos últimos anos, mas também, à ausência de sistema de filtração dos poluentes emitidos. Também destaca-se que a emissão dos veículos movidos à etanol foram muito maiores que a dos chamados veículos flex, em virtude do tamanho da frota e também da melhoria dos sistemas de controle de emissão presentes nos veículos mais novos.

No que se relaciona a distribuição espacial dos poluentes verificou-se que as maiores concentrações de $\mathrm{CO}$ calculadas foram observadas nas regiões central e sul da área estudada, como mostrado nas Figuras 4 e 5, onde há um maior adensamento das vias com grande número de veículos circulantes todos os dias. Como mostrado nas Figuras 4 e 5, há significativa variação nos valores de concentração nesta área, resultando, portanto, em diferentes valores de exposição e risco para a população 
residente. Além disso, nota-se que a distribuição do $\mathrm{CO}$ no verão foi bastante similar à do inverno. A distribuição de $\mathrm{NOx}$ e $\mathrm{PM}_{10}$ também foi bastante semelhante à distribuição do CO.

\section{CO Modelado (ppm) e Frota Diária}

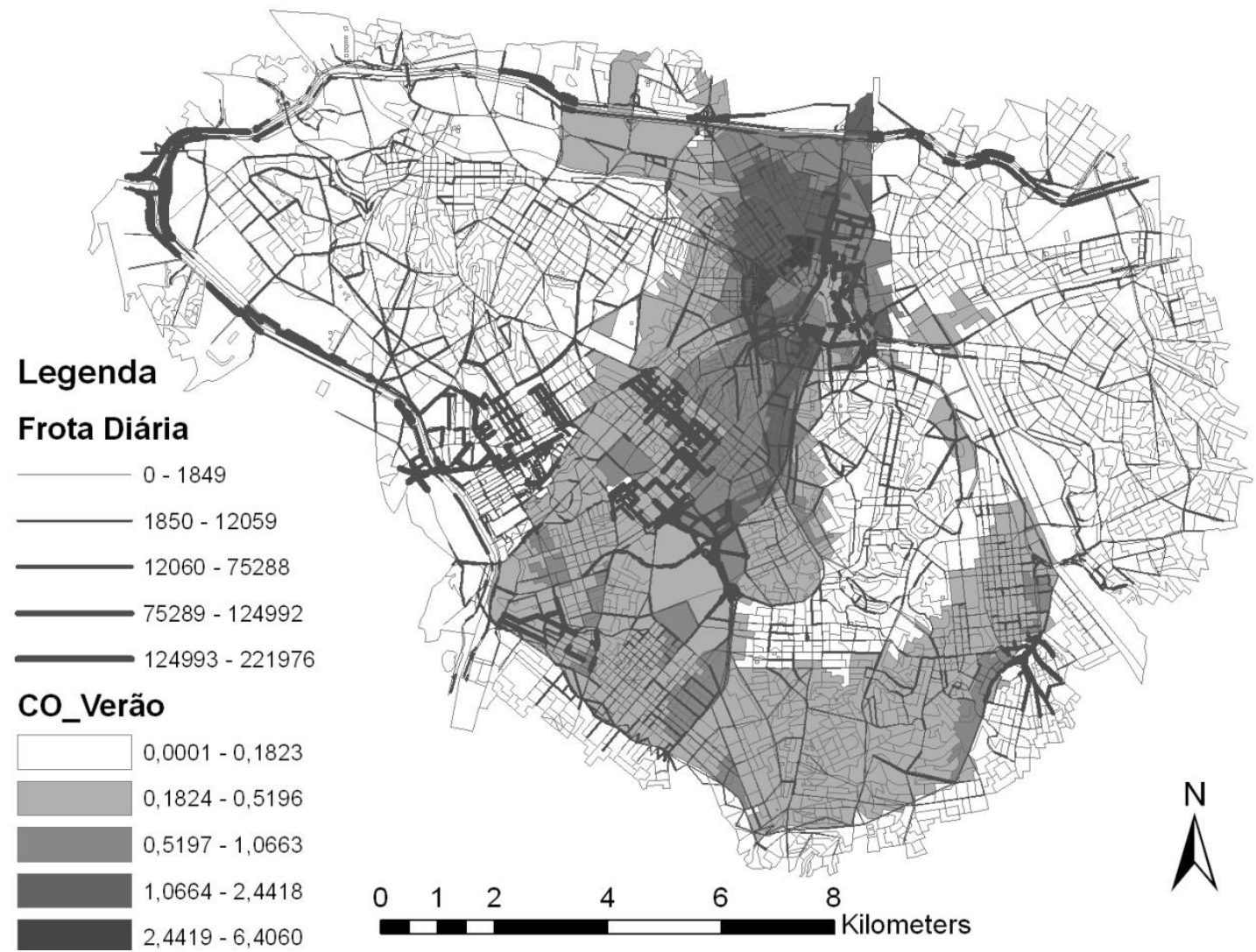

Figura 4: Distribuição do CO modelado para o mês de verão e base de dados de veículos. 


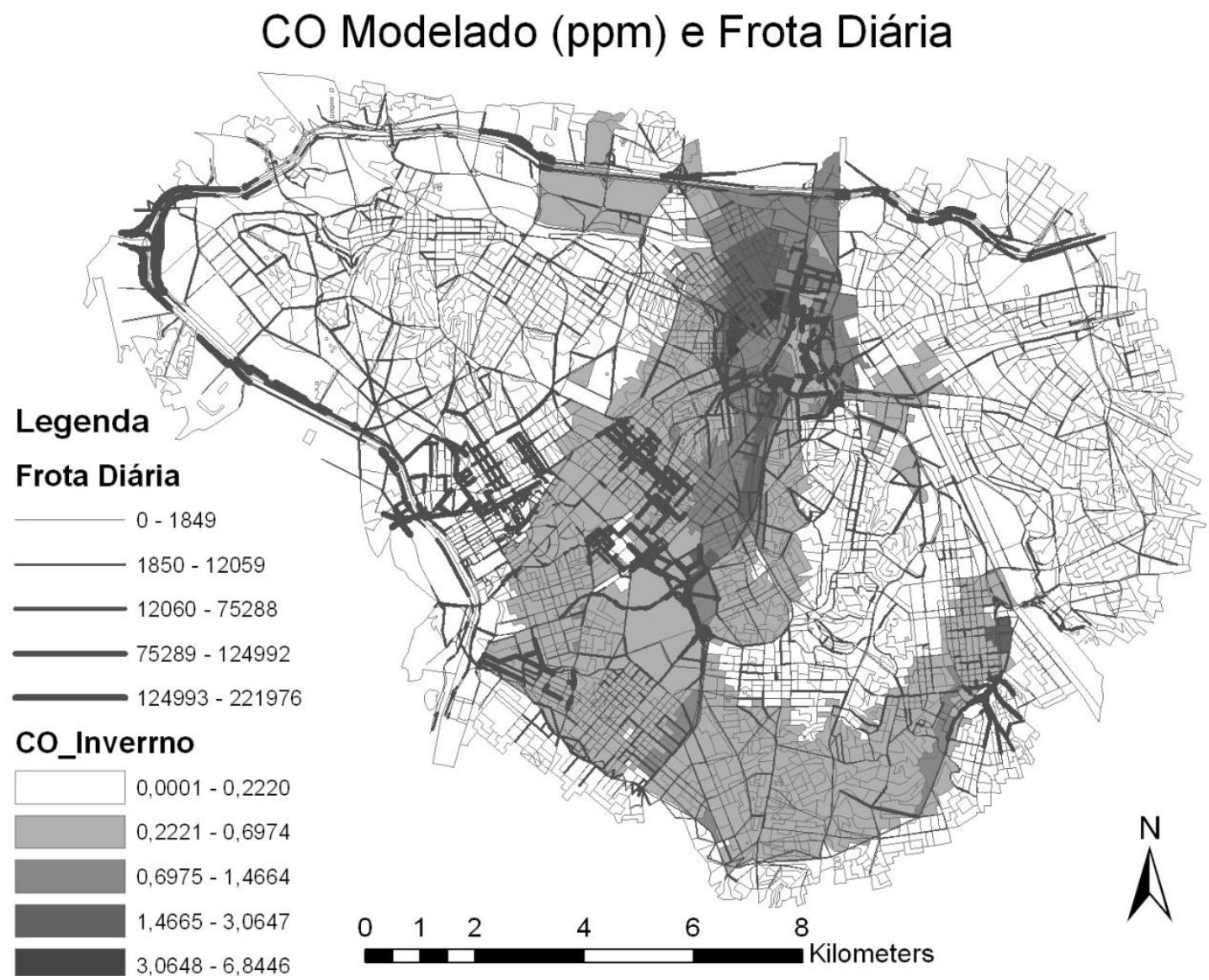

Figura 5: Distribuição do CO modelado para o mês de inverno e base de dados de veículos.

Esse modelo tem sido amplamente utilizado em estudos de exposição aos poluentes veiculares como no estudo que calculou o ruído e a poluição do ar $\left(\mathrm{NO}_{2} \mathrm{e}\right.$ NOx) provocado pelo tráfego e foi verificada a associação destes dois parâmetros com as doenças cardiovasculares. Este estudo encontrou uma correlação moderada entre as concentrações de poluentes modeladas e medidas, reportadas em literatura, (Davies, 2009).

Em outro estudo, os resultados obtidos pelo programa EMME-2 também foram utilizados como fonte de dados de tráfego, a fim de calcular as concentrações de $\mathrm{PM}_{2,5}$ em quatro áreas distintas na Finlândia. $\mathrm{O}$ coeficiente de Pearson calculado para a correlação entre os dados medidos e modelados variou entre 0,51 e 0,77 (Kauhaniemi et al, 2008). Em outro estudo de exposição que considerou os dados de tráfego simulados pelo EMME-2 foi estimada a correlação entre a intensidade de tráfego e as admissões hospitalares por doenças respiratórias, em pessoas idosas (>60 anos). Os resultados mostraram que idosos residentes em locais próximos às ruas de maior tráfego têm maior risco de serem hospitalizados por doenças respiratórias. Embora este estudo tenha encontrado correlação entre as admissões hospitalares e a intensidade veicular, o mesmo 
não reporta a correlação entre os dados de tráfego medidos e modelados (Smargiassi et al, 2006).

Um estudo em Helsinki também utilizou o EMME-2 para obter dados qualitativos sobre a distribuição espacial e temporal do benzeno. As concentrações de poluentes modeladas foram comparadas às médias anuais. Os autores consideraram que os resultados de benzeno modelados estavam de acordo com os objetivos do trabalho, embora os dados calculados tenham sido menores que os medidos, o que foi justificado pela não consideração, no modelo, das fontes de emissão evaporativas e combustão de madeira. (Hellén et al, 2005).

\section{Conclusão}

Os resultados encontrados evidenciam gradientes nas concentrações dos poluentes de emissão veicular na área do centro expandido da cidade de São Paulo e reforçam a importância da realização de estudos mais detalhados da exposição da população exposta.

No entanto, o estudo também mostra a necessidade de melhoria no levantamento das informações necessárias tanto para a entrada dos modelos como também para calibração e validação dos resultados.

Os valores de concentrações calculados foram menores que os valores medidos. Esta diferença pode estar relacionada a vários fatores como a não consideração da frota de ônibus, a pouca representatividade espacial dos dados de monitoramento, as limitações do modelo, como a não consideração da contribuição de vias além de $3 \mathrm{~km}$ de distância do ponto de exposição, as especificidades do modelo de dispersão gaussiana utilizado e ainda, as limitações dos dados de tráfico simulados pelo EMME-2.

Os veículos a diesel tiveram uma contribuição importante para o NOx (37\%). Deve ser destacada que, neste estudo a emissão da frota de ônibus não foi considerada. As maiores concentrações de poluentes, provenientes de emissões veiculares foram observadas na área central do município de São Paulo.

O Brasil, como outros países em desenvolvimento que apresentaram nas últimas décadas um rápido e desordenado crescimento das regiões urbanas, em particular, nas áreas metropolitanas, enfrentam ainda, dificuldades de recursos técnicos e financeiros para ampliar as redes de monitoramento da qualidade do ar e também de monitoramento automático do tráfego. Neste caso, como mostrado neste estudo, o emprego dos modelos apresenta-se como alternativa importante para fornecer subsídios ao planejamento das ações de saúde, transporte e ocupação do solo.

Por outro lado, a falta e/ou pouca qualidade das informações disponíveis, a dificuldade do acesso às informações já coletas ou falta de integração entre as diversas bases de dados colocam limitações importantes. No caso da cidade de São Paulo, embora o tráfego seja responsável por cerca de $90 \%$ da poluição do ar, os dados de tráfego são escassos e a rede de monitoramento da qualidade do ar é pouco representativa em termos espaciais, com medição de poucos parâmetros e com períodos de ausência de dados. 
Deve ser considerado que a melhoria dos dados de volume de veículos é uma alternativa mais rápida e barata, em curto prazo, quando comparada à ampliação da rede de monitoramento da qualidade do ar, especialmente se levado em conta a existência dos radares que permitem a contagem automática do número de veículos gerando, portanto, uma base de informações mais realistas do tráfego nas vias. Por outro lado, a validação dos resultados da simulação do CALINE-4, em curto prazo, demanda a realização de um experimento específico de coleta e amostragem de poluentes mais representativas das variações observadas.

\section{Referências}

BENSON, P.E. A review of the development and application of the CALINE 3 and 4 models. Atmospheric Environment. V26b. 3 1992. p. 379-390.

COMPANHIA TECNOLOGICA DE SANEAMENTO AMBIENTAL (CETESB). Relatório da qualidade do ar no estado de São Paulo 2007. São Paulo: CETESB. 2008. 298p. Available at: http://www.cetesb.sp.gov.br/Ar/ar_geral.asp. Accessed on: February, 06, 2009.

COMPANHIA DE TECNOLOGIA DE SANEAMENTO AMBIENTAL, Caracterização das estações da rede de monitoramento da qualidade do ar na RMSP Estação Congonhas. São Paulo: CETESB. 2004a. p 64. [Acesso em 07/02/10] Disponível em: http://www.cetesb.sp.gov.br/Ar/publicacoes.asp.

COMPANHIA DE TECNOLOGIA DE SANEAMENTO AMBIENTAL, Caracterização das estações da rede de monitoramento da qualidade do ar na RMSP Estação Cerqueira César. São Paulo: CETESB. 2004.b p 51. [Acesso em 07/02/10] Disponível em: http://www.cetesb.sp.gov.br/Ar/publicacoes.asp.

COMPANHIA DE TECNOLOGIA DE SANEAMENTO AMBIENTAL, Caracterização das estações da rede de monitoramento da qualidade do ar na RMSP Estação Ibirapuera. São Paulo: CETESB. 2004c. p 66. [Acesso em 07/02/10] Disponível em: http://www.cetesb.sp.gov.br/Ar/publicacoes.asp.

DAVIES, H.W. et al, Correlation between co-exposure to noise and air pollution from traffic sources. Journal of occupational and environmental medicine. V 66 2009. p. 347350 .

HELLÉN,H.; et al. Evaluation of atmospheric benzene concentrations in th Helsinki metropolitan area in 2000-2003 using diffusive sampling and atmospheric dispersion modeling. Atmospheric Environment. V 39. 2005. p.4003-4014. 
KAUHANIEMI, M. et al. Evaluation of a modelling system for predicting the concentrations of $\mathrm{PM}_{2.5}$ in an urban area. Atmospheric environment. V42. 2008. p.4517 -4529 .

KOUSA, A. et al. A model for evaluating the population exposure to ambient air pollution in an urban area . Atmospheric Environment. V 36 2002. p.2109-2119.

LOH, M.M. et al. Intake fraction distributions for benzene from vehicles in the Helsinki metropolitan area. Atmospheric Environment. V 43 2009. p. 301-310.

SBAYTI, H.; EL-FADEL, M.; KAYSI, I. \& BAAJ, H. Automotive emission in developing countries: traffic management and technology control measurements. Environmental Engineering Science. V 18. N6. 2001. p347-358.

SILVA, MOACIR FERREIRA DA; DE ASSUNÇÃO, JOÃO V. ; ANDRADE, MARIA DEFÁTIMA ; PESQUERO, CELIA REGINA . Characterization of metal and traceelement content of particulate matter (PM10) emitted by ethanol and gasohol powered vehicles. In: 1st Ibero-American Meeting on Toxicology and Environmental Health, Ribeirão Preto 2009,. v. Único. Program and Abstracts, 2009.

SMARGIASSI, A.; BERRADA, K.; FORTIER,I. \& KOSATSKIM,T. Traffic intensity, dwelling value and hospital admissions for respiratory disease among the elderly in Montreal (Canada): a case-control analysis. Journal of epidemiology community health. V 60 . 2006. p. 507-512.

TOLEDO, G.I.F.M; NARDOCCI, A.C. Poluição veicular e saúde da população no município de São Paulo, Brasil. Revista Brasileira de Epidemiologia. 2010. Submetido em 02/03/2010.

Os autores agradecem à Companhia de Engenharia de Tráfego de São Paulo (CET), à Prof $^{a}$ Dr $^{a}$ Maria de Fátima Andrade e ao Prof Dr. Edmilson Dias de Freitas do Departamento de Ciências Atmosféricas da USP e à Prof ${ }^{a}$ Dr $^{a}$ Jun Wu do Departamento de Epidemiologia da Universidade da Califórnia - Irvine. 
Manuscrito 3: Exposure assessment to local traffic generated air pollution in Sao Paulo, Brazil.

Giovana lara Ferreira Moser de Toledo ${ }^{(1)}$

Adelaide Cássia Nardocci ${ }^{(1)}$

Jun $\mathrm{Wu}^{(2)}$

${ }^{(1)}$ Departamento de Saúde Ambiental da Faculdade de Saúde Pública da Universidade de São Paulo. Avenida Dr. Arnaldo, 715. Cerqueira César. 01246-904. São Paulo/SP.

(2) Department of Epidemiology, University of California, Irvine. 100, Theory Drive, Suite 100. 92697-7555. Irvine - CA.

Artigo inédito a ser encaminhado para publicação 


\begin{abstract}
Sao Paulo is one of the largest and economically developed cities in South America, with approximately 11 million inhabitants. The city has around 6 million vehicles and traffic is considered the main source of air pollution. Although the city has a large population exposed to traffic-related air pollution and a great amount of pollutants is emitted, little is known about the traffic flow and how the population's health is affected by that. The aim of this study was to model the contribution of fresh vehicle emissions to $\mathrm{CO}, \mathrm{NOx}$ and $\mathrm{PM}_{10}$ air pollution and to assess children's and adolescent's (0-18 years) exposure to these air pollutants. CALINE-4 was used to estimate CO, NOx and $\mathrm{PM}_{10}$ in the centroid of 2499 census sectors. Both measured and modeled pollutants were compared to traffic volumes. While measured concentrations were poorly correlated with traffic volume, calculated concentrations presented a strong correlation, especially for $\mathrm{CO}$ and $\mathrm{PM}_{10}$. Especially for developing countries, models are important sources of information for exposure assessment studies since they are less expensive than monitoring campaigns.
\end{abstract}

Key words: exposure assessment; traffic-related; air pollution; caline-4, modeling 


\section{Introduction}

Most studies that analyzed exposure in Sao Paulo city considered an average concentration of pollutants for the whole city (SALDIVA et al, 1995; BOTTER, et al, 2002; GOUVEIA et al, 2003; MARTINS et al, 2004; O'NEILL et al, 2008). Sao Paulo is a large city with a complex distribution of the pollutant sources (traffic and stationary) and this assumption may not be adequate to evaluate exposure in local scale.

Sao Paulo counts with 17 thousand kilometers of roads and around 6 million vehicles. This number tends to increase, since Sao Paulo experiences a rapid growth of the fleet. Sao Paulo also has a unique fleet composition with $16 \%$ of the vehicles powered by ethanol. The distribution of the fleet is very complex and the expanded center, which has an area of $10 \%$ of the city, concentrates around $55 \%$ of the daily fleet, during weekdays (PAIVA, 2008).

The Environmental Protection Agency of Sao Paulo (CETESB) estimates that $97.5 \%$ of the CO and $96 \%$ of the NOx are emitted by vehicles (CETESB, 2008). Although the city has approximately 11 million inhabitants exposed to trafficrelated pollution and a great amount of pollutants are emitted, little is known about the traffic flow and how population's health is affected by that.

In this case, the detection of different scenarios is important, due to the heterogeneity of the area. The identification of peak concentrations and critical areas is essential to evaluate health conditions associated to short-time effects that are manifested mainly in the areas where exposure is more intense. 
The aim of this study was to model the contribution of fresh vehicle emissions to $\mathrm{CO}, \mathrm{NOx}$ and $\mathrm{PM}_{10}$ to air pollution and assess children and adolescents (0-18 years) exposure to these air pollutants.

\section{Methods}

Detailed traffic count, by vehicle category: heavy duty vehicles (buses and trucks), light duty vehicles (cars) and motorcycles were measured in 153 roads by the CET/SP - Engineering Traffic Company of Sao Paulo and 105 by the School of Public Health, University of Sao Paulo. These measurements were extended to link streets located up to $5 \mathrm{~km}$ from the measured point. The other

streets had their traffic estimated by an average of traffic according to its category (Expressway, Arterial1, Arterial2, Arterial3, Collector1, Collector2 and local). Emission rates were obtained from the CETESB (2006) and from SILVA (2007).

The CALINE-4 model, a modified version of the model developed by the U.S. California Department of Transportation, was used to estimate concentration of $\mathrm{CO}$, NOx and $\mathrm{PM}_{10}$, due to vehicles fresh emissions. Pollutants concentrations were estimated for 2499 census sectors of the central area of Sao Paulo city, where traffic is more intense. Census sector locations and children ( 0 -18 years) population information were obtained from the Brazilian Institute of Geography and Statistics (IBGE) from the 2000 census. Pollutant concentrations were calculated for an average hourly count of vehicles. After that, pollutant concentrations were adjusted for the hour of the day (traffic daily distribution) and the day of the week (weekdays and weekends). Two different periods were modeled: summer (January) and winter (June). 
Hourly meteorological data was obtained from 3 air quality stations by season and hour. Stability class and mixing height data were obtained from a Brazilian Regional Modeling System (B-RAMS) model output, provided by the Institute of Astronomy, Geophysics and Atmospheric Science of the University of Sao Paulo (IAG/USP).

In order to evaluate the quality of modeled data, several statistics analysis were performed. Pearson's correlation was used to compare the air quality measurements performed by the CETESB and modeled CO, NOx and $\mathrm{PM}_{10}$, using software SAS. In this case, the air quality stations (AQS) that had hourly available data of $\mathrm{CO}, \mathrm{NOx}$ and $\mathrm{PM}_{10}$ were chosen (Figure 1). A $1 \mathrm{~km}$ buffer was created around these AQS to obtain an average modeled pollutant concentration. Model and ambient concentrations were also correlated (Pearson's Correlation) with number of vehicles to evaluate how these concentrations are related to traffic. 

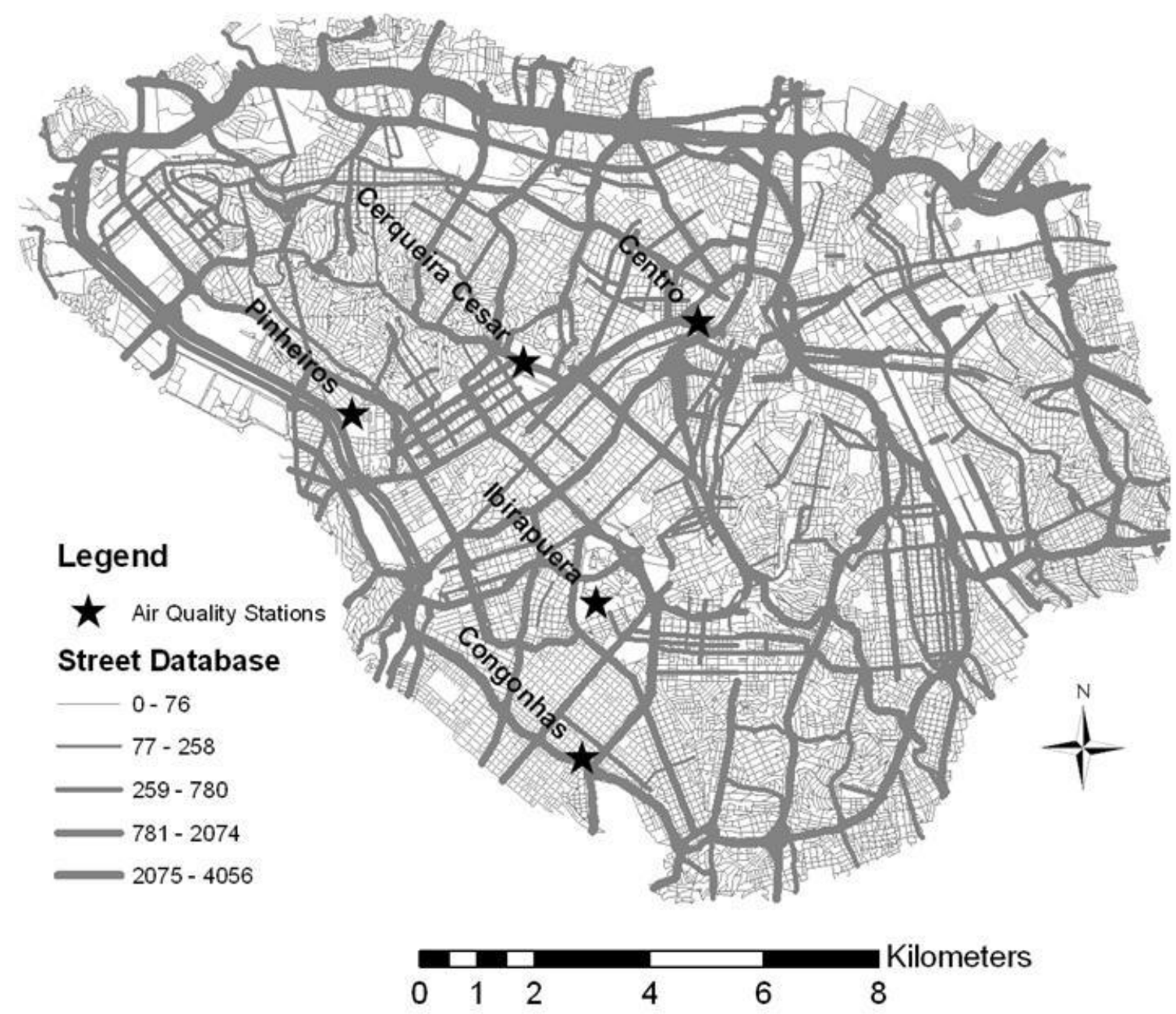

Figure 1: Location of the air quality station used to calibrate the model

Results and Discussion

Table 1 shows a comparison between modeled average concentration due to vehicular emission and average ambient concentration. It is possible to verify that ambient concentration is higher than vehicular emission. Vehicular emission was calculated only for fresh emissions. Modeled $\mathrm{PM}_{10}$ presents a low 
concentration, when compared to measured $\mathrm{PM}_{10}$ because the model account only for vehicle emissions. In general, $60 \%$ of $\mathrm{PM}_{10}$ is due to industrial emissions, particles resuspension and secondary aerosols (CETESB, 2006).

\section{Table 1: Comparison between modeled and measured concentrations (CETESB measurements)}

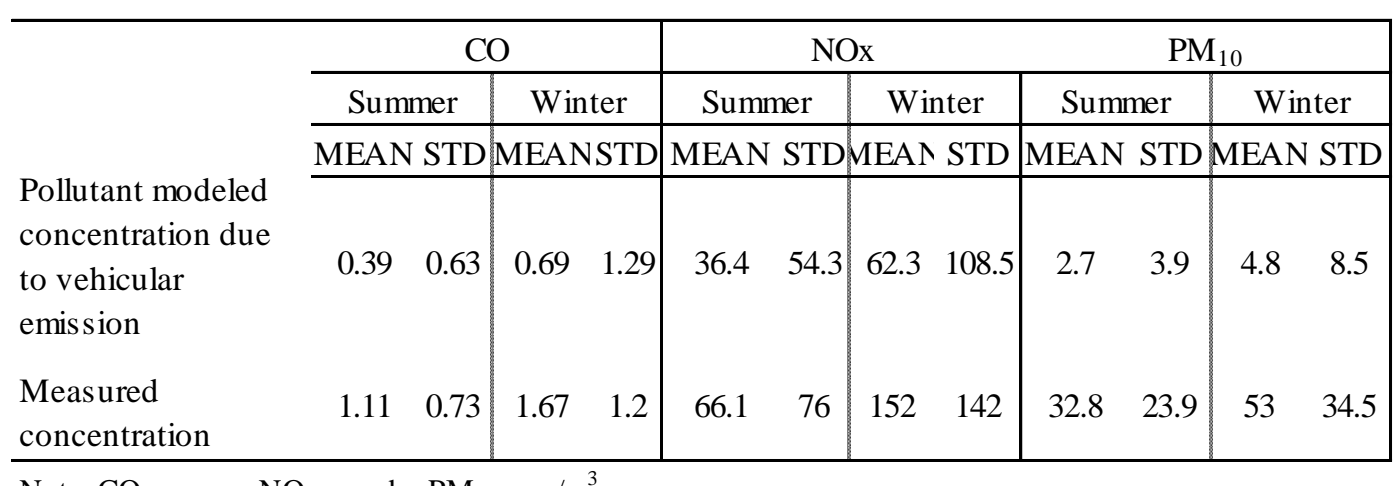

Note: $\mathrm{CO}-\mathrm{ppm} \quad \mathrm{NOx}-\mathrm{ppb} \mathrm{PM}_{10}-\mu \mathrm{g} / \mathrm{m}^{3}$

Figure 2 shows the number of vehicles and the contribution of each type of vehicle to pollutant concentrations. Gasoline vehicles contributed most to $\mathrm{CO}$ and $\mathrm{PM}_{10}$ concentrations, due to high number of vehicles powered by gasoline. Diesel contributed most to NOx concentration due to high emission rates. Both buses and trucks were considered for diesel emissions. 

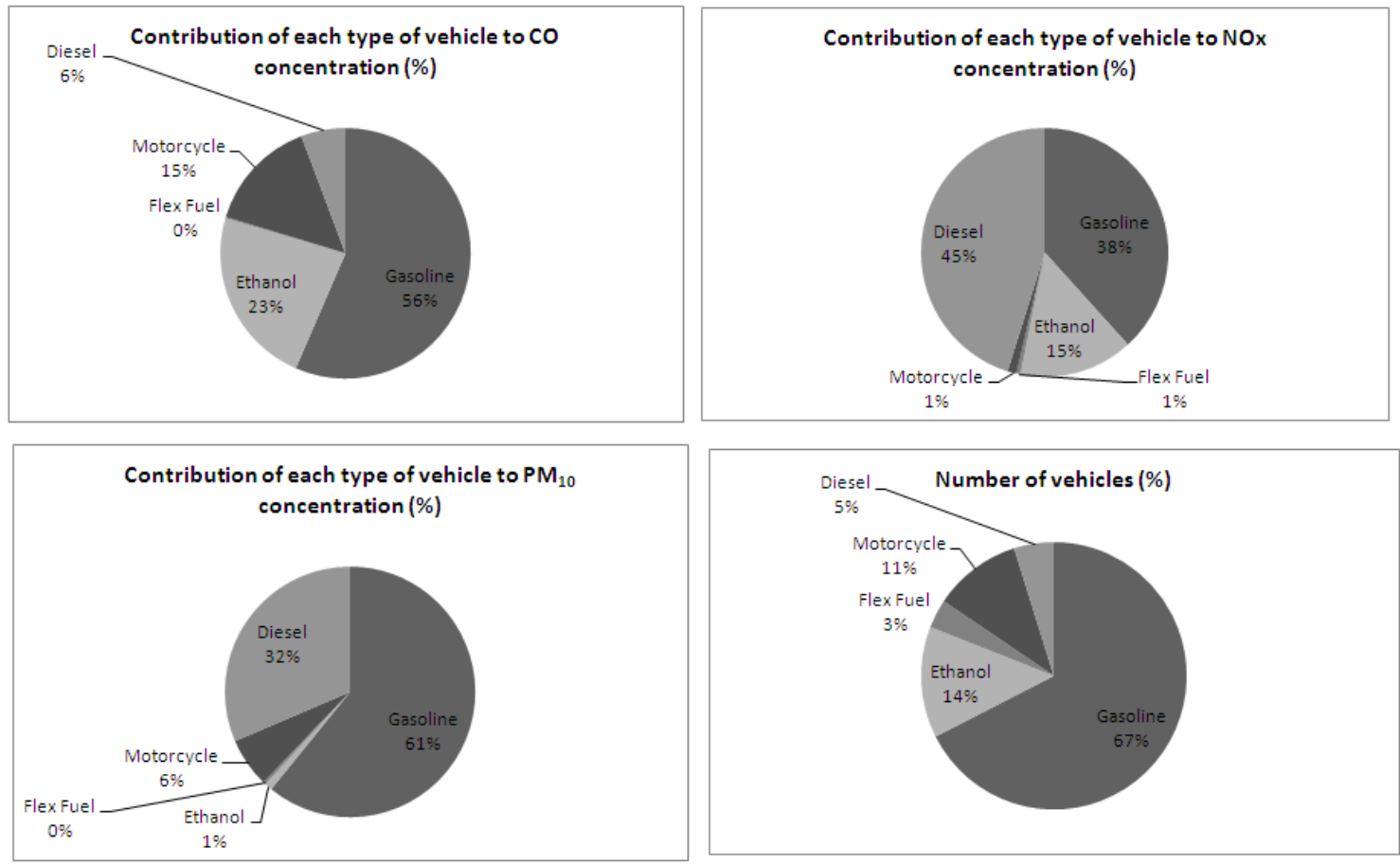

Figure 2: Number of vehicles and contribution of each vehicle type to pollutant concentration

Figure 3 shows a comparison between modeled pollutants distribution and total number of vehicles, during summer and winter time. Pollutants concentrations were higher during winter time, when precipitation is smaller and thermal inversion may occur. $\mathrm{CO}$ is higher at the central area, where higher density of vehicles is observed. $\mathrm{NOx}$ and $\mathrm{PM}_{10}$ were higher at central area only during summer time. During winter time, these pollutants occurred in higher concentrations especially at the edges areas.

Table 2 presents the correlation analysis performed between modeled and ambient (CETESB) pollutants concentration. Considering $\mathrm{CO}$, the correlation was done at Ibirapuera, Centro and Pinheiros areas. The poor performance of the model observed for Cerqueira Cesar during winter time may be due to the small number of observations. Correlation for NOx was performed only in 3 
areas (Ibirapuera, Congonhas e Pinheiros) because the lack of measured data for the other areas. Median correlations were observed at lbirapuera and Pinheiros during summer period and Congonhas and Pinheiros at winter period. Correlations for $\mathrm{PM}_{10}$ were low, except for Pinheiros during winter period. Low correlations for $\mathrm{PM}_{10}$ can be explained by the presence of other sources than vehicular, such as industrial activities, particles resuspension and secondary aerosols, that account for $60 \%$ of total $\mathrm{PM}_{10}$ (CETESB, 2006). Except for Ibirapuera, AQS are representative of a small area, of about 100m (CETESB, 2004a; CETESB, 2004b). Ibirapuera would be more representative of a neighborhood or city scale, depending on the meteorological conditions (CETESB, 2004c).

Figure 3 presents the comparison between modeled and measured (CETESB) CO during winter period (June). It is possible to verify that the modeled concentrations were smaller (since they account only for fresh emissions). However, the general behavior of both was pretty similar.

CETESB states that, in 2005, pollution emitted by traffic was responsible for $97.43 \%$ of the ambient CO, $95.77 \%$ of the NOx and $40 \%$ of $\mathrm{PM}_{10}$ (CETESB, 2006). Considering this, correlations between the number of vehicles and pollutants concentration (modeled and measured) were performed. Results are presented in Table 3. The correlation between modeled pollutants concentration and the number of vehicles was very high for $\mathrm{CO}(0.96)$ and $\mathrm{PM}_{10}(0.94)$, while the correlation between ambient pollutant concentration and traffic was negative (CO: -0.04 and $\mathrm{PM}_{10}$ : -0.01 ).

The correlation between modeled NOx and traffic was very low $(-0.68)$, while AQS presented a medium correlation (0.58). In this case, it is important to notice that the sample size for this analysis was very low $(n=3)$. These analyses show 
that the air quality monitoring stations are not able to properly measure vehicle pollution, which is now the main source of air pollution. It also reveals that the use of AQS net to calibrate the model may not be adequate. It is important to highlight that the number of air quality stations with available data is quite small, especially for NOx. Since these correlations were done for both modeled and measured data, a limited number of AQS leads to a small $n$ (number of observations). In the other hand the amount of points of vehicle counting and the type of roads analyzed were very representative.

Figure 4 shows the prevalence of exposure to $\mathrm{CO}$ during winter period. Brazilian Federal law determine a maximum exposure to $\mathrm{CO}$ of $35 \mathrm{ppm}$ (1 hour sampling) or 9 ppm (8 hours sampling) (CONAMA, 1990). The fact that CO concentrations were smaller than those established by the Brazilian law does not indicates that the population is not exposed at those levels. The prevalence of exposure was estimated by monthly averages and did not account for peak concentrations. In addition, the model accounts only for fresh emission and vehicular emissions. These higher concentrations of pollutants are observed at the central area, which is more a commercial than a residential area.

Several studies used modeled traffic-related air pollution in exposure assessment investigations. Recently, a study developed at California used a CALINE-4 model to investigate the effects of residential exposure to local traffic generated air pollution on preeclampsia and pre-term delivery. This study found a relatively high correlation between measured and modeled pollutants concentrations ( $\left.n=14 ; R^{2}=0.76\right)$, when monthly averages of ambient NOx concentrations were compared with modeled results; and concluded that the CALINE-4 model output reflected residential exposure to air pollutants (WU et al, 2009). Another study investigated the association between local trafficgenerated air pollution and repeated hospital encounters for asthma in children, 
using CALINE-4 to model $\mathrm{CO}$ and NOx pollutant concentrations. Reasonable agreement was observed between CALINE-4 modeled and measured 2-week average of $\mathrm{NO}_{2}$ concentrations at 260 residences in Southern California $\left(R^{2}=0.3\right.$ - 0.9) (DELFINO, et al, 2009). A Gaussian dispersion model was also used to verify the correlation between respiratory symptoms and allergies with trafficrelated air pollution. A comparison of measured (average 1994-1997) and modeled (1996) total $\mathrm{NO}_{2}$ levels showed good agreement ( $r^{2}:$ 0.93) (NORDLING et al, 2008; JOHANSSON et al, 1999). A Gaussian multisource dispersion model IMMIS ${ }^{\text {net }}$ was used to estimate the exposure to particulate matter and $\mathrm{NO}_{2} . \mathrm{NO}_{2}$ and particulate matter levels estimated by dispersion modeling were higher than the measured values. However, the correlation between dispersionmodeled concentrations was strong for both pollutants: for $\mathrm{NO}_{2}, r^{2}=0.83$ and for PM, $r^{2}=0.79$ (CYRYS et al, 2005).

Figure 5 shows the prevalence of exposure of inhabitants to $\mathrm{CO}$ aged 0 to 18 years old during winter period. The expanded center of Sao Paulo city is the area where the highest modeled pollutant concentrations were observed, with a great range of concentrations. At this place, the young population is not the largest group. 

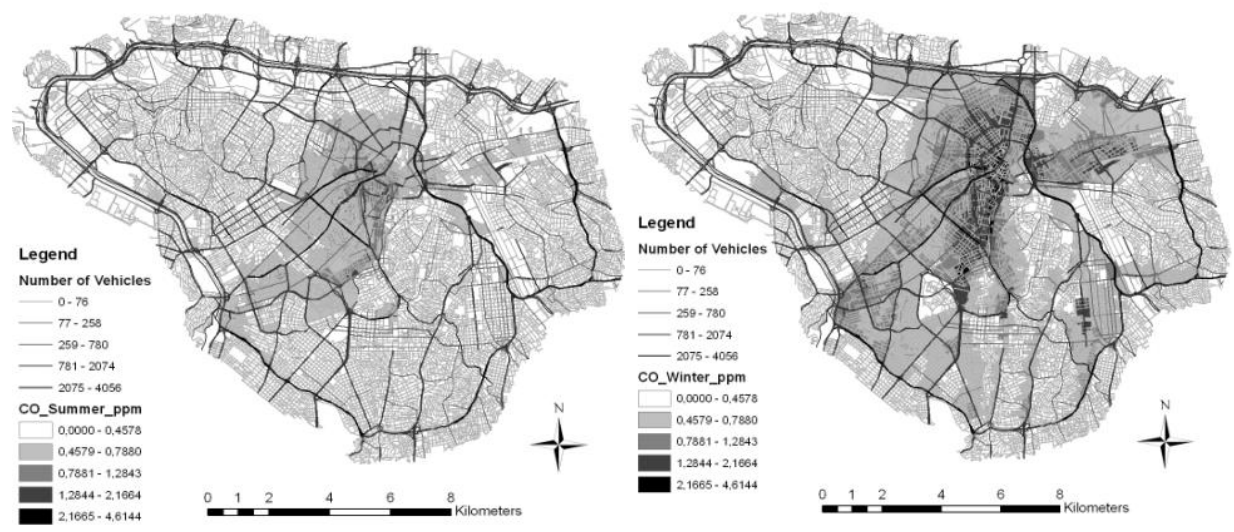

NOx Distribution: Summer

NOx Distribution: Winter
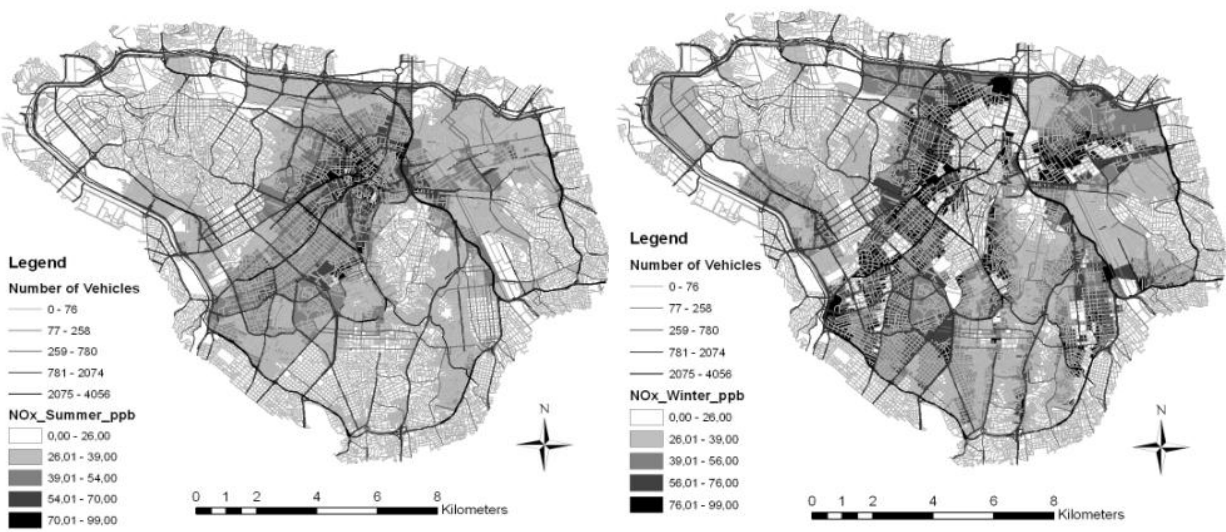

PM10 Distribution: Summer

PM10 Distribution: Winter
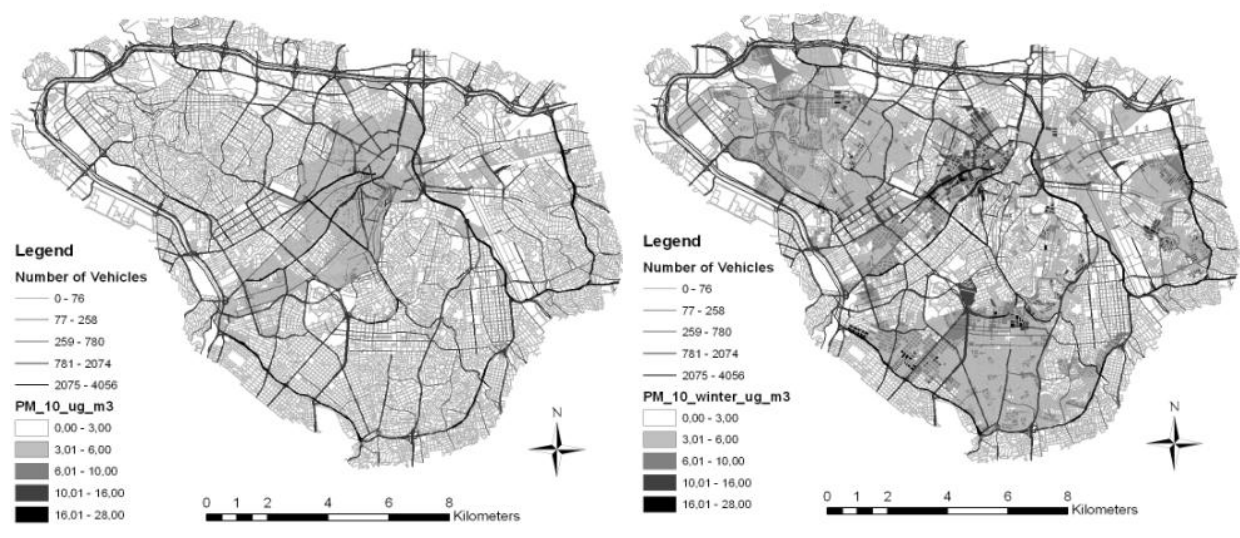

Figure 3: Comparison between modeled pollutants concentration and vehicle distribution 
Table 2: Comparison between AQ Stations (CETESB) measurements and the daily average modeled pollutant in a $1 \mathrm{~km}$ buffer

\begin{tabular}{|c|c|c|c|c|c|c|c|c|c|c|c|c|}
\hline \multirow[b]{2}{*}{$\begin{array}{l}\text { Air Quality } \\
\text { Station }\end{array}$} & \multicolumn{4}{|c|}{ co } & \multicolumn{4}{|c|}{ NOx } & \multicolumn{4}{|c|}{$\mathbf{P M}_{10}$} \\
\hline & $\begin{array}{c}\text { Summer } \\
\text { Correlation }\end{array}$ & n & $\begin{array}{c}\text { Winter } \\
\text { Correlation }\end{array}$ & $\mathbf{n}$ & $\begin{array}{l}\text { Summer } \\
\text { Correlation }\end{array}$ & $\mathbf{n}$ & $\begin{array}{c}\text { Winter } \\
\text { Correlation }\end{array}$ & $\mathbf{n}$ & $\begin{array}{c}\text { Summer } \\
\text { Correlation }\end{array}$ & $\mathrm{n}$ & \begin{tabular}{|c} 
Winter \\
Correlation
\end{tabular} & $\mathbf{n}$ \\
\hline Ibirapuera & 0.5933 & 27 & 0.7309 & 23 & 0.5574 & 27 & - & - & -0.14 & 27 & 0.45 & 21 \\
\hline $\begin{array}{l}\text { Congonhas } \\
\text { Cerqueira }\end{array}$ & 0.3547 & 31 & 0.3691 & 30 & 0.2732 & 31 & 0.6799 & 11 & 0.09 & 31 & 0.22 & 30 \\
\hline Cesar & 0.3765 & 12 & 0.5515 & 29 & - & - & - & - & -0.09 & 25 & 0.33 & 29 \\
\hline Centro & 0.1197 & 31 & 0.3337 & 30 & - & - & - & - & 0.11 & 31 & - & - \\
\hline Pinheiros & 0.49918 & 31 & 0.7063 & 30 & 0.4394 & 31 & 0.7413 & 30 & 0.14 & 31 & 0.51 & 30 \\
\hline
\end{tabular}

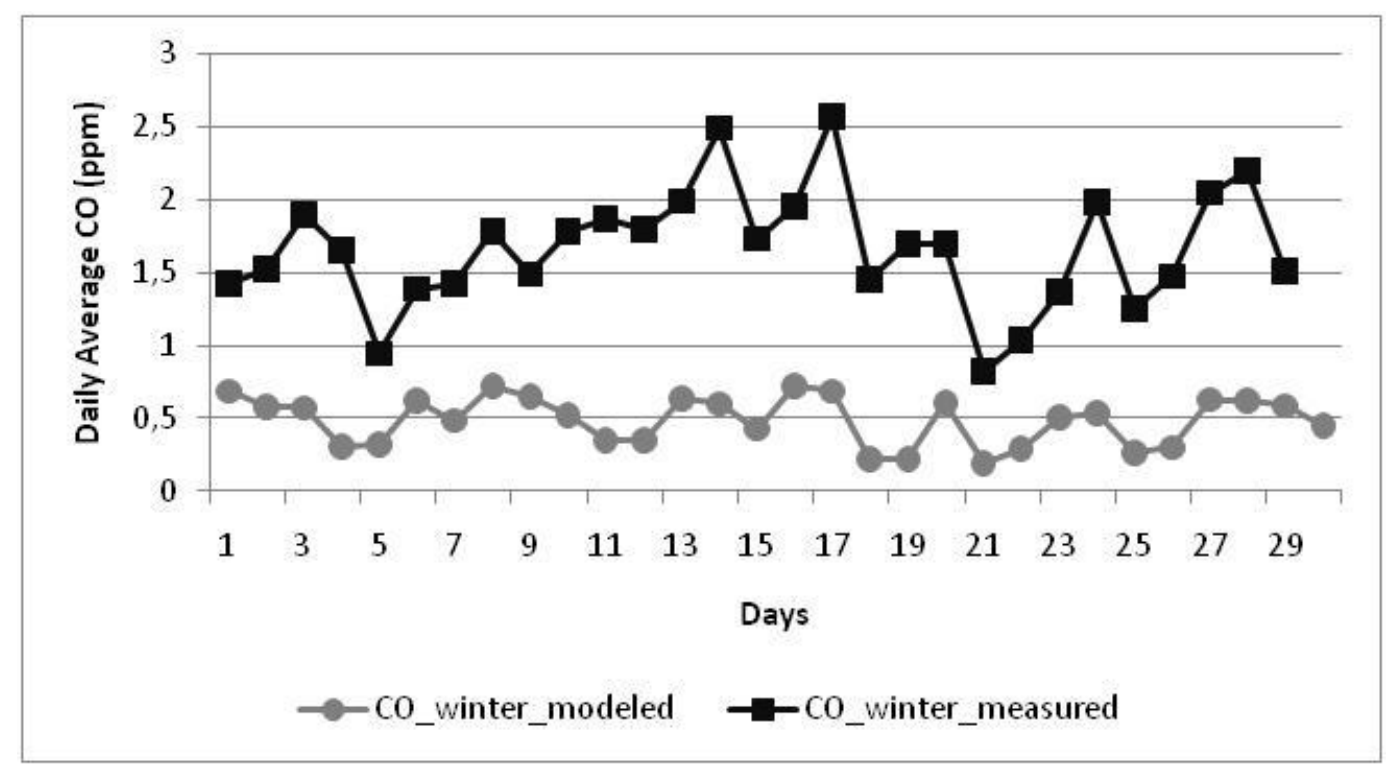

Figure 4: Comparison between vehicular and measured daily average $\mathrm{CO}$ (ppm) 
Table 3: Correlation between pollutant concentrations and total number of vehicles

\begin{tabular}{c|cc|cc}
\hline \multirow{2}{*}{ Pollutant } & \multicolumn{2}{|c|}{ Modeled } & \multicolumn{2}{c}{ Measured } \\
\cline { 2 - 5 } & Correlation & $\mathrm{n}$ & Correlation & $\mathrm{n}$ \\
\hline $\mathrm{CO}$ & 0.96 & 5 & -0.04 & 5 \\
\hline $\mathrm{NOx}$ & -0.68 & 3 & 0.58 & 3 \\
\hline $\mathrm{PM}_{10}$ & 0.94 & 5 & -0.01 & 5 \\
\hline
\end{tabular}

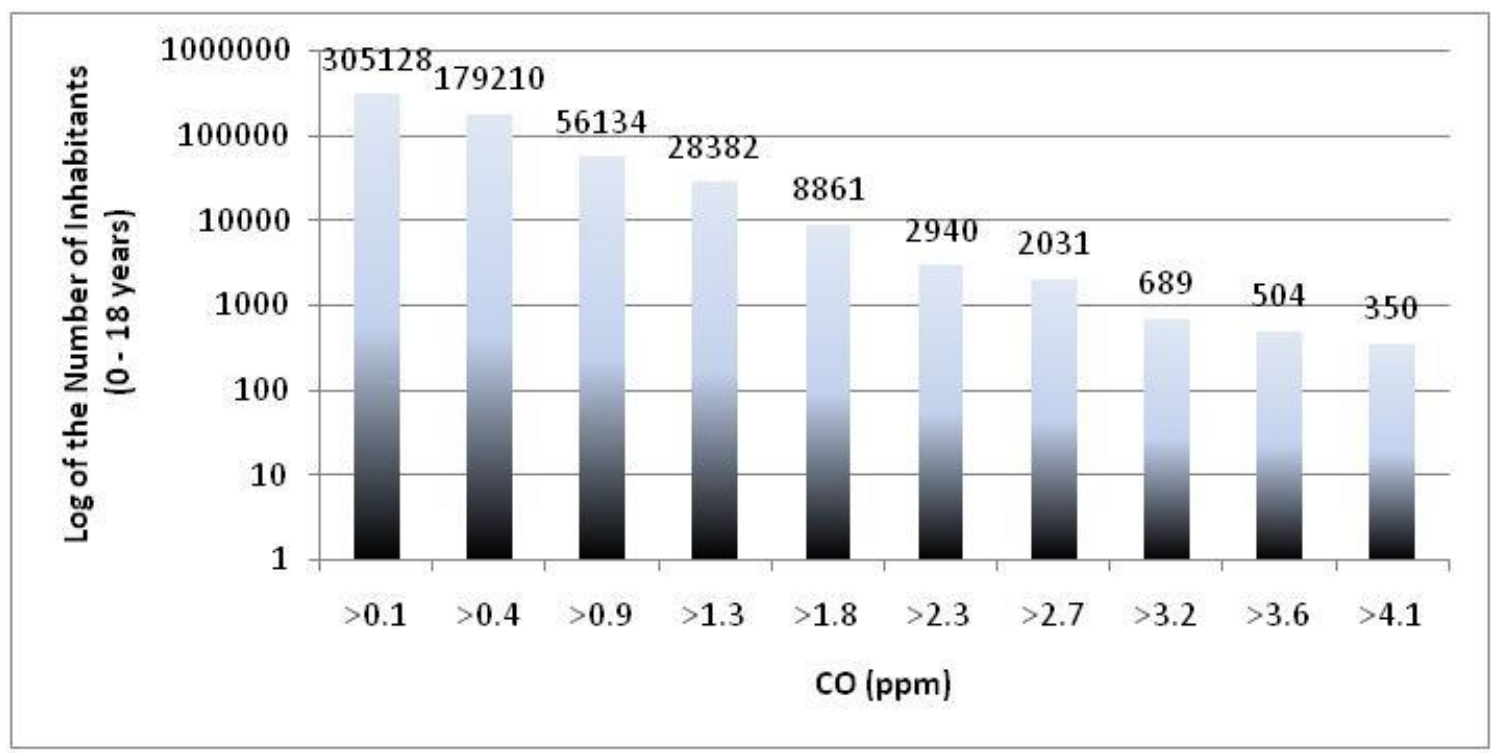

Figure 5: Prevalence of exposure of inhabitants aged 0 to 18 years old to CO during winter period

\section{Conclusions}

As expected, highest modeled pollutant concentrations were observed at winter time, due to smaller amount of rain. Generally, higher modeled pollutants concentrations were observed at the central area, where light duty traffic is more intense. During winter period, NOx and $\mathrm{PM}_{10}$ were more disperse. 
Although gasoline powered vehicles do not have the highest emission rates, they contribute most for $\mathrm{CO}$ and $\mathrm{PM}_{10}$ due to the high number of vehicles. For $\mathrm{CO}$, motorcycles presented an important contribution (14.6\%) also because of the high number. This information must be considered for public policies that intend to reduce traffic-related air pollution and contribute to an improvement in public health.

While CETESB states that traffic emissions account for the major part of the ambient pollution, correlation analyses between Air Quality Stations and traffic were low. It shows that the measurements performed at these stations are not useful to assess the population exposure or to calibrate traffic-related air dispersion models. The small amount of measured data also contributed for some uncertainty at these analyses.

Since the available AQS at the study area are not suitable to calibrate the CALINE model and this is the only source of air pollutant concentrations, it is impossible to verify how accurate the model prediction was. An extensive campaign was performed in order to evaluate the traffic volume, resulting in 258 points of measurement. It is important to highlight that correlations between modeled concentrations and traffic were high, especially for $\mathrm{CO}$ and $\mathrm{PM}_{10}$. Correlations between modeled concentrations and traffic for NOx may have been very low due to the small number of observations (n). Although it is not feasible to verify the magnitude of the concentration, it was possible to verify its correlation with traffic spatial distribution. In this situation the model would be a good source of information for studies that correlates pollutants distribution and georreferenced health outcomes.

Especially for developing countries, models are important sources of information for exposure assessment studies since they are less expensive than monitoring 
campaigns.

\section{References}

BENSON, P.E. A review of the development and application of the CALINE 3 and 4 models. Atmospheric Environment. V26b. 3 1992. p.379-390.

COMPANHIA DE TECNOLOGIA DE SANEAMENTO AMBIENTAL, Caracterização das estações da rede de monitoramento da qualidade do ar na RMSP - Estação Congonhas. São Paulo: CETESB. 2004a. p 64. [Acesso em 07/02/10] Disponível em: http://www.cetesb.sp.gov.br/Ar/publicacoes.asp.

COMPANHIA DE TECNOLOGIA DE SANEAMENTO AMBIENTAL, Caracterização das estações da rede de monitoramento da qualidade do ar na RMSP - Estação Cerqueira César. São Paulo: CETESB. 2004b. p 51. [Acesso em 07/02/10] Disponível em: http://www.cetesb.sp.gov.br/Ar/publicacoes.asp.

COMPANHIA DE TECNOLOGIA DE SANEAMENTO AMBIENTAL, Caracterização das estações da rede de monitoramento da qualidade do ar na RMSP - Estação Ibirapuera. São Paulo: CETESB. 2004c. p 66. [Acesso em 07/02/10] Disponível em: http://www.cetesb.sp.gov.br/Ar/publicacoes.asp.

COMPANHIA TECNOLOGICA DE SANEAMENTO AMBIENTAL (CETESB). Relatório da qualidade do ar no estado de São Paulo 2005. São Paulo: CETESB. 2006. 139p. Available at: http://www.cetesb.sp.gov.br/Ar/ar geral.asp. Accessed on: 08 december 2009. 
COMPANHIA TECNOLOGICA DE SANEAMENTO AMBIENTAL (CETESB). Relatório da qualidade do ar no estado de São Paulo 2007. São Paulo: CETESB. 2008. 298p. Available at: http://www.cetesb.sp.gov.br/Ar/ar geral.asp. Accessed on: 06 november 2009.

CONSELHO NACIONAL DO MEIO AMBIENTE. Resolução 03 from 28 of june of 1990.Publicated at Diario Oficial da União. on 22 of august of 1990; Section I.pg 15937-15939.

CYRYS, J. et al. GIS-Based Estimation of Exposure to Particulate Matter and $\mathrm{NO}_{2}$ in an Urban Area: Stochastic versus Dispersion Modeling. Environmental Health Perspectives. V 13. N 8. 2005. p. 987-992.

DELFINO, R.J. et al. Repeated hospital encounters for asthma in children and exposure to traffic-related air pollution near the home. Annals of allergy, asthma \& immunology. V102. 2009. p. 138-144.

JOHANSSON, $C$ et al. The Stockholm study on health effects of air pollution and their economic consequences(SHAPE). Part $\mathrm{I}: \mathrm{NO}_{2}$ and particulate matter in Stockholm. Concentrations and population exposure. Publication 1999:41; ISSN 1401-9612, Borlange, Sweden: Swedish National Road Administration; 1999. Available at: http://www.slb.nu/slb/rapporter/pdf/shape.pdf. Accessed 08 December 2009.

NORDLING,E. et al traffic-related air pollution and childhood respiratory symptoms, function and allergies. Epidemiology. V19. N3. 2008.p. 401-408.

PAIVA, C. Qual o número de veículos que circula na cidade de São Paulo. 7p. Available at: 
http://www.sinaldetransito.com.br/artigos area.php?tipo=Planejamento. Accessed on 14 of December of 2009.

SILVAM, M.F. Emissão de metais por veículos automotores e seus efeitos à saúde pública. 2007. 155p. Dissertation (Master's degree in Public Health) School of Public Health, University of São Paulo, São Paulo.

$\mathrm{WU}$, J. et al. Association between local traffic-generated air pollution and preeclampsia and preterm delivery in the south coast air basin of California. Environmental Health Perspectives. V17. N11. 2009. p. 1773-1779. 
Manuscrito 4: Evaluation of traffic related air pollution and hospital admission by respiratory problems in children and adolescents (0-18 years) living in Sao Paulo, Brazil

Giovana lara Ferreira Moser de Toledo ${ }^{(1)}$

Adelaide Cássia Nardocci ${ }^{(1)}$

Jun $\mathrm{Wu}^{(2)}$

${ }^{(1)}$ Departamento de Saúde Ambiental da Faculdade de Saúde Pública da Universidade de São Paulo. Avenida Dr. Arnaldo, 715. Cerqueira César. 01246-904. São Paulo/SP.

(2) Department of Epidemiology, University of California, Irvine. 100, Theory Drive, Suite 100. 92697-7555. Irvine - CA.

Artigo inédito a ser encaminhado para publicação 


\section{Abstract}

São Paulo is one of the most important cities of Latin America. It has almost 11 million inhabitants and around 6 million vehicles. Although traffic is the main source of air pollution few studies investigated the relation between trafficrelated air pollution and health outcomes, in Sao Paulo city. Most of studies developed at the area used an average pollutant concentration data from air quality monitoring stations to represent the whole city. In this sense, the purpose of this study is to evaluate the influence of traffic-related air pollution on children and adolescents ( $0-18$ years) hospital admission by respiratory problems, using CALINE-4 dispersion model. CO, NOx and $\mathrm{PM}_{10}$ concentrations were obtained, using CALINE-4 dispersion model, for each of 2499 census sectors of the expanded center of Sao Paulo city. A data base containing children addresses, age and date of hospitalization was used to select the cases. Statistic analysis were performed in order to calculate Odds Ratio, by Logistic Regression. Odds Ratio was corrected by HDI. Results showed that HDI highly increased the odds of children hospitalization by respiratory problems. A significant tendency of raising hospital admissions as pollutants concentrations were augmented was observed for $\mathrm{CO}, \mathrm{NO}_{2}$ and $\mathrm{PM}_{10}$ during summer period and $\mathrm{CO}$ and $\mathrm{PM}_{10}$ during winter period. The higher chance $(79.9 \%)$ of hospitalization by respiratory problems was found for $\mathrm{CO}$, at the $4^{\circ}$ quartile of winter period. This study is the first one to investigate traffic-related pollutants at a micro-scale in Sao Paulo city and relate this to health outcomes. This kind of methodology was extremely useful to analyze critical situations that could not be seen in previous studies. Other developing countries or Brazilian cities may benefit from this technique to develop traffic-related exposure studies, since modeling is a less expensive tool.

Key words: exposure assessment, traffic-related; hospital admission; respiratory 


\section{Introduction}

São Paulo is one of the most important cities of Latin America. It has almost 11 million inhabitants and around 6 million vehicles. Evaluate traffic-related pollutants concentration is a very complex task at the area, since Sao Paulo has a unique fleet, around $16 \%$ of vehicles powered by ethanol, vehicle restriction circulation at the central area and special dispersion conditions due to the verticalization of the city. According to CETESB (2006) traffic was responsible for $97,5 \%$ of the total emitted $\mathrm{CO}$ and $96 \%$ of total emitted NOx. Although the number of exposed people is huge and traffic represents the main source of air pollution little in know about it contribution to population's health.

Few studies evaluated the relationship between traffic and health aspects in Sao Paulo city (FERREIRA et al 2009; SANTOS et al 2005; MARTINS, et al, 2001; MEDEIROS et al 2009; BELL et al 2006, MIRAGLIA, SALDIVAand BÖHM, 2005). Most studies, conducted at the area, analyzed the influence of general air pollution at health outcomes, using an average of the measurements obtained from Air Quality Stations (AQS) (SALDIVA et al, 1995; BOTTER, JOTGENSEN \& PERES, 2002; MARTINS et al, 2004; GOUVEIA et al, 2003; O'NEILL et al 2008). Studies conducted using the average of AQS measurements are not able to evaluate specificities of the area, given that one unique value of pollution is considered for the hole area. But, specially, this type of methodology is not suitable to study the influence of traffic-related air pollution.

Models such as CALINE-4 have been largely used in traffic-related exposure assessment studies (WU, J. et al, 2009; DELFINO, R.J. et al, 2009; NORDLING,E. et al, 2008; CYRYS, J. et al, 2005; JOHANSSON, C et al., 1999;) It has the advantage of allowing the investigation of the influence of traffic. 
Besides it is possible to model at microscale, identifying critical areas and situations. In Sao Paulo studies like that have never been conducted and there is a lack of information about these aspects.

The purpose of this study is to evaluate the influence of traffic-related air pollution on children and adolescents ( $0-18$ years) hospital admission by respiratory problems, using CALINE-4 dispersion model.

\section{Methods}

\section{Traffic-related air pollution exposure assessments:}

$\mathrm{CO}, \mathrm{NOx}$ and $\mathrm{PM}_{10}$ emitted by traffic were estimated using a dispersion model: CALINE-4 at the expanded center of Sao Paulo city. Input data included traffic and meteorological information. Detailed traffic count by category was performed by Engineering Traffic Company of Sao Paulo - CET and School of Public Health of Sao Paulo University - FSP, at 258 points of the expanded center. Vehicles categories were divided by light duty (ethanol, gasoline and hybrid powered vehicles), heavy duty (diesel vehicles: trucks and buses) and motorcycle. Emission rates were obtained from CETESB, 2006 and SILVA, 2007. Atmospheric data such as wind direction and speed, temperature, mixing height and stability class were also input at CALINE-4 model.

A different model was run for ethanol, gasoline, hybrid (flex vehicles), diesel and motorcycle vehicles, since they have different emission factors. CO, NOx and $\mathrm{PM}_{10}$. Hourly pollutants concentrations were obtained for the centroid of 2499 census sectors. It was modeled two different months: January (summer) and June (winter). 
Modeled pollutant concentrations were correlated (Pearson's correlation) to ambient concentrations from Air Quality Stations (AQS). It was also correlated (Pearson's correlation) to traffic volume.

\section{Study population:}

It was studied children from 0 to 18 years old who lived at the expanded center of Sao Paulo city. Population information, such as age and Human Development Index - HDI were obtained from PEDROSO (2003) for each census sector. Hospital admissions information were obtained from Health Department and included two different databases: one for private health insurances and another for public health assistance. It was evaluated hospital admissions by the following International Classification of Diseases (ICD-10):

- J00-J06: Acute upper respiratory infections;

- J10-J18: Influenza and pneumonia (except J17: Pneumonia in diseases classified elsewhere);

- J20-J21: Other acute lower respiratory diseases;

- J40-J47: Chronic lower respiratory diseases.

For the summer period, it was selected hospital admissions that occurred from January/05 until March/05. For winter period, it was selected hospital admissions from June/05 until August/05.

\section{Statistical Analyses:}

It was calculated the Odds Ratio (OR) by Logistic Regression. Pollutants were divided into 4 classes ( $1^{\circ}, 2^{\circ} 3^{\circ}$ and $4^{\circ}$ quartile). The presence of disease was evaluated using Incidence (number of cases/population from 0-18years old). 
The presence of disease (1) was assumed for those census sectors with incidence higher than the median. The absence of diseases (0) was assumed for those census sectors with incidence lower than the median. Census sectors with incidence smaller than the fist quartile were not considered.

The OR was corrected by HDI considering a low social condition, those census sectors with HDI smaller than the median (1) and a high social condition, those census sectors with HDI higher than the median (0).

A total OD (not divided by pollutant classes) was also calculated. In this case, the census sector was considered polluted (1 - if pollutant concentrations were higher than the median) or not pollutant ( 0 - if pollutant concentrations were lower than median). Logistic regression analysis were using SAS and STATA statistical softwares.

\section{Results and Discussion}

Modeled concentrations were smaller than ambient concentrations, since it represents only vehicular fresh emission (Table 1). Especially for $\mathrm{PM}_{10}$, modeled concentrations were smaller, since traffic accounts only for $40 \%$ of emitted $\mathrm{PM}_{10}$ (CETESB, 2006). 
Table 1: Comparison between modeled and ambient pollutant concentrations

\begin{tabular}{|c|c|c|c|c|c|c|c|c|c|c|c|c|}
\hline \multirow{4}{*}{$\begin{array}{l}\text { Pollutant } \\
\text { modeled } \\
\text { concentration } \\
\text { due to } \\
\text { vehicular } \\
\text { emission }\end{array}$} & \multicolumn{4}{|c|}{$\mathrm{CO}$} & \multicolumn{4}{|c|}{ NOx } & \multicolumn{4}{|c|}{$\mathrm{PM}_{10}$} \\
\hline & \multicolumn{2}{|c|}{ Summer } & \multicolumn{2}{|c|}{ Winter } & \multicolumn{2}{|c|}{ Summer } & \multicolumn{2}{|c|}{ Winter } & \multicolumn{2}{|c|}{ Summer } & \multicolumn{2}{|c|}{ Winter } \\
\hline & MEAN & STD & MEAN & STD & MEAN & STD & MEAN & STD & MEAN & STD & MEAN & STD \\
\hline & 0.39 & 0.63 & 0.69 & 1.29 & 36.4 & 54.3 & 62.3 & $\begin{array}{c}108 . \\
5\end{array}$ & 2.7 & 3.9 & 4.8 & 8.5 \\
\hline $\begin{array}{l}\text { Ambient } \\
\text { concentration }\end{array}$ & 1.11 & 0.73 & 1.67 & 1.2 & 66.1 & 76 & 152 & 142 & 32.8 & 23.9 & 53 & 34.5 \\
\hline
\end{tabular}

Note: $\mathrm{CO}-\mathrm{ppm} \quad \mathrm{NOx}-\mathrm{ppb} \mathrm{PM}_{10}-\mu \mathrm{g} / \mathrm{m}^{3}$

Modeled pollution concentrations were extremely correlated (Pearson's correlation) to traffic volume, especially for $\mathrm{CO}(0.9588-\mathrm{n}=5)$ and for $\mathrm{PM}_{10}$ $(0.9364-n=5)$ (Figure 1). For NOx the correlation was negative $(-0.6795-$ $n=3$ ), but analyze was impaired by the low number of observations ( $n)$. A study developed by SILVA et al (2006) investigated the $\mathrm{NO}_{2}$ emitted by traffic, using passive Palmes' diffusion tubes on streets with different traffic characteristics. Results showed an average of $63 \mu \mathrm{NO}_{2} / \mathrm{m}^{3}$ on July of 2000 . This result is pretty similar to the average modeled concentration of NOx during winter period: June $\left(62.3 \mu / \mathrm{m}^{3}\right)$. Ambient concentrations had a negative correlation (Pearson's correlation) for CO $(-0.040-n=5)$ and for PM10 $(-0.0089-n=5)$. For NOx correlation (Pearson's correlation) between traffic and ambient concentrations was $0.5841(n=3)$. 


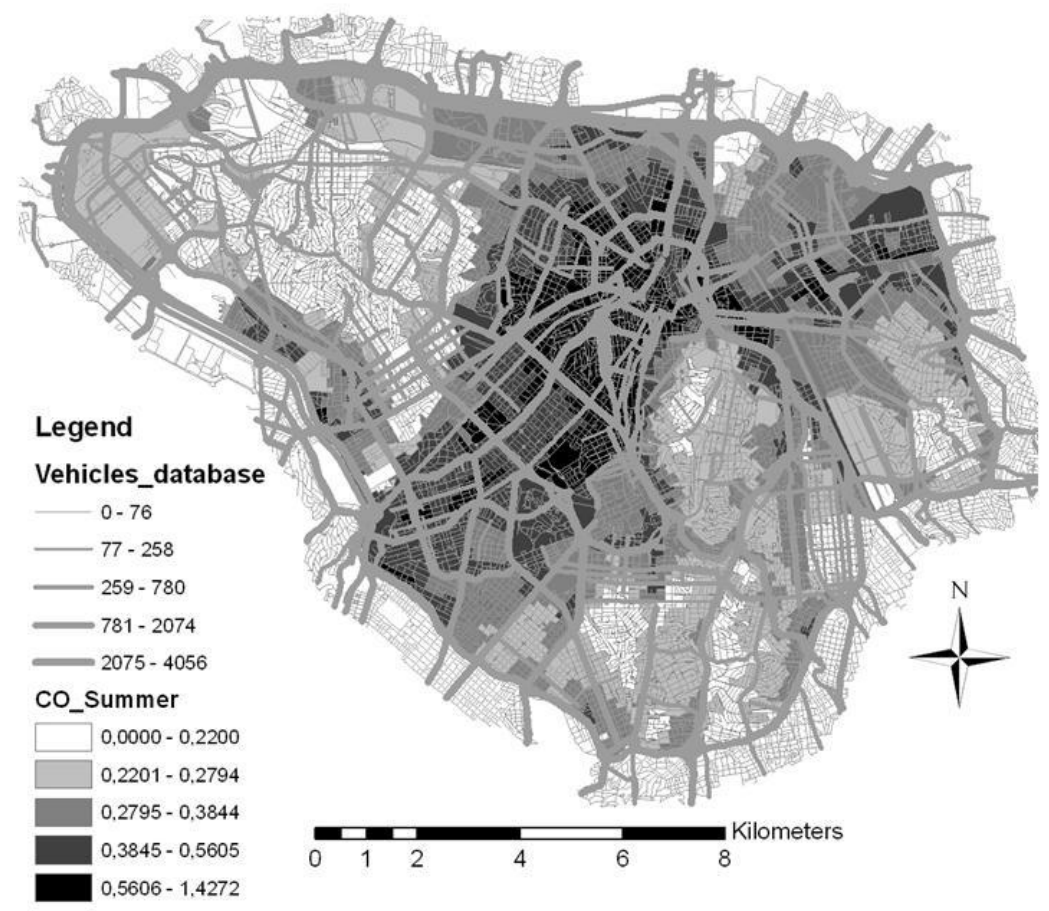

Figure 1: Distribution of modeled CO (ppm) during summer period and vehicles

HDI seems to highly increase the odds of having a hospital admission caused by respiratory problems, for both summer and winter period. For summer period (Table 2), significant $p$ revealed that the increasing in the pollutants concentrations $\left(\mathrm{CO}, \mathrm{NOx}\right.$ and $\mathrm{PM}_{10}$ ) leads to an increasing in hospital admissions by respiratory problems. OR analysis conducted, without pollutant classes, showed that if the children live in a census sector polluted (pollutant concentration higher than median) by $\mathrm{CO}$ the chances of been hospitalized by respiratory problems are $31.1 \%$ higher. The same was observed for $\mathrm{NO}_{\mathrm{x}}$ (30.5\%) and $\mathrm{PM}_{10}(23.0 \%)$. 
Table 2: Logistic regression analyze of odds ratio, corrected by HDI Summer period.

\begin{tabular}{lccc|ccc|ccc}
\hline & \multicolumn{3}{c|}{ CO_Summer } & \multicolumn{3}{c|}{ NOx_Summer } & \multicolumn{3}{c}{ PM $_{10 \_S u m m e r}$} \\
\cline { 2 - 10 } $\begin{array}{c}\text { Class of } \\
\text { Pollutants }\end{array}$ & OD & $\begin{array}{c}\text { Confidence } \\
\text { Interval }\end{array}$ & $\begin{array}{c}\text { Trend } \\
\boldsymbol{p}\end{array}$ & OD & $\begin{array}{c}\text { Confidence } \\
\text { Interval }\end{array}$ & $\begin{array}{c}\text { Trend } \\
\boldsymbol{p}\end{array}$ & OD & $\begin{array}{c}\text { Confidence } \\
\text { Interval }\end{array}$ & $\begin{array}{c}\text { Trend } \\
\boldsymbol{p}\end{array}$ \\
\hline $1^{\circ}$ Quartile & 1.210 & $0.881-1.663$ & & 1.292 & $0.823-1.548$ & & 1.369 & $0.935-2.005$ & \\
$2^{\circ}$ Q Quartile & 1.446 & $1.057-1.971$ & 0.015 & 1.285 & $0.943-1.750$ & 0.015 & 1.531 & $1.030-2.277$ & 0.001 \\
$3^{\circ}$ Quartile & 1.450 & $1.009-2.084$ & & 1.577 & $1.101-2.258$ & & 2.086 & $1.240-3.508$ & \\
$4^{\circ}$ Quartile & 1.454 & $0.981-2.155$ & & 1.419 & $0.959-2.100$ & & 1.392 & $0.806-2.401$ & \\
& & & & & & & & & \\
HDI & 2.100 & $1.667-2.630$ & - & 2.065 & $1.649-2.586$ & - & 2.065 & $1.650-2.584$ & - \\
\hline Total & 1.311 & $1.056-1.627$ & - & 1.305 & $1.052-1.619$ & - & 1.230 & $0.991-1.527$ & - \\
HDI & 2.118 & $1.696-2.646$ & - & 2.081 & $1.667-2.598$ & - & 2.078 & $1.665-2.594$ & - \\
\hline
\end{tabular}

Table 3: Logistic regression analyze of odds ratio, corrected by HDI. Winter period

\begin{tabular}{|c|c|c|c|c|c|c|c|c|c|}
\hline \multirow[b]{2}{*}{$\begin{array}{c}\text { Class of } \\
\text { Polluntants }\end{array}$} & \multicolumn{3}{|c|}{ CO_Winter } & \multicolumn{3}{|c|}{ NOx_Winter } & \multicolumn{3}{|c|}{ 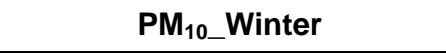 } \\
\hline & OD & $\begin{array}{c}\text { Confidence } \\
\text { Interval }\end{array}$ & $\begin{array}{c}\text { Trend } \\
p\end{array}$ & OD & $\begin{array}{c}\text { Confidence } \\
\text { Interval }\end{array}$ & $\begin{array}{c}\text { Trend } \\
p\end{array}$ & OD & $\begin{array}{c}\text { Confidence } \\
\text { Interval }\end{array}$ & $\begin{array}{l}\text { Trend } \\
p\end{array}$ \\
\hline 1ํ Quartile & 1.566 & $1.116-2.114$ & \multirow{4}{*}{0.002} & 0.685 & $0.512-0.918$ & \multirow{4}{*}{0.681} & 0.955 & $0.510-1.786$ & \multirow{4}{*}{0.001} \\
\hline $2^{\circ}$ Quartile & 1.488 & $1.093-2.027$ & & 0.998 & $0.759-1.310$ & & 1.049 & $0.562-1.958$ & \\
\hline 3 Quartile & 1.687 & $1.202-2.368$ & & 0.935 & $0.670-1.305$ & & 1.413 & $0.714-2.798$ & \\
\hline 4 Quartile & 1.779 & $1.225-2.583$ & & 0.774 & $0.523-1.144$ & & 1.512 & $0.822-2.780$ & \\
\hline $\mathrm{HDI}$ & 2.054 & $1.662-2.538$ & - & 2.068 & $1.674-2.553$ & - & 0.975 & $0.779-1.220$ & - \\
\hline Total & 1.265 & $1.031-1.552$ & - & 1.106 & $0.901-1.358$ & - & 1.488 & $1.190-1.860$ & - \\
\hline $\mathrm{HDI}$ & 2.092 & $1.696-2.579$ & - & 2.080 & $1.685-2.567$ & - & 0.975 & $0.780-1.219$ & - \\
\hline
\end{tabular}

For winter periods (Table 3 ) a significant $p$ was observed for both $\mathrm{CO}$ and $\mathrm{PM}_{10}$, but not for NOx; making evident that a rising in $\mathrm{CO}$ and $\mathrm{PM}_{10}$ concentrations during winter periods were responsible for an increasing in hospital admissions by respiratory problems. OR analysis conducted, without pollutant classes, demonstrated that children living in a census sector polluted by $\mathrm{CO}$ (pollutant concentration higher than median), the chances of been hospitalized by respiratory problems are $26.5 \%$ higher. The same was observed for $\mathrm{PM}_{10}$ (10.6\%). When OR is analyzed by classes of pollutants the consequences of 
living in a pollutant census is more evident. For children living in a census sector located at the $4^{\circ}$ quartile of $\mathrm{CO}$, the chance of hospitalization raises almost $80 \%$.

Previous studies conducted at Sao Paulo city used the average pollutants concentration to analyzed exposition at the whole area of the city. LIN et al (1999) analyzed the relation between $\mathrm{SO}_{2}, \mathrm{CO}, \mathrm{PM}_{10}, \mathrm{O}_{3}$ and $\mathrm{NO}_{2}$ and children admission in emergency rooms. The study revealed that the admission were $20 \%$ higher. BRAGA et al (1999) reports that a raising of $70 \mu \mathrm{O}_{3} / \mathrm{m}^{3}$ caused a raising of $12 \%$ in hospital admissions. Another study (BRAGA et al, 2001) found that the elevation of pollutants $\left(\mathrm{SO}_{2}, \mathrm{CO}, \mathrm{PM}_{10}, \mathrm{O}_{3}\right.$ and $\left.\mathrm{NO} 2\right)$ lead to a rising of $9.4 \%$ on hospital admission of children under 2 years old. GOUVEIA and FLCHTER (2000) reported that children hospital admission were $5 \%-8 \%$ higher, when $\mathrm{O}_{3}$ concentrations were raised and $9 \%$ higher when $\mathrm{NO}_{2}$ and $\mathrm{PM}_{10}$ concentrations were elevated. Since this studies haven't worked at a microscale, critical situation were not observed.

It is important to highlight that even if average exposure to $\mathrm{CO}$ during winter period is under the maximum exposure determined by Brazilian Federal law of 35 ppm of CO (1 hour sampling) or 9 ppm of CO (8 hours sampling) (CONAMA, 1990), the chances of hospitalization are higher for more pollutant regions.

\section{Conclusions}

$\mathrm{CO}$ and $\mathrm{PM}_{10}$ modeled concentrations were highly correlated to traffic volumes ( $0.9588-n=5$ and $0.9364-n=5$, respectively), while ambient concentrations had a negative correlation. It was not possible to correlate NOx modeled concentrations due the low number of observations ( $n$ ), caused by the lack of 
ambient data. Although NOx modeled concentrations were compatible to trafficrelated $\mathrm{NO}_{2}$ measurements described at the literature (SILVA et al, 2006).

This is the first model developed for Sao Paulo city able to evaluate traffic pollution, principally in micro-scale. A detailed vehicle counting, with 258 measuring points in a $150 \mathrm{~km}^{2}$ was performed to input traffic data at the model, assuring the good representativeness of these data at the model. Still, there are some uncertainties at the model that could be better addressed.

Some improvements may be done at the input data of CALINE-4 model, such as: better characterization of the daily distribution of the fleet and use of real measurements of meteorological data (Mixing Height, Stability Class and Temperature). A campaign may be conducted in order to obtain better ambient data that would be able to represent traffic emission and could be used to improve validation of the model.

The raising on the traffic-related pollutants $\left(\mathrm{CO}, \mathrm{NOx}\right.$ and $\left.\mathrm{PM}_{10}\right)$ concentrations were related to a greater chance of children hospitalization by respiratory problems. Children living in census sectors in the $4^{\circ}$ quartile of traffic-related $\mathrm{CO}$ will have almost $80 \%$ more chance of hospitalization by respiratory problems. Other studies conducted at Sao Paulo city were not able to observe critical situation as this, because they used an average concentration for the whole city.

In this aspect, this study had an important contribution, since it developed a model that had never been applied to Sao Paulo city or any other Brazilian city. The model permits the simulation of some critical situations or public measures adopted for traffic. Besides, since the model is less expensive than air monitoring campaigns it is a useful tool to be applied at other developing countries that need to perform exposure assessment investigations. 


\section{References}

CETESB (Companhia Ambiental do Estado de São Paulo). Relatório da Qualidade do Ar 2005. CETESB, 2006. 140p. Available at: http://www.cetesb.sp.gov.br/Ar/publicacoes.asp. Accessed on 10 of December of 2009.

CONSELHO NACIONAL DO MEIO AMBIENTE (CONAMA). Resolução 03 from 28 of june of 1990.Publicated at Diario Oficial da União. on 22 of august of 1990; Section I.pg 15937-15939.

CYRYS, J. et al. GIS-Based Estimation of Exposure to Particulate Matter and $\mathrm{NO}_{2}$ in an Urban Area: Stochastic versus Dispersion Modeling. Environmental Health Perspectives. V 13. N 8. 2005.p. 987-992.

BRAGA, A.L.F., et al. Health effects of air pollution exposure on children and adolescents in São Paulo. Brazil. Pediatric Pulmonology. Vol 31.2001. p106113.

BRAGA ALF, et al. Air pollution and pediatric hospital admissions in São Paulo, Brazil. Journal of Environmental Medicine.Vol1. 1999. p.95-102.

BELL, M.L. et al. The avoidable health effects of air pollution in three latin American cities: Santiago, Sao Paulo and Mexico City. Environmental Research. Vol 100. N3. 2006.p $431-440$. 
BOTTER, D.A.; JORGENSEN, B. \& PERES, A.A.Q. A longitudinal study os mortality and air pollution for Sao Paulo, Brazil. Journal of exposure analysis and environmental epidemiology. Vol12. N5. 2002. p 335-343.

DELFINO, R.J. et al. Repeated hospital encounters for asthma in children and exposure to traffic-related air pollution near the home. Annals of allergy, asthma \& immunology. V102. 2009. p. 138-144.

FERREIRA, C. et al. Análise da função pulmonar de motoboys: o efeito da poluição atmosférica: prevenção, a melhor forma de cuidar. Mundo da Saúde. Vol 32. N2. 2009. p 170-174.

GOUVEIA, N. et al. Poluição do ar e efeitos da saúde nas populações de duas grandes metrópoles brasileiras. Epidemiologia e Serviços de Saúde. Vol 12. N. 1. 2003. p 29-40

GOUVEIA, N. \& FLETCHER, T., Respiratory diseases in children and outdoor air pollution in Sao Paulo, Brazil: a time series analysis. Journal of occupational and environmental medicine. Vol 57. N7. 2000. p477-483.

JOHANSSON, $C$ et al. The Stockholm study on health effects of air pollution and their economic consequences(SHAPE). Part I: NO2 and particulate matter in Stockholm. Concentrations and population exposure. Publication 1999:41; ISSN 1401-9612, Borlange, Sweden: Swedish National Road Administration; 1999. Available at: http://www.slb.nu/slb/rapporter/pdf/shape.pdf. Accessed 08 December 2009. 
LIN, C. A. et al. Air pollution and respiratory illness of children in Sao Paulo, Brazil. Pediatric and Perinatal Epidemiology. Vol 13. 1999. p 477-488.

MARTINS,M.C.H. et al, Influence of socioeconomic conditions on air pollution adverse health effects in elderly people: an analysis of six regions in Sao Paulo, Brazil. Journal of Epidemiology Community Health. Vol 58. 2004. p 41-46.

MARTINS, L.C.; LATORRE, M.R.D.O.; SALDIVA, P.H.N.\& BRAGA, A.L.F. Relação entre poluição atmosférica e atendimentos por infecção de vias aéreas superiores no município de São Paulo: avaliação do rodízio de veículos. Revista Brasileira de Epidemiologia. Vol 4. N3. 2001. p 220-229.

MEDEIROS,A \& GOUVEIA,N.; Relationship between low birthweight and air pollution in the city of São Paulo, Brazil. Revista de Saúde Pública. Vol 39. N6. 2005. p 1-7.

MIRAGLIA, S.G.; SALDIVA, P.H. \& BÖHM, G.M., An evaluation of air pollution helath impacts and costs in Sao Paulo, Brazil. Environmental Management. Vol35. N5. 2005. p $667-676$.

NORDLING,E. et al traffic-related air pollution and childhood respiratory symptoms, function and allergies. Epidemiology. 2008. V19(3):401-408.

O'NEILL, M.S. et al. Air pollution and mortality in Latin America: the role of education. Epidemiology. 2008. Vol 19. N6. p 810 - 819.

PEDROSO, M. Desenvolvimento humano no município de São Paulo (2000): uma cartografia socioeconômica como contribuição ao planejamento de 
políticas públicas. 2003. Dissertation (Master's Degree in Politic Economy). PUC/SP. Sao Paulo.

SANTOS, U.P. et al. Effects of air pollution on blood pressure and heart rate variability: a panel study of vehicular traffic controllers in the city of Sao Paulo, Brazil. European Heart Journal. Vol 26. 2005. p.193-200.

SALDIVA, P. H. et al. Air pollution and mortality in elderly people: a time-series study in Sao Paulo, Brazil. Archives of Environmental Health. Vol 50. N2. 1995. P 159-163.

SILVAM M.F. Emissão de metais por veículos automotores e seus efeitos à saúde pública. 2007. 155p. Dissertation (Master's Degree in Public Health) School of Public Health, University of São Paulo, São Paulo.

SILVA, A.S. et al, 2006. Use of passive diffusion sampling method for defining $\mathrm{NO}_{2}$ concentrations gradient in São Paulo, Brazil. Environmental Health: a global access science source. Vol 5(19). Availabe at: http://www.ehjournal.net/content/pdf/1476-069X-5-19.pdf. Accessed on 10 of December of 2009.

WU, J. et al. Association between local traffic-generated air pollution and preeclampsia and preterm delivery in the south coast air basin of California. Environmental Health Perspectives. V17. N11. 2009. p.1773-1779. 


\section{CONCLUSÕES}

O monitoramento da qualidade do ar na cidade de São Paulo não é tarefa fácil . Atualmente, este monitoramento é realizado por estações mantidas e operadas pela CETESB. A maioria dos trabalhos realizados no município de São Paulo, avaliando a influência dos poluentes atmosféricos na saúde da população, considerou a média das concentrações obtidas pelas estações de monitoramento da CETESB para toda a cidade.

Estudos realizados com métodos desta natureza não são capazes de avaliar situações críticas ou a influência de picos de poluição. Estas pesquisas também não permitem avaliar o efeito do tráfego na saúde da população. Considerandose que o tráfego é a maior fonte de emissão de poluentes atmosféricos, é possível detectar uma lacuna bastante grande no conhecimento sobre a exposição da população de São Paulo à poluição veicular.

No entanto, esses estudos, ainda que apresentem limitações, têm mostrado que os efeitos prejudiciais da poluição do ar para a saúde da população são significativos.Entretanto, a aplicação de métodos mais refinados possibilita a avaliação de situações críticas de risco existentes que não foram evidenciadas nestes trabalhos.

O uso de métodos que combinam modelos de dispersão com técnicas de georreferenciamento podem produzir valiosas informações em micro-escala. $O$ uso de modelos como o CALINE-4 apresenta-se como alternativa viável para a avaliação da influência do tráfego na poluição do ar e conseqüentemente, na saúde da população. 
O desafio no uso de modelos é agrupar informações de qualidades, para que o modelo seja alimentado e validado. A qualidade destas informações para o município de São Paulo deve ser aprimorada, fazendo com que os resultados obtidos pelo modelo sejam melhor validados .

A utilização de modelos tem vantagens bastante interessantes, como menor custo, quando comparado aos experimentos de amostragem, ou à aquisição e manutenção de estações de monitoramento do ar. Além disso, a utilização de modelos permite estudar a influência de diferentes cenários de tráfego e de composição da frota na qualidade do ar e na saúde da população, informações que são muito importantes para subsidiar a tomada de decisão ou adoção de políticas públicas, na área de saúde pública, ambiente e transporte urbano.

Modelos de simulação de tráfego com o EMME-2 podem servir como fonte de informação a respeito do tráfego em estudos de avaliação da exposição a poluentes veiculares e tem sido utilizado com sucesso em diversos países. $O$ desempenho destes modelos irá depender principalmente da qualidade dos dados de entrada. No caso de São Paulo, em particular,os seus resultados devem ser melhor validados para todos os tipos de veículos e vias.

O Brasil e demais países em desenvolvimento, em geral, apresentam desenvolvimento desordenado e contam com poucos dados a respeito da frota veicular e seu comportamento. Os modelos podem ser utilizados como alternativa para obtenção de informações em curto prazo, em estudos de avaliação da exposição a poluentes veiculares No entanto, deve-se cuidar para que os dados modelados utilizados realmente representem as situações reais existentes. 
O resultado da modelagem de dispersão realizada com o CALINE-4 do $\mathrm{CO}$, NOx e $\mathrm{PM}_{10}$ provenientes do tráfego mostrou que, do ponto de vista espacial, as maiores concentrações de poluentes são observadas na área central do centro expandido de São Paulo. Quanto à distribuição temporal, as maiores concentrações foram observadas no inverno. Vale ressaltar que tanto o NOx quanto o $\mathrm{PM}_{10}$ estiveram mais dispersos durante o período do inverno.

As correlações dos resultados do modelo de dispersão (CALINE-4) com os valores medidos foram bastante altas tanto para o $\mathrm{CO}$ quanto para $\circ \mathrm{PM}_{10}$. Para o Nox a correlação com os valores medidos não foi boa, devido principalmente ao baixo número de observações (n) existentes para as concentrações ambientais deste poluente. NO entanto, os resultados modelados de NOx, obtidos com o CALINE-4, foram compatíveis com os níveis de $\mathrm{NO}_{2}$ relacionado ao tráfego, medidos na cidade de São Paulo por meio de medidores passivos (Tubos de Palmes), descritos em literatura (SILVA, 2006).

A correlação dos valores ambientais de $\mathrm{CO}$ e $\mathrm{PM}_{10}$ com os dados de tráfego foi negativa, mostrando que as concentrações de poluentes medidas pelas estações de monitoramento da qualidade do ar não são adequados para calibrar o modelo utilizado.

O modelo (CALINE-4) foi alimentado com 258 medições de tráfego, em uma área de $150 \mathrm{~km}^{2}$. Isso garante boa representatividade do volume da frota e da distribuição dos tipos de veículos. No entanto, ainda existe a possibilidade de se realizar melhorias na qualidade de alguns dados de entrada do modelo. É ainda possível também, realizar uma campanha de amostragem dos poluentes ambientais que realmente possa caracterizar a poluição veicular e, portanto, servir para validação do modelo. 
Foi possível observar uma forte relação entre os poluentes ambientais veiculares (concentrações obtidas pela modelagem) e internações de crianças e adolescentes (0-18 anos) por doenças respiratórias. $O$ aumento das concentrações veiculares de $\mathrm{CO}, \mathrm{NOx}$ e $\mathrm{PM}_{10}$ foi responsável pelo aumento no número de internações, mesmo quando os valores de $\mathrm{CO}$ eram menores que os limites estabelecidos pelo CONAMA 03/1990. A maior razão de chance $(79,9 \%)$ foi observada para o CO, nos setores censitários cuja concentração de poluente pertencia ao $4^{\circ}$ quartil. A presença de baixas condições sociais (IDH) também elevou a chance de hospitalização de crianças por doenças respiratórias.

O método utilizado no desenvolvimento deste trabalho mostrou-se bastante adequado para estudos de micro-escala de exposição a poluentes veiculares. Este método poderá ser replicado nas demais cidades brasileiras ou em outros países em desenvolvimento que necessitem de técnicas de menor custo.

A aplicação de modelos, como a realizada neste trabalho, ainda possui a vantagem de permitir a análise de diversos cenários para subsidiar políticas públicas e a influência de medidas como a restrição de circulação de veículos, mudança de combustível da frota veicular, entre outras.

Recomenda-se que estudos futuros aprimorem a qualidade dos dados meteorológicos e de distribuição diária da frota, utilizados para alimentar o modelo CALINE-4.

Sugere-se que seja avaliada a possibilidade de inclusão de módulos de reações químicas atmosféricas, para que demais poluentes, incluindo poluentes tóxicos, possam ser modelados. A relação dos poluentes tóxicos atmosféricos com a saúde da população foi minimamente investigada na cidade de São Paulo. 


\section{REFERÊNCIAS *}

BENSON, P.E.. CALINE-4: a dispersion model for predicting air pollutant concentrations near roadways. Final Report. Department of transportation of California - Division of new technology and research. 1989. 247p.

COMPANHIA TECNOLOGICA DE SANEAMENTO AMBIENTAL (CETESB). Relatório da qualidade do ar no estado de São Paulo 2007. São Paulo: CETESB. 2008. 298p. Disponível em: http://www.cetesb.sp.gov.br/Ar/ar geral.asp. Acesso em: 06 de fevereiro de 2009.

KARAM, H.A. OLIVEIRA, A.P. e SOARES, J. Application of mass conservation method to investigate the wind patterns over an area of complex topography. Journal of the Brazilian Society of Mechanical Sciences and Engineering V 25. N2.2003.

MID-WILLAMETTE VALLEY COUNCIL OF GOVERNMENTS (MWVCOG). Oregon. Disponível em:

http://www.mwvcog.org/transportation/emme2/model.asp. Acesso em 28/02/2010.

ORGANIZAÇÃO PANAMERICANA DE SAÚDE \& ORGANIZAÇÃO MUNDIAL DE SAÚDE. Classificação estatística internacional de doenças e problemas relacionados à saúde (CID-10). 10 Revisão. 9 a edição.Edusp. Volume 1. 2003.1191p. 
SILVA, MOACIR FERREIRA DA; DE ASSUNÇÃO, JOÃO V. ; ANDRADE, MARIA DEFÁTIMA ; PESQUERO, CELIA REGINA . Characterization of metal and traceelement content of particulate matter (PM10) emitted by ethanol and gasohol powered vehicles. In: 1st Ibero-American Meeting on Toxicology and Environmental Health, Ribeirão Preto 2009,. v. Único. Program and Abstracts, 2009.

* Estas referências são complementares àquelas anteriormente relacionadas nos manuscritos. 


\section{ANEXOS}




\section{INFORMAÇÕES CURRICULARES}

